TEACHERS AS AGENTS OF CHANGE:

HOW KNOWLEDGE GAINED FROM SECONDARY ENGLISH LANGUAGE ARTS

PROFESSIONAL DEVELOPMENT IMPACTS CLASSROOM PRACTICES

A Dissertation
Presented to
the Faculty of the Graduate School
at the University of Missouri-Columbia
In Partial Fulfillment
of the Requirements for the Degree
Doctor of Education
by
VICKY L. BRYAN
Dr. Carole A. Edmonds, Dissertation Supervisor
DECEMBER 2018


(C) Copyright by Vicky L. Bryan, 2018

All Rights Reserved 
The undersigned, appointed by the dean of the Graduate School, have examined the dissertation entitled

TEACHERS AS AGENTS OF CHANGE:

HOW KNOWLEDGE GAINED FROM SECONDARY ENGLISH LANGUAGE ARTS PROFESSIONAL DEVELOPMENT IMPACTS CLASSROOM PRACTICES

\author{
presented by Vicky Lynn Bryan
}

a candidate for the degree of doctor of education and hereby certify that, in their opinion, is worthy of acceptance.

Dr. Carole A. Edmonds - Dissertation Advisor

Dr. Timothy Wall

Dr. Dana Melton

Dr. Greg Rich 


\section{DEDICATION}

To my parents, Joe and Cynthia Kamphefner, for their continued love and support in all things. Thank you for giving me the best gifts: your time, trust in me making "smart" choices, and encouragement to go after whatever I wanted from dance lessons and school plays to trips abroad and being independent.

To our Lord and Father for the opportunities I've been blessed with and the call to education. I heard you early God, loud and clear!

To my grandpa, Clarence Aylsworth. Whenever anyone asked if I would get my Doctorate, you would always speak up and say, "Of course she is!" You knew I could do this before I did. "Your girl" misses you so much. I wish you were here to celebrate with me, but I know you will visit again.

To my grandmother, Dorothy Jean Ayslworth, for all prayers and blessings you have sent out for me and for making the importance of family and traditions a top priority.

To my grandpa, George Kamphefner, and grandma, Bonnie Kamphefner, I wish you could see the person I have become, and I wish I could have had you longer in my life. Your spirits are often felt in the quietest moments. I wish you both were here to celebrate with me. 


\section{ACKNOWLEDGEMENTS}

Education is a serious business, but after 22 years in the same district and classroom, I've learned not to take everything so seriously. Humor has played a large part in keeping me sane. So has my grandmother's maxim, “Develop a relaxed mental attitude and adapt to sudden changes," but I'm never going to admit that to her. If this isn't the corner stone of what I do every day in teaching, I sure don't know what is! Teaching has sustained me, but I wanted something more. I know I'm good on both sides of the proverbial desk, but something was missing. I didn't see myself as a true leader. I'm a great sidekick, Robin to Batman; Tonto to The Lone Ranger, but could I be Batman? It wasn't until the MU cohort program that I met the leader inside myself.

Thank you to my father for teaching me the leadership qualities of grit, truth, and honesty were already in me. Daddy, your discipline and fortitude is rare and precious. Thank you for working and farming to ensure my dreams could come true. Mom, your creative talents have taught me the leadership quality of service to others was already there. Thank you for giving me the gift of your time as a child. I now understand how much daddy and you sacrificed so you could stay home with me. Grandma, your faith has taught me leadership is sometimes quiet and gentle. Thank you for all the overnight sleep-overs, the vacations, the faith in a little girl's whims, and all the prayers I know you have prayed over me every day. To my aunt and uncle and cousins, thank you for always asking how everything was going with classes and really wanting to know the answer. You have taught me leadership is about asking the right questions.

My family is amazing, and I am thankful for their support as I undertook this degree. But life can be pretty amazing, and God puts people in our path whom we get to choose as 
family. To "my sister", Dawn Smith, you have taught me the leadership quality of taking care of others always, forever, no matter what has always been in me. Thank you for the phone calls, encouragement, and the reading of many drafts. Thank you for pushing me to step out of the role as the sidekick and put my talents on center stage. After $20+$ years, you continue to be a mentor, friend, advocate, and pillar of faith in my life.

To Vickey Meyer, you have taught me leadership is about sharing the joy of simple moments. May we never be farther than a wall away from each other's classrooms. Saying thank you seems insignificant for understanding and sharing the many "dances" of teaching. Thank you for always listening when there was no fix or answer, for the hugs, for the sniffs, and for reminding me to breath.

To Angela Brown, you have taught me the leadership quality that faith is stronger together than when apart. Thank you for all the talks, tears, and prayers you have shared with me. You have remained my champion for so many years; I appreciate all your encouragement and caring concern.

To Angie Dorsey and Becky Callaway, my fellow cohort 10 learners, here's to carpooling, helping me talk through my thinking, getting my mind off of unpleasant events, getting me back into a bible study, and only being able to find our class building by going through the NWSU parking lot. And all the NW cohort 10 members; what an amazing group of educators to work with.

Thank you to other teacher-friends who have blessed my life: Richard Barrette, Steve Bennett, Donna VanCleave, Dana Simms, Brandon Haskey, Jen Hoecker, JoAnn Leiman, Marcia Steeby, Gwen Funk, Marnie Jenkins, Mary Ann Dudley, Amy Barnette, Chris Danford, Nancy Piercy, JoAnn Anderson, Kristy Johnson, Kay Stevens, Barry 
Reynolds, Daryl Johnson, and Coaches Randy Morlock and Tony Dudik. You have all taught me leadership is about friendship, sharing a good laugh, and supporting each other. I wouldn't be the teacher I am today without the parts all of you have played in my life.

To my sweet beau, David. Thank you for pulling out the Marine Drill Sargent voice when I needed to work on class work or this "little paper" but didn’t want to. And thank you for understanding when I needed to study at the same time you wanted to go fishing. You truly understand how the profession of teaching and learning is a calling, and you treasure the fact I am trying to change the world by getting young people ready for their futures and our own. You have shown me the leadership quality of persistence was already in me.

And finally, to my faithful, fuzzy friends: Jolie (I miss you terribly) and Gracie and my puppy-loves Arthur and Abbey. Thank you for knowing when I needed a lick of encouragement, a nap partner, a break to play fetch, a good laugh, a nudge to get up, a paperweight, a laptop keyboard warmer, a reminder that any time is a great time for a snack, and happiness is just an ear scratch or belly rub away. May I always be the person you see me as. 


\section{TABLE OF CONTENTS}

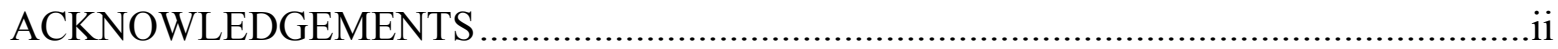

LIST OF TABLES ............................................................................................. viii

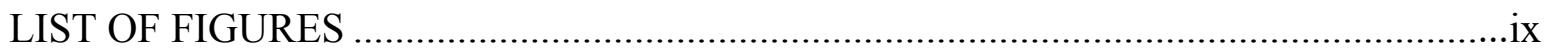

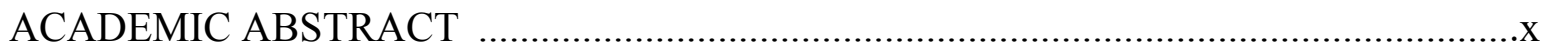

SECTION ONE: INTRODUCTION TO THE DISSERTATION-IN-PRACTICE ..............1

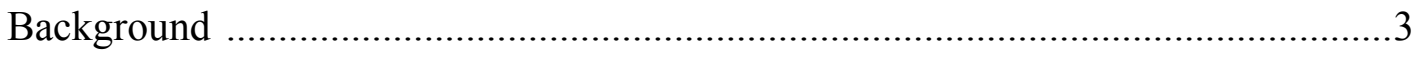

Statement of the Problem................................................................................ 4

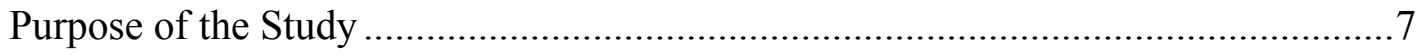

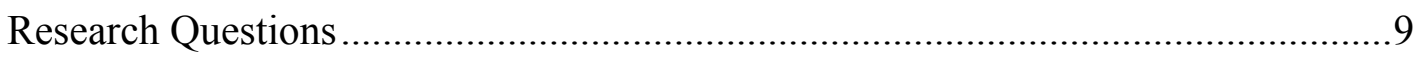

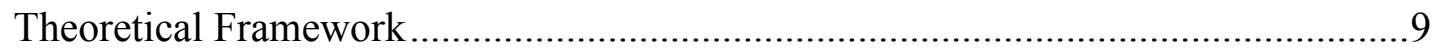

Adult Learning Theory ..................................................................... 10

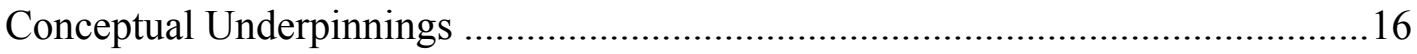

Public Education and the Introduction of English Courses .........................16

Characteristics of High-Quality and Effective Professional Development ...18

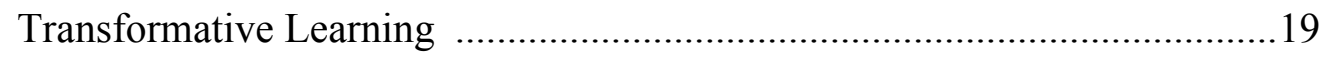

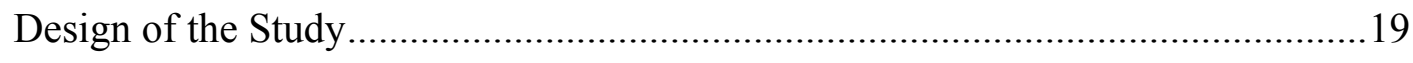

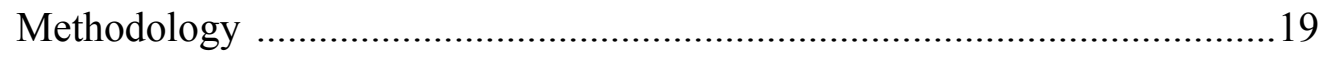

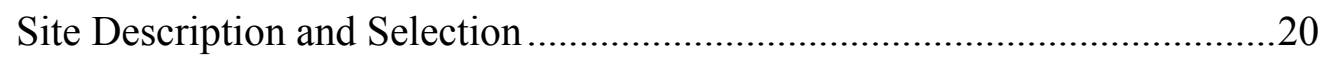

Participant Sample ..................................................................... 21

Researcher Participation and Positioning .............................................24

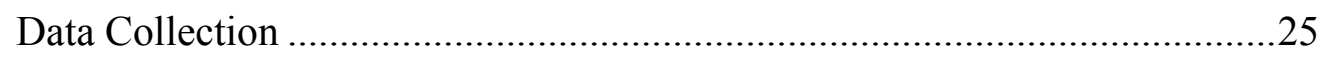

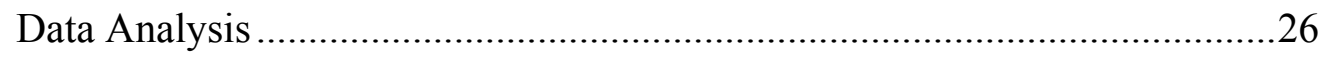




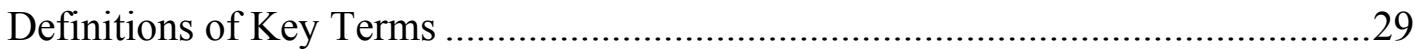

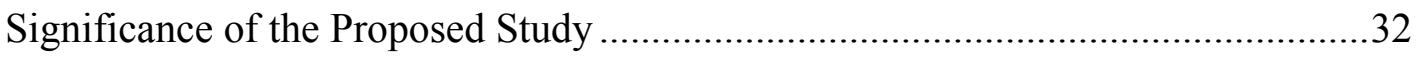

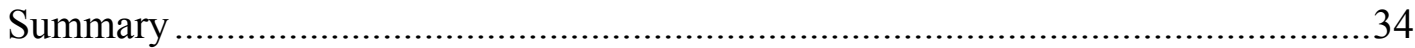

SECTION TWO: PRACTITIONER SETTING FOR THE STUDY .................................

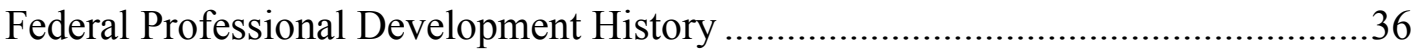

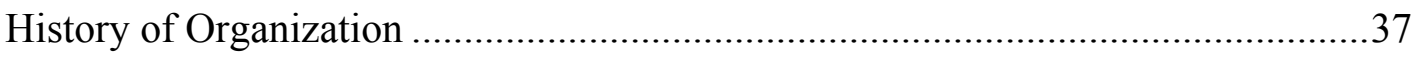

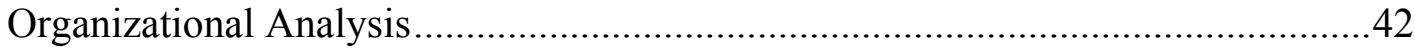

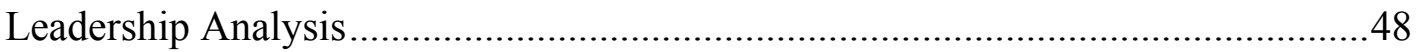

Implications for Research in the Practitioner Setting ......................................53

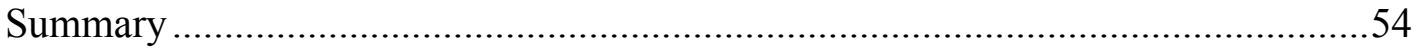

SECTION THREE: SCHOLARLY REVIEW FOR THE STUDY ................................56

Theoretical Framework: Adult Learning Theory ..............................................56

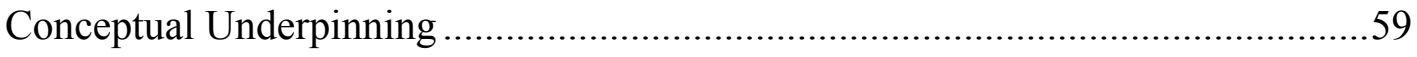

Impetus of American Public Education ....................................................59

Professional Development .............................................................65

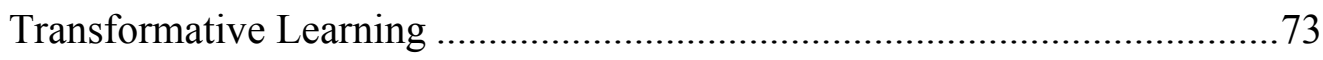

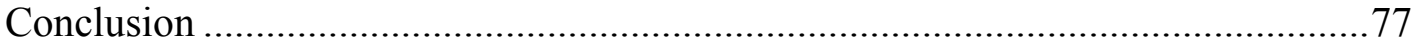

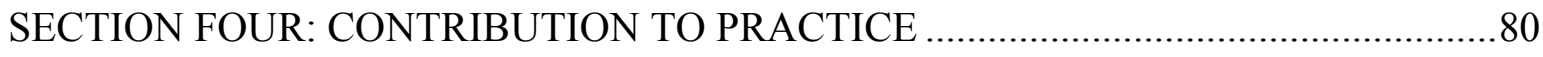

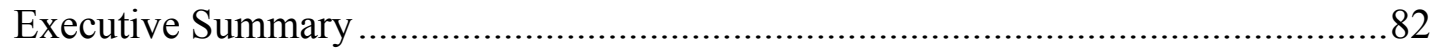

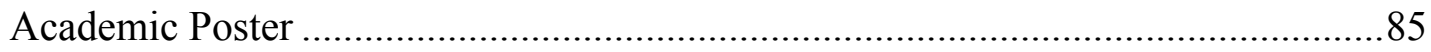

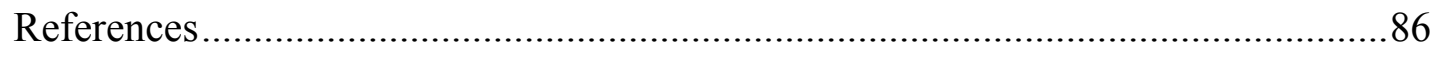

SECTION FIVE: CONTRIBUTION TO SCHOLARSHIP ......................................89 
Submission-Ready Journal Article

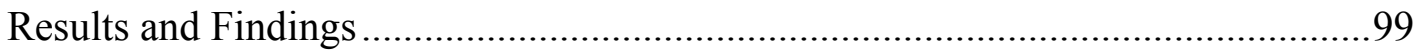

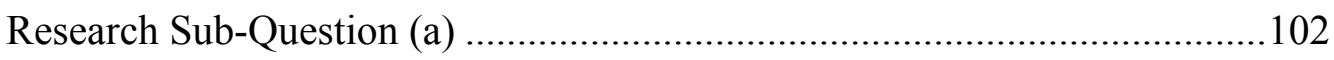

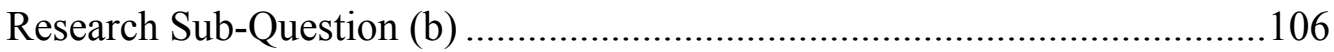

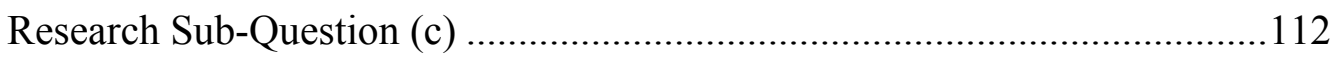

Research Sub-Question (d) ....................................................................122

Implications for Future Research......................................................................133

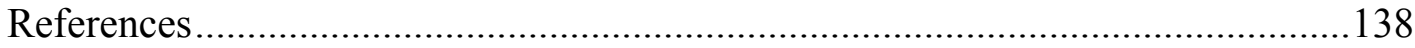

SECTION SIX: SCHOLARLY PRACTITIONER REFLECTION …………………........149

Dissertation Influencing Practice as Educational Leader ........................................149

Dissertation Process Influencing Scholarship ......................................................153

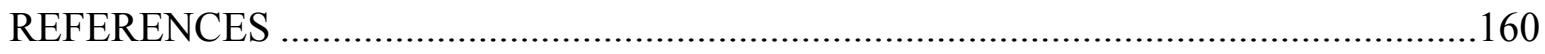

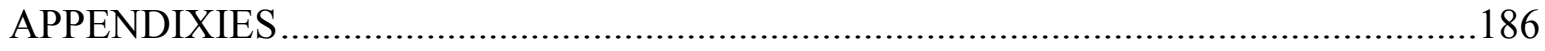

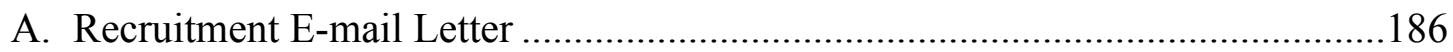

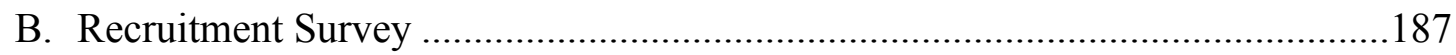

C. Participant Informed Consent Forms ………………........................................189

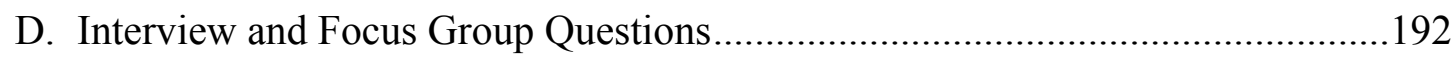

E. Approval to Conduct Research within the School District....................................194

F. IRB Approval Letter and Amended Approval Letter ..........................................195

G. District Archived Survey Questions from Post-PD Surveys 2017-18 .................197

H. Interview and Focus Group Script ...................................................................

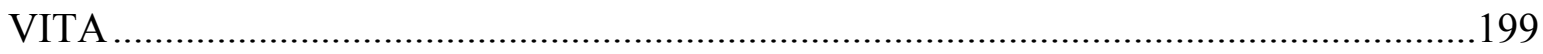




\section{LIST OF TABLES}

\section{TABLE}

1. Percentage of Participant Grouping Categories in the Study...............................23

2. Summary of Data Collection for Study .........................................................26

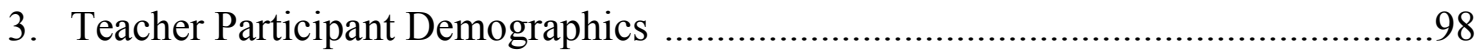

4. Relation of Research Questions to Top Emergent Themes from all Participants...101

5. Theme Emergence by Years of Teaching Experience for Sub-question (a)........103

6. Theme Emergence by Years of Teaching Experience for Sub-question (b)........107

7. Theme Emergence by Years of Teaching Experience for Sub-question (c)........114

8. Theme Emergence by Years of Teaching Experience for Sub-question (d)........123

9. Top Emergent Sub-Themes of Research Sub-Questions Divided into Years of Teaching Experience Groupings .................................................................... 147 


\section{LIST OF FIGURES}

\section{FIGURE}

1. Conceptual Framework and Underpinnings of this Study .................................10

2. Heartland School District's Last Four PD Structures .........................................41

3. Heartland School District's Secondary Leadership Hierarchy .............................49

4. Heartland School District's Current PD Structure ...............................................51

5. Compare \& Contrast Components of the Study’s Framework .................................58

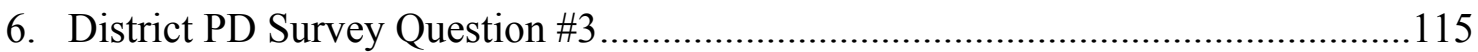

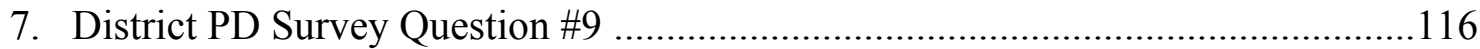




\author{
TEACHERS AS AGENTS OF CHANGE: \\ HOW KNOWLEDGE GAINED FROM SECONDARY ENGLISH LANGUAGE ARTS \\ PROFESSIONAL DEVELOPMENT IMPACTS CLASSROOM PRACTICES \\ Vicky Lynn Bryan \\ Dr. Carole Edmonds, Dissertation Supervisor
}

\title{
ACADEMIC ABSTRACT
}

Gathering information about how secondary English Language Arts (ELA) teachers use pedagogical content knowledge gained from professional development (PD) to change their classroom practices in one Midwest Missouri school district has the potential to change how future ELA PD is delivered. The researcher examined teachers' perceptions through 21 individual interviews and a focus group as well as district archival surveys administered after three ELA content PD days during the 2017-18 school year. Participants shared their thoughts on effective elements of PD, how teachers implement classroom change and how those changes influence student learning, as well as how teachers know they are growing. This research is qualitative in nature utilizing purposeful sampling, open coding, and an hermeneutic method to identify themes and interpret responses. Data discovered the use of teacher experts, time for collaboration, and participating in reflective practices as the most important elements in gaining new knowledge and impacting classroom practices. 


\section{SECTION ONE}

\section{INTRODUCTION TO THE DISSERTATION-IN-PRACTICE}

For most educators across the nation, attending professional development (PD) is a way to gain new knowledge, skills and practices to meet student learning needs. Guskey (2000) states "every proposal for educational reform and every plan for school improvement emphasizes the need for high-quality professional development” (p. 3). While educating children is an ever-evolving process through curriculum changes, technology changes, and new state and national mandates, what remains the same is educators' requirement to stay at the top of their game. In order to provide the best educational opportunities for all students to find success in college, a career, and beyond, teachers who grow in their profession strive to strengthen their teaching practices, examine their performance, and engage in lifelong learning. Darling-Hammond and McLaughlin (2011) cite effective professional development "involves teachers both as learners and as teachers" (p. 82) and must provide concrete experiences in teaching and assessment but more importantly in reflection and observation. Darling-Hammond (2013) furthers the argument supporting effective PD and links it to the essential component of teacher growth. However, the voice of teachers is lacking in research studies and is underexplored in professional development (Ajayi, 2016; Cosenza, 2015; Scarlett, 2009; Singh, 2012).

In Missouri, it is a mandate for teachers to complete 15 hours of PD annually to support their Career Continuous Professional Certificate or have 10 years of experience, a Master's degree, or National Board Certification (DESE, 2013, p. 17). How teachers obtain these hours is usually determined by individual district administration, by staff surveys, or by the staff themselves . Additionally, the federal Every Student Succeeds Act (ESSA) "prioritizes PD that is woven into the school day and allows for educators to 
cooperate" (Davis, 2017, p. 3). Such state and federal law was designed to increase more individualized learning opportunities for teachers. Current trends in PD opportunities consist of traditional lecture sessions, group project studies, data driven workshops, book studies, work studies, while a rapidly growing PD format is obtaining online microcredentials, such experiences are said to provide a more individualized experience for teachers.

Teachers are learners, teachers understand true learning takes time, and teachers need methods and strategies they can use in their classroom practices to propel them towards improvement of their craft in order to increase student achievement (Gaible \& Burns, 2005). Therefore, a one-size-fits-all approach to professional development may not be the best fit for the true purpose and definition of $\mathrm{PD}$, which is to improve teachers' professional practices and provide "sophisticated, professional knowledge that goes beyond simple rules" (Ball, Thames, \& Phelps, 2008, p. 391) in their content areas in order to gain new knowledge, information, or skills (Diaz-Maggioli, 2004; Gulamhussein, 2013; Guskey \& Yoon, 2009; Hirsch, 2006; Killion \& Roy, 2009; Little, 1987; Merriam, Caffarella \& Baumgartner, 2007). With many PD models available, districts tend to stay with one model. However, Gulamhussein (2013) states top down innovation may not adjust professional development for teachers' varying content specific needs and could be a contributor to teacher frustration of PD (Merriam et al., 2007). Additionally, many districts tend to layer innovations simultaneously in an attempt to see faster gains in improvement of student proficiency on assessments; such overlapping may cause teachers to feel "inequity, confusion, and frustration" (Bolman \& Deal, 2013, p. 109) with their PD experiences. Allowing teachers to master an 
innovation before another is added (Guskey, 2009) could be the best way to foster change in the connotation of teacher PD.

While exposure to core pedagogical content is a positive move in the direction of teacher growth, exposure alone may not cause teachers to differentiate, change, or innovate their instructional practices (Alvermann, 2001; Alvermann, Moore, \& Conley, 1987; Langer, 2000). Teachers must "transfer their knowledge and learning into classroom practice" (Greenwell \& Zygouris-Coe, 2012, p. 22). Papay and Kraft's (2016) recent study found a relationship between teacher growth and the strength of the PD provided by a school district. In fact, teachers who reported their district to be highly supportive in opportunities for collaboration with effective PD opportunities and supportive administrative guidance were $39 \%$ more willing to make changes in instructional practices (Papay \& Kraft, 2016) by career year 10 than teachers working in a less supportive district: "Strong work environments create better learning opportunities for everyone" (Papay \& Kraft, 2016, p . 38).

\section{Background}

Heartland School District HSD (pseudonym) is in the top 15 largest school districts in Missouri and serves a population of 80,000 residents. While the city of Heartland is not small, it still retains a feeling of "small town" America. The school district is considered large as it educates approximately 11,500 students and employs approximately 1,000 faculty and staff. In fact, the school district is the second largest employer in Heartland. The district is composed of fourteen elementary schools, four middle schools, and three high schools, along with other facilities for credit recovery and adult education. Many of the district's graduates attend the local university or one located 
45 miles outside the city. The district is also working to attract and retain highly skilled faculty and staff and reduce the teacher turnover rate which has increased to $18 \%$ in the past two years (DESE, 2016).

In the past seven years, the Heartland School District has utilized multiple professional development (PD) structures, had a large turn-over of district level leaders, and had a variety of initiatives to help meet the yearly improvement plan. Additionally, "those not in positions of power rarely decide what learning opportunities are offered" (Merriam, Caffarella, \& Baumgartner, 2007, p. 74). Cevero and Wilson (1994) question who should decide the "purpose, content, and format" (p. xii), those with the most power, those participating, or the planners? To be effective and change practice, various studies have shown a need for teachers to use their knowledge gained through experience, plan their own learning paths, and conduct reflective self-assessment (Drago-Severson, 2008; Knowles, 1980; Trotter, 2006).

\section{Statement of the Problem}

Research has shown professional development (PD) and reflection are considered key components in improving teacher pedagogy and student achievement (DarlingHammond \& McLaughlin, 2011; Gulamhussein, 2013; Guskey, 2000; Guskey \& Yoon, 2009; Schieb \& Karabenick, 2011; Thacker, 2017; TNTP, 2015). Equally important is the factor of teacher performance and quality in classroom practices which act as the primary catalyst for increased student achievement (Ball et al., 2008; Bucynski \& Hansen, 2010; Darling-Hammond, 2000; De Kramer, Masters, O’Dwyer, Dash, \& Russel, 2012; Garritz, 2012; Gore, Lloyd, Smith, Bowe, Ellis, \& Lubans, 2017; Guskey, 2002, 2009; Guskey \& Yoon, 2009; Kyriakides, Creemers, \&Antouiou, 2009; Park \& 
Oliver, 2008). There are many different ways teachers acquire knowledge including "interest in the subject matter; general pedagogical knowledge: and interest in pedagogy; contextual knowledge: an interest in students and their communities" (Diaz-Maggioli, 2004, p. 7). Educational studies abound offering effective practices, possible methods, and reasons for what does not promote effective PD (Garet, Porter, Desimone, Birman \& Yoon, 2001; Greenwell \& Zygouris-Coe, 2012; Guskey, 2016). Guskey (2014) explains how the lack of strong evidence of effective PD may "stem from a general absence of purpose" (p. 12). Without a clear purpose, the ultimate outcomes of PD often fall flat for many school districts and fail to change classroom practices because the PD is planned "for process, not for results" (Guskey, 2014, p. 12) such as test scores or measurable increases in student learning.

\section{Problem of Practice}

This study focused on how secondary English Language Arts (ELA) teachers use pedagogical content knowledge (PCK) gained from PD to change their individual classroom practices and influence student learning. This researcher's inquiry attempts to fill gaps where more research is needed. Methods of what works for various groups of teachers is hit and miss. In fact, "few if any professional development strategies, techniques, or activities work equally well in all [contexts]" (Guskey, 2009, p. 229). Previous studies have found if PD is organized according to the underlying concepts of adult learning theory which states learning opportunities must be self-directed, reflective, hands-on, meaningful, and motivational (Argyris \& Schön, 1974; Cercone, 2008; Hadar \& Brody, 2010; Fogarty \& Peete, 2009; Gibb, 1960; Knowles, 1980; Knowles et al., 
2015; Merriam \& Bierema, 2014) - then learning should occur producing effective changes in classroom practices.

\section{Existing Gaps in the Literature}

The voice of the English Language Arts (ELA) teacher seems to be missing from contributions to research, and teacher professional development studies are rare (Greenwell \& Zygouris-Coe, 2012; Wilson, Grisham, \& Smetana, 2009). Anders, Hoffman, and Duffy (2000) discovered less than 1\% of educational research since 1965 has addressed topics surrounding teacher PD. Additionally, investigations on the impact of PD on teacher knowledge and changes made in classroom practices have been limited in scope (Goldschmidt \& Phelps, 2010). In a study of ELA teachers conducted by Lasisi Ajayi (2016), in the "more than 217 journal articles reviewed...in 2014" few "investigated teachers' perspectives about ELA" (p. 6); most focused on PD offered to science, technology, engineering, and mathematics (STEM) teachers (Popp \& Goldman, 2016). Currently, there is a lack of information as to how ELA teachers use knowledge gained from professional development and what makes it effective to provide change within their classrooms and schools: "To date, no research appears to have examined multiple teacher perspectives of secondary ELA pedagogical content knowledge (PCK) (Scarlett, 2009, p. 26).

Many studies allude to teacher involvement in selecting PD topics and teachers as PD providers; however, there is little empirical research in professional development literature centered on personal effects or perceptions of PD on teacher practice (Garet, Porter, Desimone, Birman \& Yoon, 2001; Guskey, 2016; Mouza, 2006; Supovitz \& Turner, 2000). Jehlen (2007) states PD should be created and delivered by current or 
former master teachers. Additionally, those who develop PD should discuss essential topics with teachers in order to determine their current pedagogical requirements (Greenwell \& Zygouris-Coe, 2012) because "few if any professional development strategies, techniques, or activities work equally well in all [contexts]" (Guskey, 2009, p. 229). Ajayi (2016) supports Jehlen's (2007) argument stating how teachers' perspectives offer needed awareness of how state and national standards impact daily instructional practices in "real-world classrooms" (p. 4). While there is consensus on the variety of characteristics used to classify PD as effective, there is little evidence in how they transform the practice of teaching or improve student learning (Desimone, Porter, Garet, Yoon, \& Birman, 2002; Garet, Porter, Desimone, Birman, \& Yoon, 2001; Kubitskey, Fishman, \& Marx, 2004; Supovitz, 2001; U. S. Department of Education, 1999).

\section{Purpose of the Study}

It is important to investigate how ELA teachers gain new knowledge and how they transform their classroom practices in order to increase student learning because ELA provides the foundations of reading, writing, speaking, listening, creating, and critical thinking necessary to excel in all other subject areas and disciplines. As Eisenberg (2013/2005) supports, with the increase in modern communications media in our growing global society, "these skills are essential to the health and quality of our culture" (p. 1). As all teachers know, if these foundational skills are not practiced and mastered, students will fall below grade level mastery in all subjects which will decline interest in STEM careers.

As Danielson (2007) states, teaching is often called a "flat profession" (p. 14) because teacher knowledge often does not extend past isolated lessons or beyond one 
subject area to another. Teachers may feel isolated in their classroom; therefore, it can be difficult to become subject-specialists and develop expertise in isolation (Broad, 2015; Chen \& McCray, 2012). Such isolation can lead to feelings of dissatisfaction and can cause a large percentage -- some studies site as much as $40 \%-50 \%$-- of teachers to leave the profession in their first five years (Darling-Hammond, 2003; Hill \& Barth, 2007; Ingersoll, 2007; Wong \& Wong, 2012). Effective PD is generally defined as, "involving teachers both as learners and as teachers and allows them to struggle with the uncertainties that accompany each role" (Darling-Hammond \& McLaughlin, 2011, p. 82). Little (1987) defines professional development (PD) as "any activity that is intended partly or primarily to prepare paid staff members for improved performance in present or future roles in school districts" (p. 491). As Goldschmidt and Phelps (2010) identify, when PD is studied the focus is "typically only [on] the relation of program and student achievement" (p. 432; Garet, Porter, Desimone, Birman, \& Yoon, 2001) and not on how teachers learn, transform, or transfer acquired knowledge to students.

Little research has been devoted to the adult learning styles and ways ELA teachers use pedagogical content knowledge and reflection to improve their craft (Ajayi, 2016; Desimone et al., 2002; Garet et al., 2001; Kazempour, 2009; Thacker, 2017). Therefore, knowing ELA teachers' perspectives on PD is critical to initiating change from within schools and curricular departments and supports Eisenberg's (2013/2005) call for a need to increase the foundational skills found in ELA so students may find success in all other facets of their lives. Thus, the purpose of this study is to investigate how secondary ELA teachers use pedagogical content knowledge to change their individual classroom practices. 


\section{Research Questions}

The guiding research question for this study is: How have secondary English Language Arts (ELA) teachers, from one Midwest Missouri school district, used pedagogical content knowledge gained from ELA professional development to change their individual classroom practices? Sub-questions guiding this study include:

- (a) How do secondary ELA teachers define effective professional development?

- (b) How do secondary ELA teachers implement change in their classroom practices due to newly gained pedagogical content knowledge?

- (c) How do secondary ELA teachers know when classroom practice changes have influenced student learning?

- (d) How do secondary ELA teachers know they are growing and/or transforming professionally?

\section{Theoretical Framework}

A theoretical framework is a theory used by a researcher to guide the premise of a study's inquiry; in contrast, a theory "explains what a phenomenon is and how it works" (Torraco, 1997, p. 115). This framework acts as a positioning lens for the study including how questions are asked, how data are collected and studied, and how the phenomena being studied can elicit change in the world (Creswell, 2014). Within this framework is the social constructivist paradigm in a phenomenological study where backgrounds shape interpretations through interactions with others (Creswell, 2014). Guiding this study is the theory of adult learning with the underlying concepts of selfdirected learning, reflective practice, and teacher self-efficacy and motivation. Figure 1 
presents the cyclical nature of the underlying concepts surrounding the main theoretical framework.

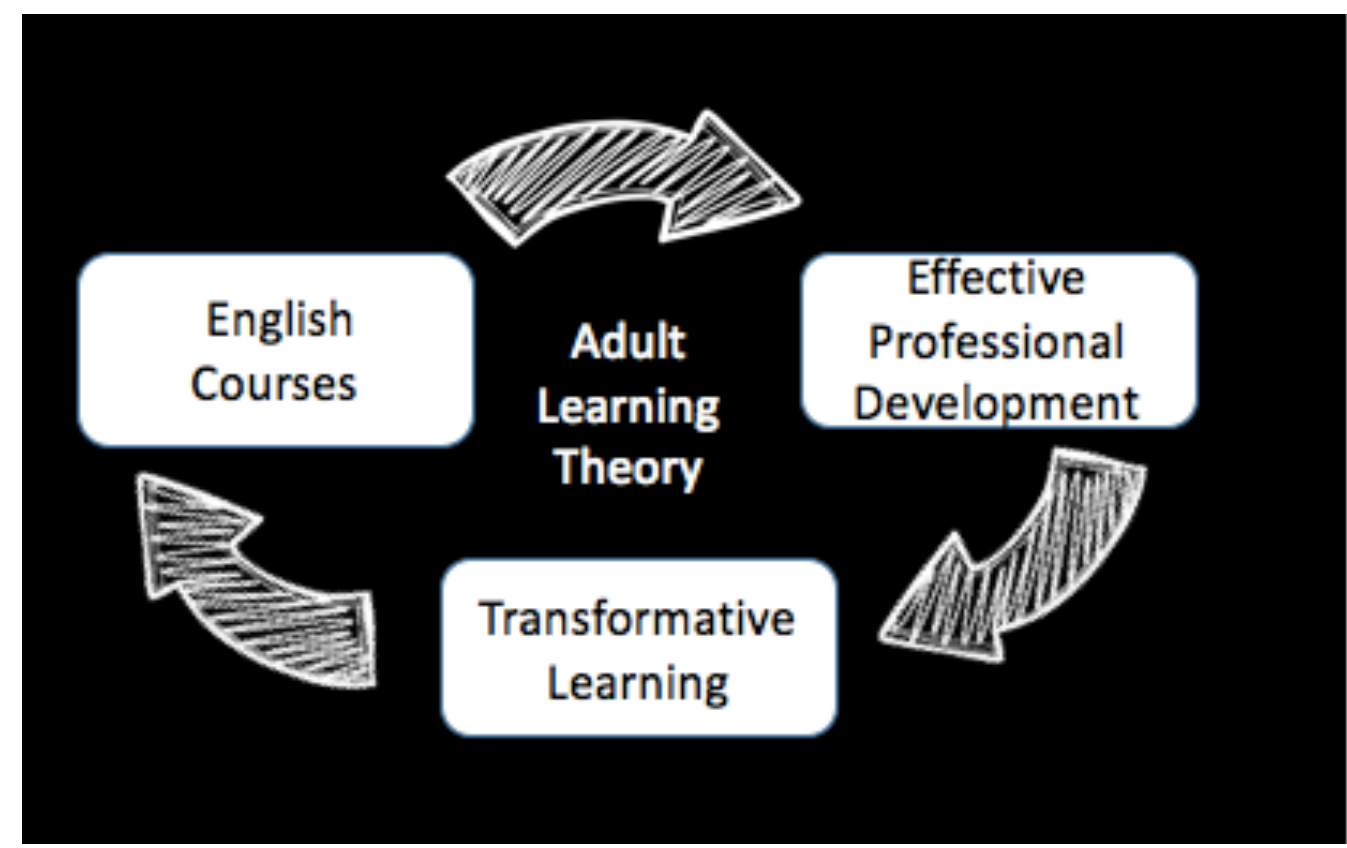

Figure 1. The conceptual framework and underpinnings of this study are depicted through cyclical motion around Adult Learning Theory. This shows the process of how knowledge is gained, transformed, and specific to a teacher's content area.

\section{Adult Learning Theory}

This study is guided by adult learning theory. For educators, learning and growing are at the epicenter of the teaching profession: "New knowledge always begins with the individual" (Nonaka, 1991, p. 97). Adults learn differently than children, and one dimension separating the two types of learning focuses on adults' previous learning experiences (Merriam \& Bierema, 2014). Society is accustomed to thinking about learning happening only in educational institutions instead of the learning occurring during daily life, and most adults do not interpret or classify the informal knowledge gained daily "as learning events" (Merriam \& Bierema, 2014, p. 17). Trotter (2006) 
determined the first key theme of effective adult learning to be using "experience as a resource" (p. 12).

\section{Andragogy.}

Malcom Knowles (1980) first introduced the concept of andragogy in adult learning theory in order to separate the process of how adults learn, "a learner-centric approach," from pedagogy which is the process of how children learn, also called an “instructor-centric approach,” (Gilstrap, 2013, p. 503 emphasis in original; Knowles, 1980; Knowles, Holton, \& Swanson, 2015). Knowles (1980, 2015) argued children need the content focus of pedagogy, but adults need a "process design" in order to relate new information gained to life-long and self-directed learning (Gilstrap, 2013). Additionally, Gibb (1960) emphasized adult learning opportunities must be problem-centered, experience-centered, hands-on, and meaningful to the learner in order to be effective (Fogarty \& Peete, 2009; Knowles et al., 2015).

\section{Self-directed Learning.}

The first concept supporting the guiding theoretical framework of adult learning is teacher self-directed learning (Knowles, 1980; Knowles et al., 2015). The informal nature of daily knowledge acquisition supports how adults become self-directed learners (Merriam \& Bierema, 2014). Many adult learners are also "highly motivated and task oriented" (Cercone, 2008, p. 139) in addition to being self-directed. In fact, adults need to understand how new knowledge will impact their daily lives; therefore, Gibb (1960) stresses how new learning must be relevant in order to be effectively implemented and change established practices (Ajayi, 2016). This premise is especially true to classroom teachers: "Because professional development often presents information that teachers see 
as irrelevant to student learning in their specific school settings, teachers often don't learn and apply what professional development programs offer" (King \& Newmann, 2000, p. 576). Therefore, teachers need the freedom to self-direct their inquiries to meet their individual needs as learners; then, as Trotter (2006) states, their professional development will become learner-centered and meaningful. "Give [adults] the big picture, offer options for learning, support their practice stages, and they will take charge of their own learning paths" (Fogarty \& Pete, 2009, p. 32).

Traditional PD tends to be formal in structure around a predetermined topic on designated days built into the school calendar and delivered by an outside expert who provides information to encourage teachers to try new strategies. Yet the methods used to provide instruction is standardized in delivery and may dismisses the individual learning styles of adult learners (Diaz-Maggioli, 2004; Hunefeld, 2009; Knowles et al., 2015). Instead, teachers need to be involved in the decisions of selecting and presenting PD. Without direct hands-on input, many teachers will disengage or feel their professional needs are not being met (Diaz-Maggioli, 2004; Fogarty \& Pete, 2009; Gibb, 1960; Hunefled, 2009; Knowles, 1980; Knowles et al., 2015). While input is often collected only through an interest or needs survey, in reality, "employee wants are only sometimes related to real performance improvement needs" (Knowles et al., 2015, p. 160 emphasis in original) and may generate low-risk decisions yielding comfort in PD topics rather than true professional growth.

Trotter (2006) furthers this premise by outlining a second key theme for effective adult learning through experience-centered choices: "adults [need] to plan their own educational paths based on their interests and their classrooms" (p. 12; Hunefeld, 2009). 
Fogarty and Pete (2009) emphasized, "There must be clear expectations and understanding of authentic transfer and the application of learning. And every session must include time to allow participants to make real-world connections to their everyday work" (pp. 33-34). Without these connections of relevancy which promote the internalization of new ideas, changes in teaching practices will not evolve. In fact, prior experiences can impede new learning or alternative thought from occurring due to learned biases and prejudicial mental habits or blind spots (Banaji \& Greenwald, 2013; Knowles, 1980; Knowles et al., 2015; Merriam \& Bierema, 2014).

\section{Reflective Practice.}

The second concept supporting the guiding theoretical framework of adult learning is teacher reflective practice in order to achieve, internalize, and evaluate professional change (Knowles et al., 2015). Since adults learn by talking and collaborating to share experiences and come to common understandings (Bouchard, 2015), the inclination to obtain new knowledge comes from the essential element of intrinsic motivation combined with engagement in reflective practices. Zhao (2012) defines reflection as, "the process through which teachers comprehend and learn from their teaching experiences and assign significance to their teaching practices" (p. 57). Argyris and Schön (1974) state, “All human beings...need to become competent in taking action and simultaneously reflecting on this action to learn from it" (p. 4). Reflective practice, "or practice-based learning, ... is learning that is acquired through reflection on or in practice (experience)" (Merriam \& Bierema, 2014, p.115). This links to Trotter's (2006) final key theme uncovered in the search for effective techniques for 
adult learners who should "promote individual development by encouraging reflection and inquiry" (p. 12).

As simplistic as the concept seems, reflecting on personal performance or practice is not a process taught to learners, but in order to grow professionally, teachers must learn to learn (Chalikandy, 2014; Rolfe, 2001). While the concept of reflection stretches back to the time of Socrates (Rolfe, 2001), it is often seen as a passive activity. Such reflection is termed by Schön (1983) as reflection-on-action in which the practitioner consciously thinks about what has occurred earlier and how to make changes for future practice (Rolfe, 2016; Merriam \& Bierema, 2014). Passive reflection will not provide the creation of new knowledge or lead to changes in classroom pedagogy; therefore, teachers should act as the "originator of her own context-specific practice-based knowledge" (Rolfe, 2001, p. 27).

If a shift which decreases the focus on distributing knowledge were to happen, leaders can instead facilitate discussions and PD which allows practitioners to investigate their own pedagogy through reflection-in-action (Merriam \& Bierema, 2014; Nonaka, 1994; Rolfe, 2001, 2016; Schön, 1983). “The characteristic mode of ordinal practical knowledge" (Schön, 1983, p. 54) is that of reflection-in-action which is "the attempt to articulate [sic] tacit knowledge and bring it into conscious awareness" (Rolfe, 2016, p. 1). The difference from reflection-on-action lies in when the reflection is taking place. Reflection-in-action occurs at the time the practitioner is engaged in her practice.

Teachers must be willing to experiment with strategies and techniques to stimulate direct change, test these changes, modify them, and then test them again in what Rolfe (2001) coins as a reflexive cycle. In fact, Schön (1987) states how such a 
reflexive cycle in reflective practices "reshapes what we are doing while we are doing it" (p. 26). In other words, it is only possible for teachers to learn the advanced skill of reflective practice when they are immersed and active in the teaching field. Additionally, results from the study conducted by Park and Oliver (2008) supports Fernandez-Balboa and Steihl's (1995) observation on effective teachers' need for integration of the components of pedagogical content knowledge (PCK) organized on modifications made in a specific class, with a particular group of students, at an exact teaching moment. Evidence shows reflective growth in one component of PCK will lead to growth in other PCK areas; however, improvement in only one area "may not be sufficient to stimulate significant change in practice" (Park \& Oliver, 2008, p. 814).

\section{Teacher Self-efficacy and Motivation.}

The third concept supporting the guiding theoretical framework of adult learning is teacher self-efficacy and motivation to gain new knowledge and implement what has been learned (Knowles et al., 2015; Merriam \& Bierema, 2014). Motivational factors such as program content, time duration, activities, and where the PD takes place can be beneficial to those determining and delivering a learning event, yet such factors are rarely considered during program planning or studied in research (Cave \& Mulloy, 2010; Merriam et al., 2007; Schieb \& Karabenick, 2011). However, motivation is about more than getting teachers to attend PD; it is about pushing them to participate and be active in the learning opportunity though collaboration or engaging in discussion (Bruffee, 1999) in order to enhance "individual; motivation and clarity of thought" (Hadar \& Brody, 2010, p. 1647). Furthermore, a lack of motivation or feelings of low self-efficacy can 
keep teachers from gaining the benefits of PD yet are vital elements in successful PD (Cave \& Malloy, 2010; Merriam \& Bierema, 2014; Schieb \& Karabenick, 2011).

Merriam and Bierema (2014) outline two types of motivation: intrinsic and extrinsic. Intrinsic motivation comes from within the person and extrinsic comes from a source outside the person (p. 147). In a study conducted by Cave and Malloy (2010), participants were more likely to engage in implementing an innovative program to a greater degree if extrinsic motivational rewards such as consistent feedback, financial compensation, support from their district, and forms of appreciation including public acknowledgement or leading PD outweighed intrinsic motivation or personal value rewards such as increased student enthusiasm, limited behavioral issues, or increased positive views on their teaching abilities (pp. 16-17). Additionally, teachers who struggled to understand the initiatives and purpose of the innovative program felt their "efficacy lowered and decreased their intrinsic motivation" (Cave \& Malloy, 2010, p. 17). Therefore, teachers who are highly motivated stay in the profession longer, participate actively in district and personal developmental pursuits, and are more likely to “implement innovative programs to increase student learning" (Cave \& Malloy, 2010, p.

5). In contrast, Knowles et al., (2015) state adults will learn if the knowledge acquisition "helps them solve problems in their lives or results in internal payoffs... which are a more potent motivator" (p. 183).

\section{Conceptual Underpinnings}

\section{Public Education and the Introduction of English Courses}

The first concept supporting the guiding theoretical framework is the history of American public education and the emergence of English as a core course of study. The 
first public or "common" schools in America were established in Massachusetts in 1935 to educate young boys seeking a religious based vocation (Baines, 2006; Singer, 2016; Watson, 2008). For decades, children of all age groups and abilities were taught together in a one-room schoolhouse until Horace Mann, "father of public education" and former Secretary of the Massachusetts Board of Education 1837-1848 (Baines, 2006, p. 272; Finkelstein, 1990), foresaw the separation of students into age level groups with a standardized curriculum as the best approach to meet age specific learning needs (Baines, 2006; Education News, 2013; Mondale \& Patton, 2002). Mann's vision has carried through to current educational separation of grades based on students' ages and abilities. Students were traditionally taught the three Rs which included reading, writing, and arithmetic. With the instruction of reading and writing came instruction in grammar, rhetoric, and oration.

The separation of what we know today as an English course came about through the merging of the individual subjects of grammar, writing, reading, rhetoric, oration, and the inclusion of literature beyond historical and biblical passages into poetry, fiction, and creative writing (Applebee, 1974; Applebee, Langer, Nystrand \& Gamoran, 2003). When Harvard University required the study of literature in 1873 as a graduation requirement, the English curriculum recognized by today's teachers was formed (Applebee, 1974). The founding of the National Council of Teachers of English (NCTE) in 1911 (Applebee, 1974; Applebee et al., 2003; NCTE, 1996) cemented Mann's core educational beliefs by preparing students for a widening range of literacy requirements (NCTE, 1996). Current pedagogical beliefs and adoption of the common Core State Standard (CCSS) have placed English Language Arts (ELA) teacher on the front lines of 
the fight for improved literacy with ever increasing pressure to be the sole providers of reading and writing instruction (Applebee 2013; NCABP \& CCSSO, 2010; Wilson, Grisham, \& Smetana, 2009). Therefore, English teachers are often seen as the cornerstone of education because of the subject's ability to produce new knowledge in open and creative ways other core subjects such as math and science cannot (Ajayi, 2016; Kress, Jewitt, Bourne, Franks, Hardcastle, Jones, \& Read, 2005; Reutzel, 2013).

\section{Characteristics of High-Quality and Effective Professional Development}

The second concept supporting the guiding theoretical framework is determining the elements of high-quality and effective professional development (PD). While PD is common place in the world of education, teachers are expected to attend PD each year for their content areas, building initiatives, state and national conferences and workshops, and their own interests. However, Greenwell and Zygouris-Coe (2012) note the biggest transformation with knowledge gained in PD may come about "not so much in the discovery of new knowledge, but in [the] capacity to use...the knowledge we have" (p. 10). By focusing on content knowledge (CK) or pedagogical content knowledge (PCK), teachers will increase and refine their classroom practices; furthermore, $\mathrm{PD}$ in a teachers' content area has a greater impact on teacher and student performance than PD focused on pedagogy alone (Garet, Birman, Porter, Desimone, \& Harman, 1999; Park \& Oliver, 2008; Shulman, 2013). Yet, the more PCK a teacher possesses, the larger their anticipated impact on classroom practices and increased student learning (Ball et al., 2008; Park \& Oliver, 2008). Experts and researchers are able to agree on a few defining characteristics of effective and high impact PD. These characteristics include collaboration, active/hands-on learning experiences, sustained learning over time, attitude 
toward learning, collaboration and dialogue, and assessment (Bennett \& Jessani, 2011;

Bruffee, 1999; Darling-Hammond \& Richardson, 2009; De Kramer et al., 2012;

Desimone, 2011; Fogarty \& Peete, 2009; Gill, 2010; Guskey, 2002; Killinger, 2004;

Knowles et al., 2015; Merriam \& Bierema, 2014; Nonaka, 1991; Reeves, 2010).

\section{Transformative Learning}

The final concept supporting the overarching theoretical framework centers on transformative learning with a learner's prior experience as the "primary medium of transformative learning" (Taylor, 2009, p. 5). The original definition of learning is linked to "a change in behavior" (Merriam \& Bierema, 2014, p. 24). A change in behavior is integral to the process of transformation. Emphasis has been put on the role of experience as a key element of learning (Bruffee, 1999; Gill, 2010) and defines transformative learning as "the process of learning through critical self-reflection" (Mezirow, 1990, p. xii). Also essential to the adult learning process is the action of making decisions based on insights (Mezirow, 1990, 1997, 2000). "Effective PD brings our habits of mind about teaching into consciousness... The goal is to open up alternatives, introduce new ways of thinking about teaching - a goal that is potentially transformative" (Cranton \& King, 2003, p. 34).

\section{Design of the Study}

\section{Methodology}

In order to understand the ways in which teachers grow professionally and perceive professional development, the researcher used a qualitative method from a pragmatic view of reality, wherein "a worldview arises out of actions, situations, and consequences rather than antecedent conditions" (Creswell, 2016, p. 10). Within this 
method, participants were able to express their perception of professional growth based on experiences and processes through a phenomenological qualitative methodology where "the research describes the lived experiences of the individuals about a phenomenon as described by participants" (Creswell, 2016, p. 14; Creswell, 2014; Seidman, 2015). A qualitative methodology builds "from particulars to general themes" allowing for "interpretations of the meaning of the data" (Creswell, 2014, p. 4).

This embedded, single-case study investigated "a unique occurrence or critical instance" (Martinson \& O'Brien, 2015, p. 185) and included a unit of analysis at one location. This differentiates the study from other types of qualitative research (Merriam $\&$ Tisdell, 2016). Therefore, it is considered a bounded study as it encompassed research gathered from only secondary ELA teachers within the same school district on the same topic (Creswell, 2014; Yin, 2009, 2012).

\section{Site Description and Selection}

The Heartland School District (HSD) is a bounded system purposefully selected due to its current administrative, financial, and programs restructuring which focused on using professional development as a vehicle to move students toward success. Heartland is situated 40 miles north of a major metropolitan area separated by small towns and farm land. According to a 2015 US Census Bureau survey, Heartland has a population of 76,596. The population is predominantly White $87.8 \%$, African American 6\%, Hispanic or Latino 5.7\%, and Asian 0.9\%. The median household income is $\$ 43,298$ which is $12 \%$ below the state's average income of $\$ 48,173$. Almost twenty percent of citizens in Heartland are living below the poverty level compared to the $14.8 \%$ mean poverty level across the state of Missouri. Of the three high schools and four middle schools, the 
average free and reduced lunch rate is $58 \%$ of all secondary students according to the 2016 statistics report from the Missouri Department of Elementary \& Secondary Education. The district's 2018 annual report states $71.5 \%$ of enrolled students are eligible for free and reduced lunch; this is $20 \%$ higher than the state of Missouri's rate of 51\%. Additionally, teachers in the Heartland District have a median longevity of 12.2 years, and $49.6 \%$ of teachers have obtained a master's degree or higher (DESE, 2016).

\section{Participant Sample}

HSD employs 56 secondary English Language Arts (ELA) teachers. Stakeholders for PD also include an ELA Curriculum Advisor, departmental chairs, building principals, and central office district administrators. In order for participants to express their perceptions of professional growth based on their own experiences and processes in a real-world context (Bromley, 1986; Yin, 2012; Yin, 2009) the researcher used purposeful sampling by selecting maximum variation and theoretical sampling as defined by Merriam and Tisdell (2016, pp. 97-99). The researcher balanced ethical issues in terms of relationships with colleagues as participants and critical, qualitative research by doing work for the greater good (Drake \& Heath, 2011, Seidman, 2012).

The researcher sent out recruitment email letters to all secondary ELA teachers in order to gage and increase interest in participation; then a survey was launched to gain information from those teachers who were willing to participate in the research. The recruitment email is located in Appendix A and the survey in Appendix B. Individual interviews were then scheduled using a purposeful sampling technique allowing the researcher to select interviews from those educators whom the most can be learned (Merriam \& Tisdell, 2016). Prior to all interviews and the focus group, the researcher 
obtained informed consent from all participants according to the American Educational Research Association guidelines. The informed consent forms provided participants with an overview and purpose of the study, procedures involved in participation, any foreseeable risks to participation, compensation for participation, a statement of voluntary participation and the right to stop participation at any time, as well as a statement outlining and guaranteeing the participant's right to confidentiality (Fink, 2017). The IRB approved informed consent forms can be found in Appendix C. The open-ended interview and focus group guiding questions can be found in Appendix D.

A total of 21 teachers participated in individual interviews and a focus group; this is $37.5 \%$ of the ELA district teacher population. Responses were analyzed as a whole and also by dividing teacher participants into groups based on their number of years in the profession. Experience groupings were broken down into four categories: novice teachers with one to five years of experience, transitional teachers with six to ten years of experience, mid-career teachers with 11 to 20 years of experience, and veteran teachers with 21 to 30 years of teaching experience. Table 1 provides the number and percentage of teacher participants within each experience group category. This breakdown is representative of the district with a median longevity of 12.2 years of teaching experience (DESE, 2016). 
Table 1

Percentage of Participant Group Categories in the Study

\begin{tabular}{lcc}
\hline $\begin{array}{l}\text { Groupings by Years } \\
\text { of Teaching Experience }\end{array}$ & $\begin{array}{c}\text { Number of Teacher } \\
\text { Interview Participants }\end{array}$ & $\begin{array}{c}\text { Percentage of Total } \\
\text { Study Participants }\end{array}$ \\
\hline $\begin{array}{l}\text { 1-5 Years of Teaching } \\
\text { Experience }\end{array}$ & 3 & $14 \%$ \\
$\begin{array}{l}\text { 6-10 Years of Teaching } \\
\text { Experience }\end{array}$ & 4 & $19 \%$ \\
$\begin{array}{l}11-20 \text { Years of Teaching } \\
\text { Experience }\end{array}$ & 10 & $48 \%$ \\
$21-30$ Years of Teaching & 4 & $19 \%$ \\
Experience & $21 / 56$ & $37.5 \%$ of all ELA \\
$\begin{array}{l}\text { Total ELA Teacher Participants } \\
\text { Teachers }\end{array}$ & & \\
\hline
\end{tabular}

\section{Rational of Category Creation}

The created category of novice teacher was limited to the first five years of teaching experience because $40-50 \%$ of teachers leave the profession in the first five years and never make it out of the novice category where most professional growth occurs (Darling-Hammond, 2003; Ingersoll, 2007; Hill \& Barth, 2004; Papay \& Kraft, 2015; Wong \& Wong, 2012). The category of transitional teacher was created for those with six to ten years of experience. At this career point, they have established themselves in the classroom, developed their professional reputation, and generally remain eager to learn and grow despite the predicted plateau of growth after five years of experience (Clotfelter, Ladd, \& Vigdor, 2006). Berliner (2001) describes teachers in this experience rage as those who are becoming advanced beginners and are developing essential skills of becoming teacher experts. The category of mid-career teacher was created for those with 11-20 years of experience. Teachers in this range generally stay in the profession until 
they retire. Despite the findings of a 2008 study conducted by Ladd which claimed midcareer teachers are no more effective than their colleagues with five years of experience, mid-career teachers tend to seek advanced degrees, attend more PD, and use reflective practices more than those with less experience and are entering the proficient stage of becoming a teacher expert (Berliner, 2001). Glaser (1996) found teachers in this range are more in control of their own learning, engaging in deliberate practice of skills and seeking performance feedback. Finally, the category of veteran teacher was created for those with 21-30 years of experience. Teachers in this range tend to be the master teachers within a district and looked to as teacher experts. At this stage, teachers are able to pull from past experience using reflection, collaboration, and research to make difficult decisions about teaching strategies (NBPTS). Dubliner (2001) supports the NBPTS findings while Glaser (1996) finds these teachers to be the most self-regulatory in their practices and learning. For many, learning has become their passion.

\section{Researcher Participation and Positioning}

The researcher of this study will use action research to engage participants as a means to "improve their practice" (Merriam \& Tisdell, 2016, p. 49) and "to develop and maintain social interpersonal interactions" (Stringer, 2014, p. 23). In doing so, the researcher transferred between being an insider-outsider simultaneously and moved back and forth between the two (Drake \& Heath, 2011, Merriam \& Tisdell, 2016). The researcher is employed by the Heartland School District and teaches at one of the three high schools within the district. Some of the survey participants and interviews were held within the district but outside the researcher's teaching school. All research was collected from the seven secondary schools. 


\section{Data Collection}

The researcher of this study first had to obtain approval from the Heartland School District's Office of Research data task force (Appendix E) to conduct research within the district and interview current ELA teachers (Cresswell 2016). Once the district approved the study and the researcher successfully completed a proposal defense, Institutional Review Board (IRB) approval from the University of Missouri, Columbia was sought and approved on 5/5/2018 with an amended approval granted on 5/17/2018 (Appendix F). Because the researcher was not gathering data from students or any at-risk population, the IRB review was expedited.

This research study collected data from multiple sources in order to form a triangulation of data (Merriam \& Tisdell, 2016) which ensured internal validity and gained multiple perspectives on the topic (p. 245). The researcher used archival district departmental surveys launched in the 2017-18 school year; the surveys were open to all secondary ELA teachers in the district in order to determine PD interests and ensure all teachers had a voice in the research findings. Questions from district surveys analyzed for this study are presented in Appendix G.

The interviews were conducted face-to-face and recorded using the services of www.Rev.com for transcription. Interviews were semi-structured in design (Merriam \& Tisdell, 2016, p. 110; Smith, Flowers, \& Larkin, 2009), and used a neo-positivist framework (Merriam \& Tisdell, 2016, p. 112) in which the interviewer was able to "[ask] good questions, [minimize] bias... [generate] quality data and [produce] valid findings" (Roulston, 2010, p. 52). Interviews were short in duration, ranging between 15-30 minutes, and applied Fink's (2017) reliability and validity test by asking all participants 
included questions. In addition, a homogeneous focus group (Krueger \& Casey, 2015) of mid-career and veteran secondary ELA teachers with 11 to 30 years of experience was held to further explore perceptions and ideas about PD gathered from individual interviews. The researcher followed a directional script (Appendix H) to ensure each teacher participant had a similar interview experience. Once transcription was completed, the researcher sent a copy of the interview to individual participants so they could review their responses and ensure their intentions were accurately portrayed. Table 2 presents the triangulation of data collection strategies linked to the over-arching research question's sub-questions.

Table 2

Summary of Data Collection for Study

Sub-Questions

How do secondary ELA teachers define effective professional development? (Interview questions 1-5)

How do secondary ELA teachers implement change in their classroom practices due to newly gained pedagogical content knowledge? (Interview questions 6-9)

How do secondary ELA teachers know when classroom practice changes have influenced student learning? (Interview questions 10-11)

How do secondary ELA teachers know they are growing and/or transforming professionally? (Interview questions 12-16)
Data Collection Strategies

Interviews, Focus

Group

Interviews, Archival PD Surveys, Focus Group

Interviews, Focus

Group, (possible Student Artifacts), \& Archival PD Surveys

Interviews, Past PD Surveys, Focus Group

\section{Data Analysis}

After all data were collected, the researcher utilized an hermeneutic method (Goodrick \& Rogers, 2015) and Creswell's (2016) concept of planning backwards to find emergent themes. Open coding was used on all interview transcripts, focus group 
transcripts, and qualitative questions on district and departmental archival surveys using the online www.Atlas.it program. Then by recoding findings using axial coding; emergent themes were then grouped (Creswell, 2016; Gallicano, 2013; Goodrick \& Rogers, 2015; Krueger \& Casey, 2016; Merriam \& Tisdell, 2016). Archival district and department surveys were used to validate participant data. Reports were created in www.Atlas.ti using code concurrent table crosschecking; hand coding was used to further validate researcher findings and uncover sub-theme emergence within already identified themes . From this process, relationships between themes formed naturally into refined categories from what the data directly stated (Seidman, 2013). The use of multiple methods (Caffarella \& Daffron, 2013) open process showed how "multiple sources of data helps build the codes, and in turn, the evidence for the theme[s]" (Creswell, 2016, p. 157). Through this process the researcher was able to eliminate any redundancy and overlap of categories and themes. Follow-up interviews were conducted as needed based on initial findings from the coding process.

\section{Limitations, Delimitations, and Assumptions}

\section{Limitations}

This study focused on the perception of secondary English teachers from one school district; therefore, the researcher must monitor generalizability of findings as representation of all secondary English teachers (Merriam \& Tisdell, 2016). Qualitative case studies are limited by what and how much information participants are willing to share, their perceived truth of an event or idea, and the researcher's interpretation of gathered data (Merriam \& Tisdell, 2016). Participants were assured their responses would only be used for investigative purposes and would not impact their job 
performance in any way. Some teacher participants may be intimidated by the researcher's recent promotion to English Language Arts secondary professional development and curriculum advisor within the district. While the researcher's new role is not evaluatory, some teachers may view the position as authoritative or administrative in nature and therefore may be less inclined to be candid or completely open in their responses. A further limitation may be based on teacher participants' perception of actual classroom practice change from learning gained at ELA PD. Beyond accepting participant stories collected during interviews to be true accounts of personal and classroom changes, the research is limited in ability to verify specific changes.

\section{Delimitations}

Case studies have natural boundaries and parameters (Merriam \& Tisdell, 2016). The geography of the district's location may not be a true representation of the feelings of all secondary English Language Arts teachers across the state or nation. No data are included in this study about participants' lives or how their life experiences have impacted their teaching practices or perceptions of professional development provided by the district.

\section{Assumptions}

Not only does this study include limitations and delimitations, there are also assumptions present. Several assumptions must be kept in mind when interpreting the findings of this study: all participants gave individual and honest responses to all questions with no discussion or input from other participants, building, or district leadership; cultural differences held no bias or impact on participant answers, and participants were not compensated for their participation in this study. The participants 
interviewed showed trust in the researcher by providing what the researcher felt were honest and candid responses to questions. Participants were encouraged to express their ideas, and all reports of collected data are an accurate reflection of participants' own words and have not been changed for the purpose of this study. Therefore, no pattern of teachers' perceptions of district provided professional development was assumed. Yet, making assumptions based on previous knowledge or interaction with participants can skew researcher findings and limit the purpose of qualitative research design: learning from subjects (Creswell, 2014).

\section{Definitions of Key Terms}

Adult Learning: Is "the process of adults gaining knowledge and expertise" (Knowles et al., 2015, p. 157). Additionally, learners desire control over their learning and learning increases as a result of this individual control of the learning process.

Classroom Teaching/Instructional Practice: While there is no one way to best define classroom teaching or instructional practice, studies have agreed "the effectiveness of classroom practice is domain specific as well as goal-specific" (TALIS, 2009, p. 97). However, the quality of instruction within the classroom is critical to student learning. Practices may include "structuring practices" such as stating learning goals or objectives, checking work, or checking for understanding through formative assessments; "studentoriented practice" such as small group work or ability grouping; and "enhanced activities" where students produce a product, an essay, or debate a topic (TALIS, 2009).

Content Knowledge (CK): This is the teachers' personal knowledge of the content area they teach and how to implement instructional materials to best meet curricular and state objectives. Content knowledge must go beyond the comprehension 
of facts and concepts of a subject's domain and delve into the principles and structure of a subject area (Shulman, 2013).

Effective Professional Development: Is aligned to performance standards as well as state and district curriculums, deepens educators' content knowledge and pedagogical content knowledge, uses student learning outcomes and models to implement change within the classroom, and supports sustained professional communication through collaboration with other teaching professionals (DESE, 2013). Additionally, the end result of effective PD is based on the students' ability to show growth in knowledge and abilities (Strickland, 2009).

English Language Arts (ELA): This is a specific content area centered around the reading of literature, informational texts, and non-print texts; writing expository, narrative and argumentative texts; speaking and listening skills for collaboration and presentations, as well as instruction in grammar and conventions of the English language (NCTE, 1996).

Learning: Is "the acquisition of knowledge or skills through experience, study, or being taught" (New Oxford Dictonary, 2010). A change in behavior or thinking due to experiences.

Pedagogy: The tools to support the art and science of teaching; "the 'how' of teaching" (Curtiss-Williams, 2009).

Pedagogical Content Knowledge (PCK): Researchers have failed to reach a consensus of a definitive definition of pedagogical content knowledge or a focus of what it entails for specific content areas (Ball, Thames, \& Phelps, 2008). However, Shulman (2013) expressed how PCK bridges and joins content knowledge and the practice of 
teaching into "a special kind of technical knowledge key to the profession of teaching" (Ball et al., 2008, p. 390) which is instinctive to expert teachers (Park \& Oliver, 2008), and "[is] the result of a transformation of knowledge from other domains" (Magnusson, Krajcik, \& Borko, 1999, p. 96).

Personal Growth: In the state of Missouri, each teacher must have a personal growth plan which outlines the professional development activities on which the teacher intends to focus as part of the annual evaluation process. Areas for personal growth may include but not be limited to seeking an advanced degree, participation on committees or teams, reflective journaling, participation in a book study, participation in a mentoring program, conference attendance, or peer observations.

Professional Development (PD): The term "professional development" is defined by the National Staff Development Council, now Learning Forward, to mean "a comprehensive, sustained, and intensive approach to improving teachers ${ }^{\text {ee }}$ and principals, effectiveness in raising student achievement, and may be supported by activities such as courses, workshops, institutes, networks, and conferences" (Wei, DarlingHammond, Andree, Richardson \& Orphanos, 2009, p.4). Additionally, effective PD “accommodates teachers as learners, recognizes the long-term nature of learning, and utilizes methods that are likely to lead teacher to improve their practice as professionals" (Gaible \& Burns, 2005, p. 16).

Reflection: The cyclical practice of thinking about one's own previous experiences "reshapes what we are doing while we are doing it" (Schön, 1987, p. 26) and is a core principle of adult learning and transformative learning. 
Self-Efficacy: Self-efficacy influences how individuals think, feel, act, and are motivated in regards to their personal judgement about their capability to complete a task and produce a desired effect (Bandura, 1995).

Teacher: A certified educator in a specific content area or grade level who is accountable for implementation of national, state, and district curriculum and its impact on student learning.

Transformative: Transformative learning is a process where adult learners "transferring current frames of reference (meaning, perspectives, habits of minds, and mind sets) to make them more inclusive, discriminating, open, emotionally capable of change, and reflective" (Mezirow, 2012, p. 76).

\section{Significance of the Proposed Study}

The purpose of this study is to address a gap in the current research focusing on the lack of information on how English Language Arts (ELA) teachers' use PCK to change individual classroom practice when new learning has occurred during professional development because little research has been devoted specifically to the learning styles and methods of ELA teachers (Ajayi, 2016; Thacker, 2017). Additionally, most studies centering on ELA teachers focus on how writing and reading skills are taught to students, not how and what teachers do to grow professionally and prepare to teach students the essential skills of reading, writing, speaking, listening, creating, and critical thinking. Therefore, this study intends to shed light on how teachers can improve student success from their own learning obtained during PD and generate school improvement from within by changing their classroom practices. 


\section{Scholarship}

This study aims to contribute to the research by "adding a needed voice of the English language arts teachers" (Greenwell \& Zygouris-Coe, 2012, p. 25) who require ongoing, site-based support in order to truly change their practices (Thacker, 2017). Traditionally, when PD is studied the focus remains on student growth and achievement (Goldschmidt \& Phelps, 2010) rather than how teachers learn or transform acquired knowledge (Garet, Porter, Desimone, Birman, \& Yoon, 2001). Therefore, knowing ELA teachers' perspectives on PD (Greenwell \& Zygouris-Coe, 2012) is critical to initiating change from within curricular departments and schools.

\section{Practice}

This study is significant because it is meant to show not what is wrong or does not work with PD delivery, but instead it aims to endorse and enable teachers to share their expertise and knowledge with colleagues as there is a "need for large-scale research about...expert teachers (who can provide models of effective instruction)" (Ajayi, 2016, p. 16). Uncovering ways to improve PD is a true grand challenge (Colquitt \& George, 2011, p. 432) because of the quick changes in curricular demands from national and state legislation. Avoiding the familiarity trap (Colquitt \& George, 2011, p. 433) of simply determining what does not work and continuing to do more of the same (Gulamhussein, 2013) in traditional PD models is not enough. This study aims to fill in one more piece of the ever changing educational puzzle. Teachers can change their districts from the inside out by sharing their expertise and knowledge "[highlighting] the effect[s] of new and important practices" (Colquitt \& George, 2011, p. 434). The profession of teaching requires constant growth as it is a field marked with economic problems and changing 
needs which includes the challenge of covering a growing expanse of content while teaching specific skills at an in-depth level. Therefore, it is important to understand how ELA teachers use newly acquired knowledge to initiate classroom practice transformation.

\section{Summary}

Learning to learn (Chalikandy, 2014) is the basic premise of growing professionally and is an active response to the teaching profession, and it is important to remember "all educators are learners first" (Merriam \& Bierema, 2014, p. 251). Teachers can choose to grow and put forth the effort to do so, or they will languish or stagnate ((Ettling, 2012; Kotter, 2011; Merriam \& Bierema, 2014). Scrivener (2005) states "the first important steps towards becoming a better teacher involve an increased awareness about what one does now and openness to the possibility of change" (p. 376; Preskill \& Brookfield, 2009). Such openness to change allows educators to acknowledge new possibilities and move forward in approaches and aims in their personal and professional practices through self-directed learning, reflective practice, self-efficacy, and internal motivation (Argyris \& Schön, 1974; Cercone, 2008; Fogarty \& Peete, 2009; Hadar \& Brody, 2010; Knowles, 1980; Knowles et al., 2015; Merriam \& Bierema, 2014). By researching the Heartland School District's ELA Departmental PD practices, PD leaders will understand the successes and challenges of providing learner focused growth opportunities. Innumerable studies exist focusing on effective practices, methods, and reasons for why professional development does and does not work (Ajayi, 2016; Guskey, 2014; Thacker, 2017). Through the exploration of adult learning theory and literature related to public education's introduction of English courses, characteristics of high impact professional 
development and barriers, with transformative learning, this study seeks to add the perceptions of secondary English Language Arts teachers which is lacking in current research (Ajayi, 2016; Greenwell \& Zygouris-Coe, 2012; Scarlett, 2009).

This bounded, single-case study used a phenomenological qualitative methodology. In addition to semistructured individual interviews, the triangulation of data also included the use of focus groups and an archived survey. Using these design elements, the researcher will provide insight into how other districts can encourage teachers to foster changes in learning throughout their districts. Discovering the perceptions of how teachers accomplish such growth is the directing principle for this research study. 


\section{SECTION TWO}

\section{PRACTITIONER SETTING FOR THE STUDY}

\section{Federal Professional Development History}

In 1983 A Nation at Risk was published by the National Commission on Excellence in order to expose what DuFour and Eaker (1998) pinpoint as threats to national security: inferior educational practices and services provided in the nations' public schools. Thus, public education entered an age of reform, restructuring, and regulations. Harris and Levin (1992) note in 1986, the release of a second report, $A$ Nation Prepared, focused on restructuring America's teaching force by offering teachers more freedom in determining instructional practices to best meet students' achievement needs.

President Bill Clinton signed the Goals 2000: Educate America Act (Public Law 103-227) on March 31, 1994 as a catalyst for school improvement and improved education for all students by the year 2000. DuFour and Eaker (1998), based on -, state in addition to focusing on graduation rates, adult literacy, and increased parental involvement, teachers were pushed to continue their professional growth and find opportunities to increase their pedagogical and content knowledge. The No Child Left Behind Act (NCLB) was signed into law by President George W. Bush in 2001 as a means to once again reform educational standards and raise all students to a level of proficient or advanced by 2014 (Public Law 107-110, 2001). Section 910 (34)A of NCLB designated achievement standards for staff to include high-quality, sustained, and intensive PD opportunities be evident in all school district improvement plans. 
In 2009, President Barack Obama introduced a 'Top 10 by 20' initiative which "aims to propel Missouri's student achievement into the top 10 states by the year 2020" (MoDESE, 2016). This Race to the Top initiate offered states monetary incentives for embracing educational policy determined by the Obama administration (Klein, 2017). This initiative falls under the Every Student Succeeds Act (ESSA) signed into law on December 10, 2015 and focuses on "high-quality classroom instruction through professional development" (U.S. Department of Education, 2015). Missouri applied for the initiative, adopted the new CCSS and teaching practices but was ranked 33 overall (Howell \& Magazinnik, 2017). Thirty-six states and the District of Columbia have elected to continue to utilize the CCSS (Klein, 2017). However, for Fall 2017, Missouri elected to repeal the Common Core State Standards (CCSS) and replace them with newly aligned Missouri Learning Standards. Under Missouri Revised Statute § 161.092 goal three, updated in January of 2016, the state will "prepare, develop, and support effective educators" (p. 2) in addition to retaining highly qualified teachers. The revised ESSA prevents any future initiatives which offer states enticements (Klein, 2017).

\section{History of the Organization}

\section{Heartland Public School District}

Heartland (pseudonym) was the second city in the state of Missouri to open a public high school in March of 1861 through the beginning of the Civil War in June of 1861; it reopened in 1864 (Foley, 2015). From its reopening, Heartland School District has maintained the vision of "the teacher [as] the school" (Foley, 2015, p. 14) as the district has moved to its current mission statement of "Educating each Child for Success." The district continues to support three core values: commitment to excellence, integrity 
of actions, and culture of collaboration. Despite many setbacks and declines in manufacturing and production as well as agriculture employment opportunities within Heartland, the school district continues to graduate $88.6 \%$ of its students which is $2.9 \%$ higher than the state average (Census Bureau, 2015) despite a free and reduced lunch rate at $58 \%$ of secondary students (DESE, 2016). Many of the district's graduates stay in Heartland to attend the local university, an online technical university, one of two technical schools, or a university located 45 miles outside the city.

Heartland School District (HSD) is in the top 15 largest school districts in Missouri and serves a population of 76,596 residents making it the eighth largest city in the state. The ethnic population is comprised of predominantly White $87.8 \%$, African American 6\%, Hispanic or Latino 5.7\%, and Asian 0.9\% (Census Bureau, 2015). While the city of Heartland is not small, it still retains a feeling of "small town" America as it is surrounded by other small towns and farm land. The median household income is $\$ 43,298$ which is $12 \%$ below the state's average income of $\$ 48,173.19 .9 \%$ of citizens in Heartland are living below the poverty level compared to the $14.8 \%$ mean poverty level across the state of Missouri (Census Bureau, 2015).

Heartland is located 40 miles north of a major metropolitan area. The school district is considered large in it educates approximately 11,500 students and employees just over 1,000 faculty and staff. In fact, the school district is the second largest employer in Heartland. The district is composed of fourteen elementary schools, four middle schools, and three high schools, along with other facilities for adult education and secondary credit recovery. In addition, there are two private school districts within Heartland city limits. 
The district is working to attract and retain highly skilled faculty and staff and reduce the teacher turnover rate which has increased to almost $20 \%$ over the past two years and continues to climb according to an internal district report. In the past five years the HSD has undergone several high profile investigations, the loss of a recent tax levy, recent changes in administrative leadership, and deep budget cuts upwards of eight million dollars. Despite high turnover rates, the teachers of Heartland have a median longevity of 12.2 years of teaching experience, and $49.6 \%$ of teachers have obtained a master's degree or higher (DESE, 2016).

\section{Four Professional Development Structures}

In the past seven years, the district has undergone rapid and multiple changes in the structure of professional development (PD) along with the elimination of core departmental curriculum advisors for classroom instruction and intervention. Therefore, it often seems "those not in positions of power rarely decide what learning opportunities are offered" (Merriam et al., 2007, p. 74). Cevero and Wilson (1994) question who should decide the "purpose, content, and format" (p. xii), those with the most power, those participating, or the planners? To be effective and change practice, various studies have shown a need for teachers to use their knowledge gained through experience, plan their own learning paths, and conduct reflective self-assessment (Drago-Severson, 2008; Knowles, 1980; Trotter, 2006).

In multiple formats of $\mathrm{PD}$, departmental advisors occasionally participated in the planning process. This may have been a factor leading to the numerous PD focus topics over the course of the past seven years. Archival ELA departmental feedback surveys from 2011-2016 indicate an increase in teacher frustration because of "a lack of 
communication between district leaders, building level leadership, and departmental specialists," "gaps in individual improvement plan focuses for the district, departments, and buildings," and "being asked to implement practices which do not meet classroom instructional needs." Previous district administration mandated three separate foci: one as an entire district, one for each department, and one for each building in the district.

In the past seven years, the district restructured its format for delivering PD using four different methods. Refer to Figure 2 for a breakdown for each structure of the district's professional development delivery formats and determination methods. The first structure included the scheduling of ten or more days during the school year where students were dismissed two hours early so faculty and staff could attend three or more hours of professional development designed by individual building administration. Most of these meetings occurred during the first quarter of school and focused on compliance training, reviewing school safety issues, and general building housekeeping matters. The second structure also included ten days of early dismissal and assigned principals, viceprincipals, and instructional coaches from all middle and high schools to a random content area. Therefore, educational leaders who had no background in English Language Arts (ELA) were assigned to develop and present content PD. Content leaders under this model were not involved in developing the topics or the dissemination methods used in PD. Neither of these PD formats were based around a specific content area, instead; content was left up to administrative leaders' discretion and choice. 


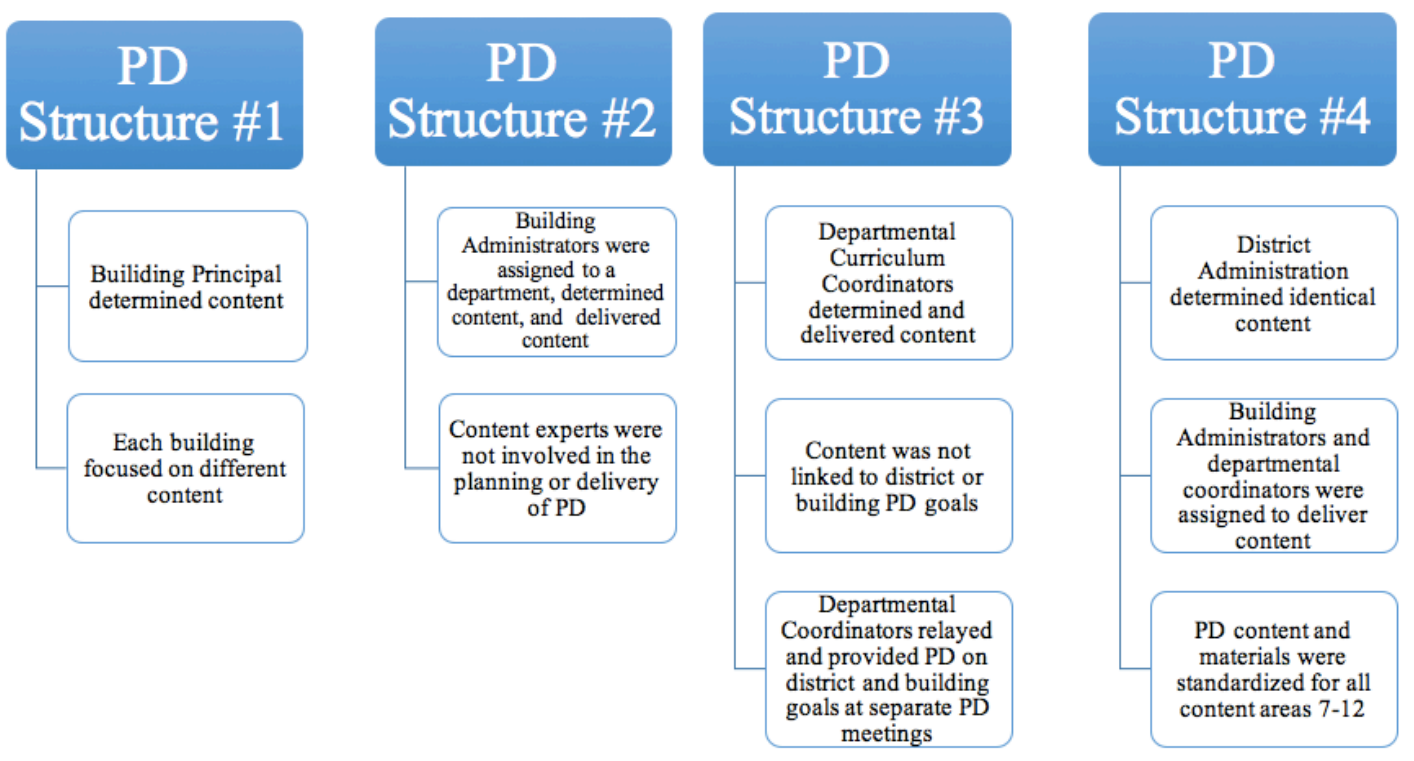

Figure 2. This figure outlines the delivery and content methods of the district's past four professional development structures for all content areas including English Language Arts from 2011-2016.

The third incantation of PD positioned departmental advisors with administrative support to deliver three full days of PD throughout the year. Administrative duties were often reassigned the day of PD causing administrators to leave the PD early to attend other meetings. These changes caused departmental advisors to adjust to last minute changes. In addition, second quarter had begun before the district's focus for the year was unveiled along with the department's focus and each building's focus, which held little to no overlapped in content. With information and mandates coming after instruction started, it was well into the school year before teachers could begin to incorporate assigned strategies and goals into their instructional design.

In the fourth structure of PD, the district determined each content area should receive identical professional development in order to expose all teachers to the demands 
of the newly proposed Common Core State Standards (CCSS) and to better prepare students for upcoming state tests. CCSS built ELA standards into cross-curricular subjects; therefore, the same instructional material used to discuss the year's topic of argumentative writing with ELA teachers, was the same material presented to Algebra I teachers, Fine Arts teachers, and Special Education teachers. Therefore, Family and Consumer Science and Physical Education teachers had to incorporate the writing of an argumentative essay into their lesson plans even though argumentative writing was not a component of their curriculums. Those delivering the PD content had limited knowledge of how the writing standards could be applied to classrooms and content areas outside ELA. Many presenters sought help from ELA teachers to aid in understanding.

\section{Organizational Analysis}

Heartland School District is similar to other large organizations in how there is a complex hierarchy with many working parts. According to Bolman and Deal (2013), "the structural frame looks beyond individuals to examine the social architecture of work" (p. 66). In Heartland's case, the top-down innovation failed to adjust professional development for content specific needs. The narrow focus of implementing how to write an argument from the Common Core Standards in all content areas was used to expose students to the concept of argumentative writing in all classes to hopefully raise future test scores. How the standards could be implemented into the curricula once the state adopted them left teachers with more questions than answers about how to meet the advanced level of critical thinking required of students. Thus teachers felt, as Bolman and Deal (2013) describe, "inequity, confusion, and frustration" (p. 109) when asked to 
go beyond established building and departmental goals and intertwine new teaching standards with current curricula and state test preparation.

\section{Structural Frame}

Through vertical coordination (Bolman \& Deal, 2013), former district administration (none of whom are still employed within the district) assumed the best method to disseminate information was to provide identical PD to all district teachers over the course of a two-year period. This directive focus on specific standards came from a former Director of Curriculum and a former Assistant Director of Secondary Education to teachers and staff. The inclusion of diverse voices, points of view, and ideas were missing from PD when departmental curriculum advisors', chairs', and teachers' input was not sought by district and building administration during PD planning or dissemination of material (Bolman \& Deal, 2013). The architecture of what teachers needed was determined by an authority figure who imposed a form of Mintzberg's technostructure (1979/2005) where specific administrators designed the vision and the work to be completed but may be removed from the actual implementation process.

Another key concept of the structural frame involves aligning the structure of the presentation with the work to be completed (Bolman \& Deal, 2010). The lack of a content specific professional development plan for teachers' individual classroom needs may be significant not only because it may not provide vertical alignment and the scaffolding of critical skills, but may not provide tangible improvement in instruction. Teachers may have felt those who designed the PD were "affecting the work of others" but not improving it (Mintzberg, 2005, p. 227). Therefore, district administration subjugated the view of an unequal division of power (Merriam \& Bierema, 2014) by 
appointing instructional coaches to disseminate information and provide the instructional link teachers' may have felt was absent.

Bolman and Gallos (2011) state, "Faculty, in particular, are not always convinced that administrative authority is helpful or worth heeding” (p. 57). When authority and directives about classroom practice come from presenters who have limited background knowledge in a specific content area, teachers, who are content experts, immediately doubt their credibility. This disparity could cause a chasm between teachers and those in leadership positions. In addition, teacher buy-in to the district's initiative may have been lost because teachers perceived those who planned PD lacked pathos for what teachers needed. Additionally, there may have been a disconnect of the logical implications of how inaccurate and piece-meal information along with too little time, "a precious and scarce resource" (Couros, 2015, p. 164), could impact classroom instruction.

In addition, there was a low level of incentive for teachers to design and implement the two assigned lesson plans centered outside the existing curricula. Even though teachers were to use the collaborative process to design the lessons and submit examples of student work to their departmental chair, there were no known consequences for teachers who did not create, implement, and submit the two lessons. Therefore, very few teachers submitted lesson plans. This low rate of response to the PD directive is indicative of what Bolman and Deal (2013) describe as a structural frame missing the key components of developing a mutual purpose and a balance in expertise due to possible flaws of a top-down delivery approach: "When the structure is wrong, even bright and talented people find it hard to be productive" (Bolman \& Gallos, 2011, p. 51). Authority works best when it is "both endorsed by subordinates and authorized by superiors" 
(Bolman \& Deal, 2013, p. 52). In addition, the district created argument writing scoring guide allowed for a wide array of assessment styles and added confusion during evaluation by focusing on students' completed products rather than the instructional process outlined in Mintzberg's action planning (1979/2005).

A perceived lack of accountability may have been influenced by the absence of a protocol for continuity in teacher learning objectives from year to year. Teachers came to expect a new focus would be introduced each year, and teachers were told to continue to implement the previous year's focus. With a high staff turnover rate at $20 \%$, it was difficult to continue the learning progression or connect the new learning plan for returning teachers. New teachers to the district struggled to understand the previous years' topics which may have led to the frustration of not only trying to acclimate to a new district but to playing catch-up on information and instruction they did not receive. Manning (2013) calls such an approach a bureaucratic outlook which sees teachers as interchangeable and expendable. Such oversight to set clear and measurable expectations for PD learning along with no consequences for non-compliance, may have given new and veteran teachers the opportunity to dismiss professional development mandates. Placing "talented teachers into a confusing system wastes their energy and undermines their effectiveness" (Bolman \& Deal, 2010, p. 89). Therefore, many teachers did not design lessons which integrated past year's topics and current classroom instruction. Thus they recanted their academic and ethical responsibilities in the form of a silent protest.

As a final theory of the structural frame, Bolman and Deal (2013) suggest, "Strategy and goals shape structure..." (p. 64); however, in the case of individual and differentiated professional development, the district's hierarchical structure did not 
support teachers' understanding of how the inclusion of additional standards would benefit student learning. Such planning may inhibit how action can be detrimental to the end results (Bolman \& Deal, 2013). And this may have led to teacher confusion in the usefulness of including standards of a yet to be adopted Common Core Standards national curriculum. In addition, there was resistance from teachers to add more to their already exhaustive list of curricular objectives. The fourth PD structure provided limited time for teachers to work collaboratively and discuss how and why the implementation of changing standards would positively or negatively affect their classroom instruction.

\section{Political Frame}

Bolman and Deal (2013) describe how information, expertise, and power moves from "those with the information and know-how to solve important problems" (p. 197). A former Director of Education was a former elementary principal while a former Director of Curriculum had only a few years' experience in a business classroom. Thus teachers may not have viewed district leaders as credible experts with essential content specific knowledge (Bolman \& Deal, 2013) or as having expert power (French \& Raven, 1959/2005). Assigning instructional coaches and vice principals to departments without regard for their individual content expertise to present content material may have caused ELA teachers to dismiss the validity of the content presented. Teachers may have felt this structure lacked what French and Raven (1959/2005) called legitimate authority which creates an environment of equality and greater teacher buy in. Additionally, a math specialist does not possess the content knowledge to accurately present advanced writing and English Language Arts standards in a usable way for other math teachers to be able to incorporate argumentative writing into their classroom assignments. Spending such a 
great deal of time trying to figure out what and how the year's focus could be integrated may have contributed to the creation of an organizational structure which was less supportive of one of the key strengths of Manning's (2013) Modernist Theoretical Foundation which "allows people to adjust slowly to incremental change (p. 113). A final theory within the organizational analysis fits the political frame. It focuses not on who maintains power but rather who lacks power. Special Education (SpEd) teachers were not present when determining their professional development. If a SpEd teacher primarily taught history classes, he was instructed to attend the history department's meetings. Since all teachers in the district received the same information, it fell upon the individual $\mathrm{SpEd}$ teacher to try and modify content to fit his students' needs. Many SpEd teachers concluded their students could not reach the proficiency levels required of the Common Core Standards being presented, and teachers determined students would not attempt to implement the concept. Those who Mintzberg (1979/2005) labels as first line supervisors, or administration, seemed to leave core area advisors and department chairs, whom held no evaluative authority over teachers, to encourage and oversee the classroom implementation of the new standards.

"Bargaining is central to decision making" (Bolman \& Deal, 2013, p. 215), but there may have been a lack of bargaining and negotiating between teachers and district administration. Teachers were left to individually determine which district focus was most important in their classrooms. Most chose to maintain their current curricular demands, "conflict raises the possibility that lower levels will ignore or subvert management directives" (Bolman \& Deal, 2013, p. 201). The people producing the work were given limited power in determining the work. Therefore, many teachers chose to 
uphold the integrity of their current curriculum and to not incorporate the assigned CCSS lessons in their classroom.

\section{Leadership Analysis}

Since the implementation of the fourth professional development structure, there has been a radical turn over in district leadership from two new superintendents to new curriculum directors and departmental advisors. In 2016, new administrative positions were added to the district's hierarchy including an associate superintendent, an academic services office, and an office of continuous improvement. See Figure 3 for the current structural hierarchy of Heartland School District's administrative leadership. Along with new leadership, a fifth structure of PD was adopted. Changes in leadership have promoted a revised philosophy of leader-follower relationships (Bolman \& Deal, 2013).

The new director of secondary education in conjunction with the associate superintendent and the director of assessment and PD have passed much of the responsibility and duty of selection and delivery of PD topics to the secondary departmental curriculum advisors. Seen as content experts, advisors are currently able to determine the PD most appropriate and most needed by their content's teachers; whereas, before the turnover of administrative leadership, curriculum advisors were not granted the authority to "facilitate decision making" (Levi, 2014, p. 185). The new administration has not managed the team of curriculum advisors; instead, administration has given authority to departmental advisors to take ownership of PD and act how Levi (2014) defines as a self-managing team. 


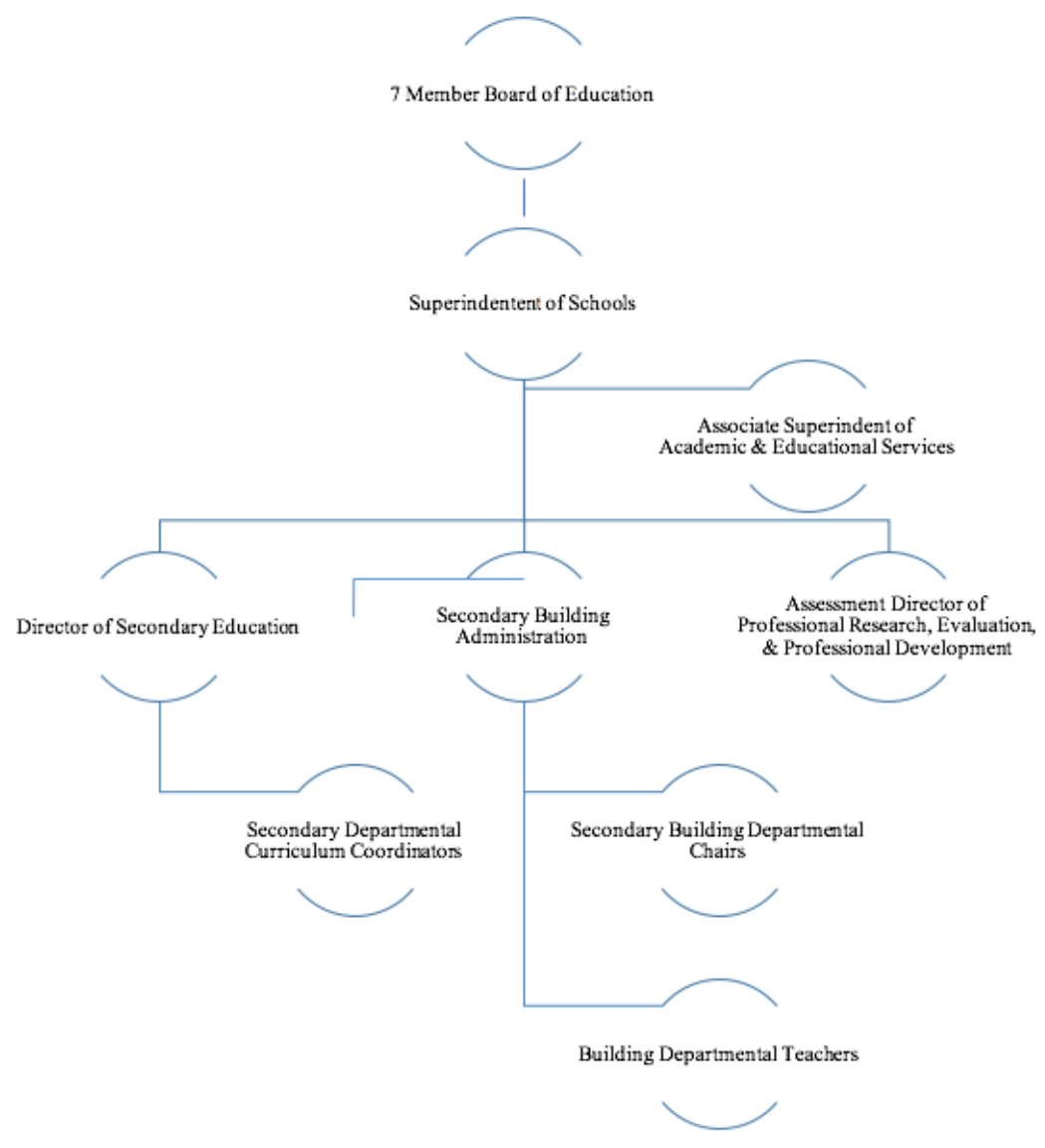

Figure 3. This figure represents the organizational structure of district leadership for secondary educators grades 7-12.

As a means to ensure all curriculum advisors and administrators are in agreement of PD topics and maintain a coaching or supporting role, advisor meetings are held each month. Using situational leadership theory, (Meier, 2016; Northouse, 2016; Wright, 2017) one of the most commonly used leadership strategies, district administration chose to adopt a delegation style of leadership in which there is low task function and low relationship building with team members and a supporting leadership style in which there is low task function and high relationship building (Levi, 2014; Meier, 2016).

Situational leadership has provided administrative leadership the chance to hear concerns and ideas from the bottom-up rather than dictating a path of focus from the top down. 
“Team leaders who are actively involved impact the team's cognitive, motivational, emotional, and coordination process" (Levi, 2014, p. 196; Zaccaro, Rittman, \& Marks, 2001). Embracing choice in which leadership style to adopt when working with advisors allows for a delegation rather than an autocratic overseeing (Meier, 2016) and leads to positive human resource growth which "create[s] an environment where communication is open, concerns and thoughts are expressed freely, and mutual understanding can become the norm within the organization" (Wright, 2017, p. 29). See Figure 4 for the district's current structure of PD practices. Delegation has worked well for both administration and departments as advisors are able to rely on their own content and pedagogical expertise, commitment, and competence (Luizzi, 2017) while implementing innovative design and delivery of PD. Additionally, individual building PD is created and delivered by principals. 


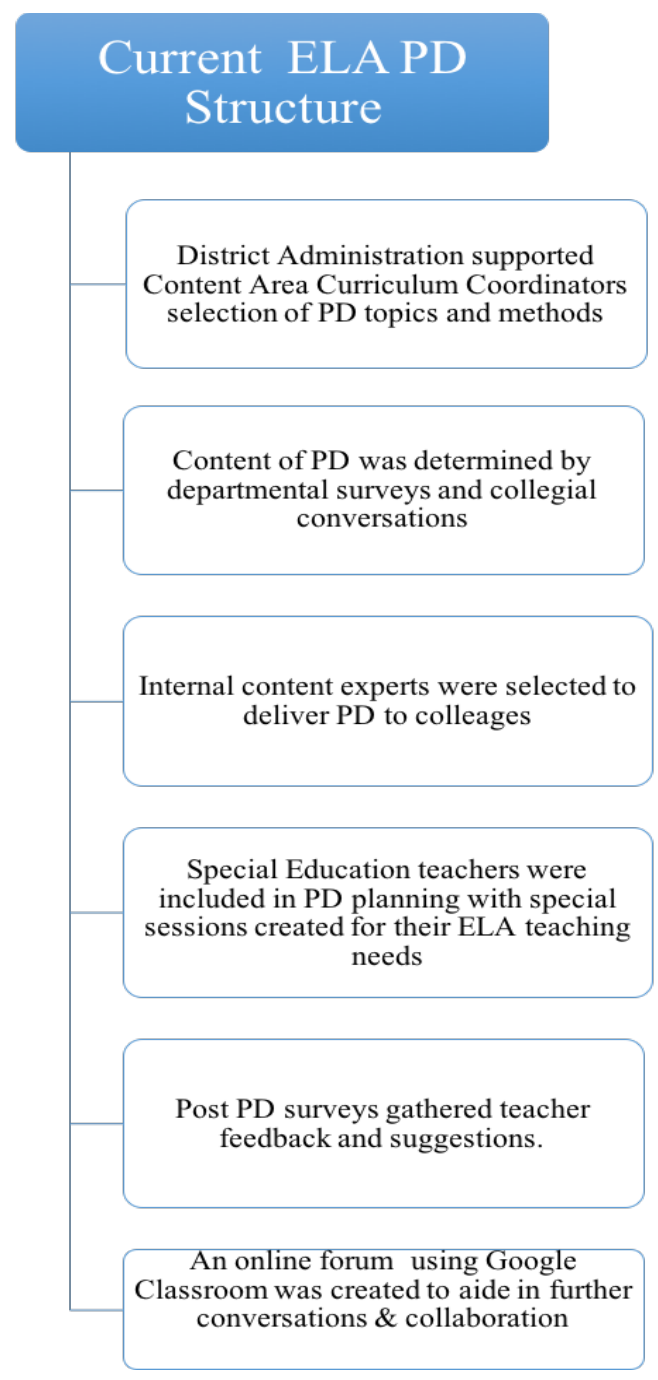

Figure 4. This figure represents the current (2016-2018) structure of professional development (PD) planning and delivery for the English Language Arts department within the Heartland School District. This is the fifth structure of PD used in the district in the last seven years.

Generally, teachers have had limited opportunities to voice ideas or help determine what content should be addressed during PD (Burbank \& Kauchak, 2003; Guskey \& Yoon, 2009; Lewis, 2015; NEA, 2018; “Teachers Know Best,” 2014; TNTP; 2015; Van Tessell, 2014). Having little to no influence in the design of PD generally elevates teachers' frustration levels and decreases their buy-in (Bolman \& Deal, 2013; Reeves, 2010); they feel their expertise is disregarded by a bureaucratic structure resistant 
to change (Roseler \& Dentzau, 2013). When they are so often shut-out, teachers'

motivation to attend PD and expectations for the usefulness of PD diminish and the gap increases between "what we know and what we do" (Reeves, 2010, p. 23). Hayes Mizell (2009) offers insight into expectations of PD:

"Expectations are at the heart of professional development. Many educators don't expect much because they have often been the victims of poorly conceived and executed professional development... Each day, for thousands of educators, this syndrome of low expectations jeopardizes the quality and results of professional development" (p. 1).

For this reason, leaders of PD and the new district administration show a change in understanding the integral link between their guidance and successful implementation in daily classroom practice. Therefore, they have encouraged departmental advisors to survey teachers, gather their responses, and hear what they are asking for. When participative leadership is employed, subordinates feel more satisfied because they are involved in the decision-making process; their ideas, opinions, and recommendations are taken into account (Amir \& Kamarudin, 2009; Northouse, 2016). Decisions are now being made in group consultation between departmental advisors and district administrative leadership which creates a shared relationship to achieve a specific set of goals and a more positive environment in which adult learning can occur (Amir \& Kamarudin, 2009; Levi, 2014; Northouse, 2016). Additionally, the current district administration's delegation of PD allows content advisors to aid in developing teachers as content leaders to grow their collegial leadership within departments so they may realize their full potential for "custom tailor[ing of] a program to elicit the highest productivity from each employee...for a happier and more productive organization" (Luizzi, 2017, p. 66). 


\section{Implications for Research in Practitioner Setting}

This study extends the reach of analysis of the research question: how have secondary English Language Arts teachers, from one Midwest Missouri school district, used pedagogical content knowledge gained from ELA professional development to change their individual classroom practices? Teachers, district administration, and other district leaders will benefit from the in-depth look into how PD provides classroom change and student learning in the Heartland School District. In addition, the feedback from ELA teachers can be used to influence the approach to PD and the content other departments may wish to emulate.

Analysis of the collected responses from secondary ELA teachers in the Heartland district will provide valuable information into how the learning opportunities presented to teachers through content and pedagogical PD impact their daily classroom practices and ultimately their students' learning. This research will provide the Heartland School District and other large districts like Heartland with the opportunity to see how PD influences the most important job of schools: teaching students. With the goal of providing teachers with effective opportunities to gain new knowledge to transform their teaching practices, the ELA teacher's voice must be heard. To further the educational conversation, gathering responses from participating ELA teachers will expand the literature as there is little empirical research which includes ELA teachers' perspectives (Scarlett, 2009) and will provide district and state policy makers with information about how best to meet teachers' learning needs. Further study on the impact of PD on ELA classroom practices would uphold the framework of Adult Learning Theory and rationale of this study. 


\section{Summary}

Those who practice the craft of teaching are under tremendous pressures from local and state governments to raise test scores, remain highly qualified, do more with less, and grow their pedagogical and content knowledge (DuFour \& Eaker, 1998;

MoDESE, 2016; U. S. Department of Education, 2015). How do classroom teachers and administrators meet these requirements? Professional Development (PD) offerings are the standard vehicle by which districts deliver information, yearly improvement plans, and methodology. However, most PD is administered by district administrators employing a top down structure which often fails to adjust professional development for content specific needs (Gulamhussein, 2013; Merriam et al., 2007). Maintaining a top down delivery structure which places decision making control in the hands of only a few high-ranking administrators bypasses the true learning needs of teachers for what administrators think teachers need (Bolman \& Deal, 2013; Cevero \& Wilson, 1994; Gulamhussein, 2013; Merriam et al., 2007).

For many years the Heartland School District has provided teachers with various PD structures and formats built on a top down delivery approach. Four of the five PD structures did not allow district leaders to work collaboratively with departmental advisors or content experts. This may have caused a disjointed and fragmented presentation of ideas and knowledge to teachers. This suggests low accountability, low monitoring, and no known or enforced consequences for non-compliance of district mandated classroom practices, may have impacted how past PD content may not have been implemented with fidelity across classrooms and buildings. This supports Mintzberg's technostructure (1979/2005) where administration designed the work to be 
completed but were removed from the learning and implementation processes. Bolman and Deal (2013) emphasize the importance of aligning the presentation structure with the work and tasks to be completed. Without alignment, teachers are quick to dismiss the validity of content presented by a leader outside the designated content area (French \& Raven, 1959/2005). Many districts including the Heartland School District struggle for effective PD which pushes adult learners to gain new content and pedagogical content knowledge in ways which improves classroom practices and student learning (Papay \& Kraft, 2010; Luizzi, 2017). Through a radical change and increase in district leadership, delegation rather than a top down autocratic overseeing (Meier, 2016) has become the current structure of implementation for PD at Heartland.

With each content area acting as a self-managing team (Levi, 2014), district administration is able to adapt their involvement through situational and participative leadership styles (Northouse, 2016). This places the task of transforming learning changes in instructional practices in the hands of teachers due to district administration's supports of Reeves' (2010) view of limiting the number of initiatives to be addressed. Reeves (2010) feels the implementation of too many initiatives at one time decreases the long-term effectiveness those initiative may have on positively changing classroom practices. Thus, teacher buy-in to district objectives and improvement plans has increased because teachers feel they are involved in the decision process for selecting the top priorities for PD instruction (Amir \& Kamarudin, 2009; Bolman \& Deal, 2013; Levi, 2014; Mizell, 2009; Reeves, 2010; Roseler \& Dentzau, 2013; Northouse, 2016). 


\section{SECTION THREE}

\section{SCHOLARLY REVIEW FOR THE STUDY}

There is a lack of information as to how English Language Arts (ELA) teachers define and perceive professional development (PD) (Ajayi, 2016) and how PD leads to changes in classroom practices, "better teaching, and increased student achievement" (Desimone, Porter, Garet, Yoon, \& Birman, 2002, p. 82). Little (1987) defines professional development as "any activity that is intended partly or primarily to prepare paid staff members for improved performance in present or future roles in school districts" (p. 491). For educators across the nation, PD is the logical way to gain new knowledge, techniques, and methods to meet student learning needs. In Missouri, it is a mandate for teachers to complete 15 hours of PD annually to support their Career Continuous Professional Certificate or have 10 years of experience, a Master's degree, or National Board Certification (DESE, 2013, p. 17).

This literature review explores the theoretical framework of Adult Learning Theory (ALT) by defining andragogy and explaining the essential components of ALT including self-directed learning, reflective practices, as well as self-efficacy and motivation (Knowles, 1980; Knowles, Holton, \& Swanson, 2015; Merriam \& Bierema, 2014). The pillars of public education's introduction of English courses, professional development, and transformative learning will be explored as to how they support ALT.

\section{Theoretical Framework: Adult Learning Theory}

Kolb (1984) insists the most effective and productive "Learning is a continuous process grounded in experience. Knowledge is continuously derived and tested out in the experiences of the learner" (Merriam, Caffarella \& Baumgartner, 2007, p. 161). Such 
experiences are not often created for the average teacher; learning is directed not experienced. The four main components of adult learning theory (ALT) used to guide this study include the premise of andragogy, teachers' self-directed learning, reflective practices, and teachers' self-efficacy and motivation (Argyris \& Schön, 1974; Cercone, 2008; Hadar \& Brody, 2010; Fogarty \& Peete, 2009; Gibb, 1960; Knowles, 1980; Knowles et al., 2015; Merriam \& Bierema, 2014).

Andragogy focuses on the education of adults and their unique learning needs; such learning opportunities need to be problem-centered, experience-centered, hands-on, and meaningful to the learner in order to be effective (Fogarty \& Peete, 2009; Knowles et al., 2015). As many adult learners are highly motivated and prefer to guide their own learning events (Cercone, 2008), they understand how new learning will affect their daily lives. Therefore, teachers need the freedom of individual choice to direct their own learning paths (Trotter, 2006) rather than predetermined topics by district or building administration.

Knowles et al., (2015) indicates one of the most essential concepts of ALT is reflective practice. By encouraging reflection and inquiry through collaboration and dialogue (Bruffee, 1999; Gill, 2010; Trotter, 2006), teachers can improve their PD experiences and deepen their acquired knowledge. Such reflection will deepen their content knowledge and pedagogical practice (Schön, 1983). Finally, self-efficacy centers on a teacher's judgements and perceptions about her capabilities and beliefs in herself to succeed in a specific task; however, such beliefs do not guarantee success at the task's culmination (Bandura, 1995). (Malm, 2008; Vartuli, 2005). "Numerous studies have shown teacher efficacy is important for improving student performance and stress 
the need for PD programs that incorporate this element into their design" (Schieb \& Karabenick, 2011, p. 13). Figure 5 indicates the overlap of key features between the theoretical framework of Adult Learning Theory and the conceptual underpinnings of effective PD and Transformative Learning. These three areas which guide this study share the elements of collaboration, reflection, motivation, and prior experiences.

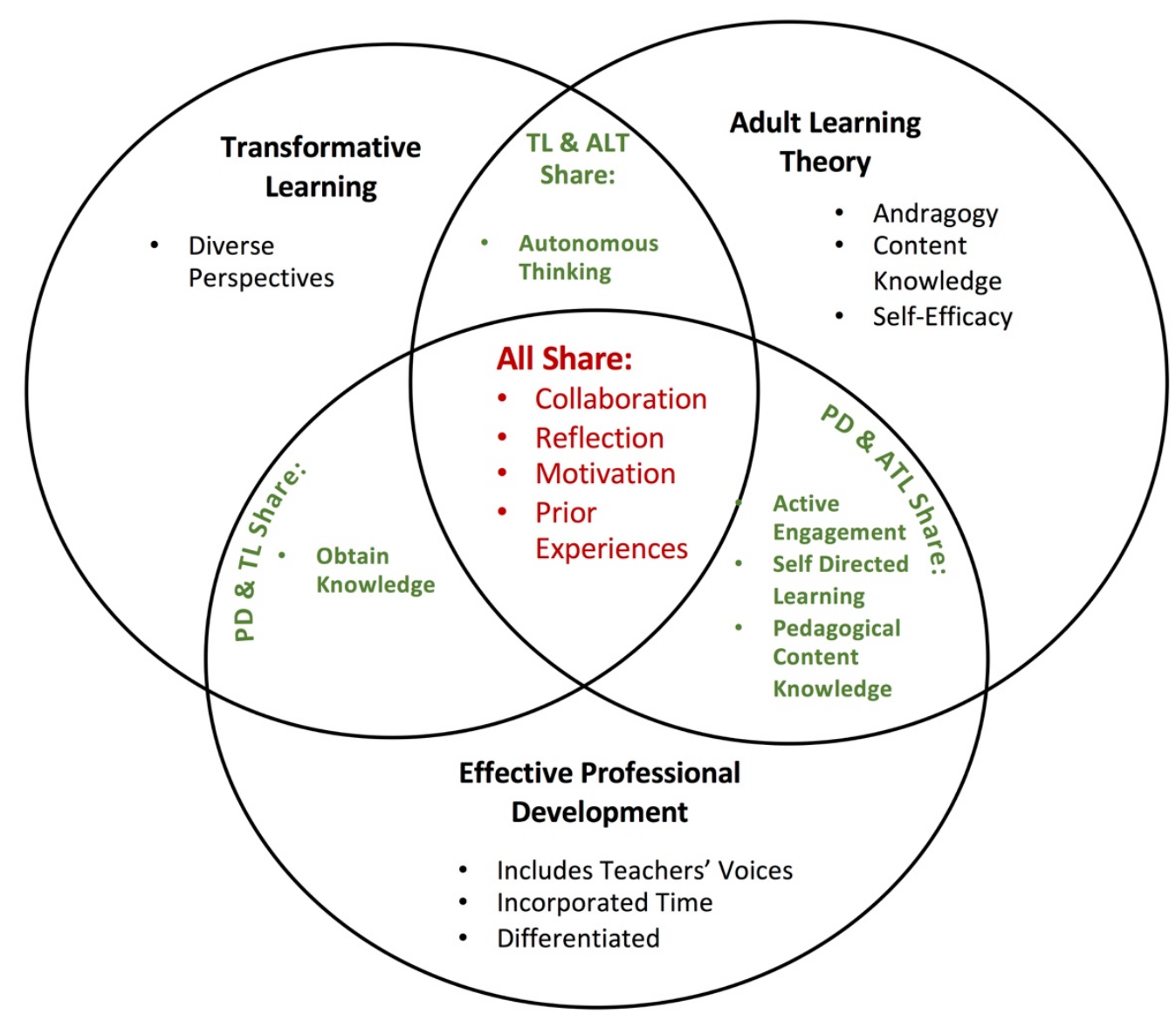

Figure 5. This figure represents the interconnection of the Theoretical Framework and Underpinnings of this study. The areas in green and black compare and contrast the essential components shared by the study's pillars. The area in red denotes the similarities all pillars within the study share. This figure should serve to further explain the interconnection within each area of the framework shown in Figure 1. 


\section{Conceptual Underpinnings}

\section{Impetus of American Public Education}

The National Council of Teachers of English (NCTE) (1996) endorses our nation's highest objective which is to provide equal educational opportunities to all students. America's founding fathers foresaw the new nation's survival only if citizens were educated, and former Vice President, Adlai Stevenson claimed, "The free common school system is the most American thing about America" (Campbell, 2001; Mondale \& Patton, 2002, p.1). Furthermore, Cremin (1957) declared the vocation of teaching to be "the most difficult of all the arts, and the profoundest of all sciences" (p. 21). How has public education, specifically the subject of English, developed? What can teachers do to ensure the survival of our nation's future citizens? It is important to look at the evolution and impetus of English Language Arts (ELA) as all other subject areas depend on solid student competency and mastery in the areas of reading, writing, listening, speaking, and critical thinking. As the $21^{\text {st }}$ Century Learning Skills expand, viewing has become an essential area to include in classroom instruction. Such rapid changes in this core subject's development, illustrate the importance of continual learning on the part of the ELA teacher to monitor and change individual classroom practices.

\section{The Public School System.}

While the first public school in Massachusetts was founded in 1635 to teach boys to read the bible, Massachusetts remained the most progressive state in the nation and opened the first compulsory "common schools" in 1852 (Baines, 2006; Singer, 2016; Watson, 2008). Students of all ages and abilities were typically taught together in a one room school house which also functioned as a church and a community meeting hall 
(Education News, 2013; Mondale \& Patton, 2002). By 1918, all American children were required to attend elementary school focusing on reading, writing, and arithmetic (Campbell, 2001; Education News, 2013; Mondale \& Patton, 2002; Singer, 2016). At the start of the $20^{\text {th }}$ century, states and school districts had no unanimity on curriculums, standards, or processes to evaluate the quality of its teachers, instructional methods, or subjects (Barone \& Morrell, 2007). Horace Mann, "father of public education" and former Secretary of the Massachusetts Board of Education 1837-1848 (Baines, 2006, p. 272; Finkelstein, 1990), felt the separation of students into age level groups with a standardized curriculum would best provide direct instruction by ability levels and ensure equitable, high-quality learning across the country (Baines, 2006; Education News, 2013; Mondale \& Patton, 2002). Mann proposed a sound education through commonality would be the antidote to social ills and "obliterate factitious distinctions in society" (Cremin, 1957, p. 87) by educating all children and not just the wealthy or intellectually gifted (Baines, 2006).

In the early 1900s, children generally left school after completing the eighth grade. They often obtained jobs, helped on the family farm, or even married and started families of their own. As the nation's economy became more complex and jobs more plentiful, children were able to attend a secondary school in order to obtain more skills and knowledge (Mondale \& Patton, 2002). With the increase in immigration to America so increased the demands on public schools and teachers to meet the needs of a diverse and growing student population, two-thirds of whom from 1880-1920, could not speak English (Mondale \& Patton, 2002). Secondary or "high schools" opened "at the rate of one a day" (Mondale \& Patton, 2002, p. 97) across the country. As the number of 
schools rose, so did the need for more teachers, a more standardized curriculum, and choices in educational paths for students who were not college bound. However, such opportunities were not extended to all students, and despite Mann's fight for equal education, schools remained segregated by race and socioeconomic status until the Supreme Court ruling of Brown v. Board of Education found separate and segregated schools were not equal (Mondale \& Patton, 2002). Tensions of achievement gaps between race and socio-economic status increased as the United States rose as a world power, and its schools became "the premier flagship institution of its kind, a model for the world to follow" (Barone \& Morrell, 2007, p. 167).

\section{The Emergence of English as a Core Subject.}

Education in the subject of English Language Arts (ELA) is considered a modern subject with its implementation emerging as a core educational subject in the 1890's (Applebee, 1974; Applebee, Langer, Nystrand \& Gamoran, 2003). Instruction in grammar became the first wide spread curricular emphasis and was perceived as a doorway to higher learning and college preparation by concentrating on the rules of grammar through usage and practical application (Applebee, 1974). The study of literature soon followed but not to the depth and breadth of grammar instruction. English studies were relegated to finishing schools for young ladies who were not preparing to further their education because literature was seen as "an appropriate subject for polite conversation" (Applebee, 1974, p. 13). In 1889, the U.S. Commissioner of Education conducted the first survey of curricular components and reported English to be a popular subject in business schools, "schools for the blind, deaf, and feebleminded, but not in public or private secondary schools" (Palmer, 1965, p. 70; Applebee et al., 2003). 
While literature was slowly integrated into typical classroom study, the genres of fiction, drama, and poetry were seen as suspect with their focus on imagination instead of logical truths, theology, or morality: "If literature had the power to do good, it must also have the power to do evil" (Applebee, 1974, p. 22). Not until Harvard University required the study of literature as a subject for composition in 1873 (Applebee, 1974) did literature join grammar, spelling, rhetoric, and oration to complete the content of current ELA curriculum. Teachers of English in New England formed the first association specifically for English teachers in 1901, and by December 1, 1911, the National Council of Teachers of English (NCTE) was formed in Chicago (Applebee, 1974; Applebee et al., 2003; NCTE, 1996) to provide teachers with 12 instructional standards. NCTE’s (1996) standards embody Mann's core educational beliefs by preparing students for future literacy requirements through a wide scope of texts; creating a shared vision of knowledge and process strategies to foster development, and stimulating all students' ability levels to "acquire knowledge and develop competency over time" (p. 12).

\section{The current state of ELA.}

In current educational practices, ELA is perceived to incorporate all subject areas, and as Mann felt, literacy can provide liberation, opportunity, and resiliency for all students (Applebee et al., 2003; Finkelstein, 1990). However, many secondary teachers outside the content area of ELA perceive literacy instruction to be the primary responsibility of English teachers (Lester, 2000). Other content area teachers "have difficulty balancing literary and content instruction" (Wilson, Grisham, \& Smetana, 2009, p. 708). In order to be literate, students must learn to think critically, read, write, speak, listen, and be skilled in speaking and writing in order to "function socially in a print- 
based society" (DeFauw \& Taylor, 2015, p. 3; NCTE, 1996; NGABP \& CCSSO, 2010; Venezky, 1995). With the adoption of the Common Core State Standards (CCSS) which recognizes all disciplines must implement reading and writing instruction, every teacher has become an "English" teacher (Applebee, 2013; NGABP \& CCSSO, 2010; Wilson et al., 2009). Applebee (2013) further notes English teachers should play a supportive role to colleagues in other content areas; exposure to literacy skills cannot only occur in an ELA classroom (NGABP \& CCSSO, 2010). Moreover, English teachers "should not be called on to take over this discipline-based language learning" (Applebee, 2013, p. 28).

$\mathrm{Au}$ and Gourd (2013) support and validate the positive impact English teachers have on students' education through creative curricula seen "as the heart and soul of curriculum, instruction, and assessment" (p. 14). ELA is focused on exploring enduring themes for all mankind; therefore, knowledge and texts in ELA are regarded with deference to knowledge and texts in other core contents (Au \& Gourd, 2013; Beavis, 2013). English can be detached from other disciplines due to students' abilities to create knowledge in ways "that cannot readily be imagined in subjects such as mathematics, science, geography, and others" (Kress, Jewitt, Bourne, Franks, Hardcastle, Jones, \& Reid, 2005, p. 4). NCTE (1996) and the CCSS confirms ELA courses can strengthen achievement across content areas to propel learners towards attaining high standards which "value a variety of student abilities... and then build on those strengths" (p. 7).

\section{The nexus of change in ELA.}

Regarded as the all-inclusive subject with a nexus of change (Au \& Gourd, 2013), the content area of English has recently been victim to public criticism, pressure, conflict, and debate due to students' lack of proficiency in the college and career readiness 
standards of CCSS (Ajayi, 2016; NGABP \& CCSSO, 2010; Thomas, 2011). The move towards CCSS, current high-stakes, high-pressure testing, and the "Accountability Movement of the 1990s" (Ajayi, 2016, p. 1) has also brought censure to the subject of English. Applebee (2013) isolates the quick fix strategy many districts' have adopted in order to combat such pressures: teaching directly to the test and "turning the curriculum and instruction into test prep" (p. 31).

Strict governmental and state policies restrain ELA teachers' abilities to deliver equitable literacy instruction (Au \& Gould, 2013; Bean \& Harper; 2011; Luke \& Woods, 2008). Harsh criticisms and high demands placed on ELA teachers contradicts NCTE's push for innovation and universal teaching standards (Au \& Gourd, 2013). Experienced teachers feel the strain of demands and high-stakes testing in the loss of their classroom autonomy (Barone \& Morrell, 2007; Jewitt, Bezemer, \& Kress, 2010; Taubman, 2014). NCTE's 12 teaching standards are the guiding vision to provide opportunities for teachers to maintain innovation and creativity while remaining their classroom's curricular designer (NCTE, 1996).

English teachers are the cornerstone of students' success because "effective implementation of the standards depends on the knowledge and effectiveness of instruction provided by individual educators" (Ajayi, 2016, p. 3; Reutzel, 2013). In order to combat governmental and state constraints and mandates, teachers need opportunities to think deeply about their discipline, pursue intellectual interests, participate in group collaboration and discussion, have time to self-reflect, and increase pedagogical knowledge at a deeper level of mastery (Ajayi, 2016; Barone \& Morrell, 2007; Taubman, 2014). Building knowledge at a high level is not meant solely for young students; 
continual improvement opportunities for ELA teachers through effective professional development will strengthen instructional practices (Wilson et al., 2009; Popp \& Goldman, 2016).

\section{Professional Development}

Professional development (PD) is the primary way to evoke a transformation in schools (Desimone, 2011; Goldschmidt \& Phelps, 2010; Guskey, 1995; Thacker, 2017). However, if teacher learning is not sufficient and does not improve classroom practices, the PD has failed. Therefore, the primary goal of PD is to be effective and generate high impact changes to the practice of teachers' roles in the teaching and learning process (Kubiskey, Fisherman, \& Marx, 2004). "Effective professional development is not about meeting the requirements of a list, it is about carefully considering and planning according to desired outcomes and standards that will contribute to success" (Hirsch, 2006, p. 59). While many teachers and districts understand the need for intensive and sustained PD, what is often presented does not provide "opportunities for application, practice, reflection, or reinforcement" (Reeves, 2010, p. 23). While compiling lists of PD guidelines, Greenwell and Zygouris-Coe (2012) found more transformation may come about "not so much in the discovery of new knowledge, but in [the] capacity to use...the knowledge we have" (p. 10) which is then transferred to daily practices.

Furthermore, knowledge is "constructed through the accumulation of experiences, folding new information into prior knowledge" (Roseler \& Dentzau, 2013, p. 620). New knowledge and an increase in student learning develops through collaborative participation from within a network of teachers working on specific teaching strategies and not from an outside entity hired to create change (Desimone et al., 2002; Reeves, 
2010; Roseler \& Dentzau, 2013; “Teachers Know Best,” 2014; TNTP, 2015). In fact, content-focused PD centered on teacher practices, evidence of student learning, and curriculum materials may have the highest effect on teacher performance and increased student learning (Garet et al., 2001; Hill, 2009). Teachers are learners, teachers understand true learning takes time, and teachers need methods they can use in their daily practices to propel them towards improvement of their craft (Gaible \& Burns, 2005).

\section{High-Quality and Effective Professional Development.}

In conducted studies, Darling-Hammond, Wei, Andree, Richardson, and Orphanos (2009) found the most high-quality PD is job-embedded (occurring during standard working hours) and includes five critical components: collaborative learning, links between curriculum, assessment and teaching context, active learning, deeper knowledge of content, as well as sustained learning. Additionally, Darling-Hammond and Richardson (2009) continue to list the critical elements of PD to include "active teaching, assessment, observation, and reflection rather or abstract discussions" (p. 47). Similarly, Desimone (2011) found high-quality PD includes content focus, active learning, engagement in leadership roles, duration, and collective participation (p. 69; Desimone et al., 2002; U.S. Department of Education, 2009). Strickland (2009) merged the key principles of PD from numerous state and federal organizations such as The National Staff Development Council, Sec 901 of the general provisions of education from The U.S. Department of Education, and from Goals 2000 into the following key points to define high-quality, effective PD:

- High-quality professional development leads teachers to gain and refine knowledge of both content and pedagogy. 
- High-quality professional development reflects best practices in teaching and learning, helping adults with varied interests, learning profiles, and readiness learn to work together and feel part of a community of learners.

- High-quality professional development has a positive impact on the classroom in terms of both teacher effectiveness and student learning (p. 3; DESE, 2013). Additionally, Stoll, Bolman, McMahon, Wallace, and Thomas (2006) furthered the elements of high-quality PD and delineated how effective PD includes:

At the heart of the concept, however, is the notion of community. The focus is not just on the individual teachers' professional learning but of professional learning within a community context - a community of learners, and the notion of collective learning. (p. 225)

Succinctly, Reeves (2010) lists three essential characteristics of effective PD which includes "(1) a focus on student learning, (2) rigorous measurement of adult decisions, and (3) a focus on people and practices, not programs" (p. 21). Furthermore, Kilinger (2004) feels:

"educators benefit from long-term support that facilitates their understanding and implementation of new strategies... By adapting a new strategy to fit their needs, teachers make the strategy more relevant to their classrooms and develop a sense of ownership, promoting its sustained use in their classrooms." (p. 249)

Aligning with these characteristics, the goals of and definition of PD seeks change in teachers' practices, their attitudes toward implementing new knowledge, and increased student achievement (Desimone et al., 2002; Guskey, 2000, 2002). With the inclusion of follow-up activities such as reflection, feedback, and additional learning activities, PD can provide added mastery and can positively impact teachers' self-efficacy and classroom practices for the duration of their careers (Bandura, 1995; Bruffee, 1999; 
Desimone et al., 2002; Fogarty \& Peete, 2009; Garet et al., 2001; Knowles, 1980; Knowles et al., 2015).

What type of content is most needed during PD in order to change teacher practice and student achievement? Desimone et al. (2002) notes the level of focus and the duration of the focus is directly related to the amount of change within a teacher's classroom practices. Goldschmidt and Phelps (2010) argue teachers need more content knowledge $(\mathrm{CK})$ than they typically receive during pre-service courses, and what practicing teachers need is more pedagogical content knowledge (PCK). In fact, the focus on specific $\mathrm{CK}$ is vital for changes in instructional practices linked to "students' conceptual understanding" (Desimone et al., 2002, p. 82). Moreover, teachers' CK does affect what and how much learning occurs during PD (Minor, Desimone, Lee, \& Hochberg, 2016).

In a study of teachers with weak CK, targeted PD increased their knowledge in many areas while teachers with a great amount of $\mathrm{CK}$ focused more on growing their PCK (Minor et al., 2016). Additionally, the study found when teachers increased their CK they increased their confidence and sense of empowerment in daily classroom practices (Minor et al., 2016). Furthermore, research has proved PD in teachers' content areas has a greater impact on teacher and student performance than PD focused on pedagogy alone (Garet, Birman, Porter, Desimone, \& Harman, 1999). Those who provide and present PD must possess a concrete understanding of what makes the absorption of specific PCK knowledge easy or difficult (Shulman, 2013). Opportunities to increase knowledge, strategies, and motivation to change their practices is also essential to providing effective PD experiences for adult learners (Goldschmidt \& Phelps, 
2010). Such findings support the essential components of adult learning theory and the importance of the direct application of CK to educational practices in order to increase PCK (Garet et al., 1999).

\section{Barriers to Professional Development.}

Barriers to adult learning are rarely addressed (Merriam, Caffarella \& Baumgartner, 2007), yet more is known about why PD fails than what succeeds (Guskey, 1995). These barriers can be separated into three main areas of concern: lack of time for transformative learning within the school day or year, PD mandated from superiors rather than adult learners working with students, and lack of PD organically developed by teachers and learners based on student and classroom needs (Gulamhussein, 2013; Hill, 2009; Reeves, 2010; “Teachers Know Best,” 2014; TNTP, 2015).

\section{Limited time.}

The top cited barrier for effective PD is not having enough time built into the school day for learning and is a teacher's scarcest resource (Burbank \& Kauchak, 2003; Couros, 2015; Kazempour, 2009; Merriam et al., 2007; “Teachers Know Best,” 2014; TNTP, 2015). According to a study entitled "The Mirage," conducted by The New Teacher Project (TNTP.org) (2015), 10\% of the average school year is spent on teacher and staff PD while districts spend about 3-6\% of their annual budget on it, yet "only about 40 percent [of teachers] reported that most of their professional development activities were a good use of their time" (p. 2). Extended time for PD has been shown to produce more effective teachers; in fact, Gulamhussein (2013) found it takes an average of 20 separate exposures or "as many as 50 hours of instruction, practice, and coaching" (p. 14) before a teacher can be considered a master of a skill. In conducted studies, 
Darling-Hammond et al., (2009) found the most effective PD is job-embedded and occurs during the standard school day or on days specifically set aside for PD.

\section{Top down approach.}

The architecture of what teachers need is usually determined by an authority figure who imposes a form of Mintzberg's technostructure (1979/2005) where district administration designs the vision and the work to be completed but is far removed from the actual implementation. Roseler and Dentzau (2013) state, "professional development opportunities that are mandated, or implemented, in a top-down fashion are not in the best interest of student learning or the development of teacher practices" (p. 621). 75\% of teachers in a 2018 study indicated district leaders to be the primary decision makers in regards to all PD offerings (NEA, 2018). Additionally, "those not in positions of power rarely decide what learning opportunities are offered" (Merriam et al., 2007, p. 74) when professional learning is directed rather than experienced.

A one-size fits all and a top-down approach to delivering PD and identical instructional direction does not provide teachers with strategies to increase classroom performance (Gulamhussein, 2013; Guskey \& Yoon, 2009; Reeves, 2010; Roseler \& Dentzau, 2013). Bolman and Gallos (2011) state, "Faculty, in particular, are not always convinced that administrative authority is helpful or worth heeding" (p. 57). This disparity causes a chasm between teachers and leaders (Roeseler \& Dentzau, 2013) making either side resistant to change (Ettling, 2012).

In addition, teacher buy-in to a district's goal is often lost because administration lacks pathos for what teachers need. They also lack the logical connections of how delivering disconnected information impacts classroom instruction. "In lieu of this top- 
down model, a bottom-up approach to tackling the difficult issues that surround education and student learning" (Roeseler \& Dentzau, 2013, p. 62) could increase participation and learning. Teachers should not feel deprived or left to feel their knowledge and expertise is less effective for classroom and pedagogical change than someone seen as an external expert (Van Tassell, 2014).

Ravitch (2014) echoes teachers' frustration for a one-size-fits-all approach when stating, "the district leadership is responsible for guaranteeing that every school has the resources and personnel it needs..." (p. 203), especially when district leadership is not providing what they need. What truly transforms learning are established and researched practices to improve instruction in richly diverse classrooms (Ravitch, 2014). Teachers often do not view district leaders as credible experts with essential content specific knowledge (Bolman \& Deal, 2013) or having expert power (French \& Raven, 1959/2005). Therefore, leadership practices and content specific information must be altered in order for teachers to "transfer their knowledge and learning into classroom practice" (Greenwell \& Zygouris-Coe, 2012, p. 22) to increase student performance.

Traditional top-down PD plans created by administrators or outside consultants “[muffle] the teachers' voices and [place] priority on administrative needs...instead of solution[s] to classroom problems" (Diaz-Maggioli, 2004, p. 2), and a top-down method of delivery also fails to take advantage of the content experts within a district (Butler \& Schnellert, 2012; Guskey \& Yoon, 2009; Roseler \& Dentzau, 2013). Even if best practices are presented during $\mathrm{PD}$, if proper time, training, and collaboration are not incorporated into a practice's inclusion, such efforts will fail to change teacher's 
processes for implementation or increase classroom achievement (Greenwell \& ZygourisCoe, 2012; Gulamhussein, 2013; Van Tassell, 2014).

\section{Limited teacher voice in professional development creation.}

Every year, millions of teachers participate in a traditionally designed workshop approaches to PD delivered by a hired expert, yet the results of such one-shot workshops in classroom and student performance continues to show little growth of learning achievement (Abadiano \& Turner, 2004; Avalos, 2011; Butler \& Schnellert, 2012; Greenwell \& Zygouris-Coe, 2012; Gulamhussein, 2013; Guskey \& Yoon, 2009; Langer, 2000; Mouza, 2006; Roseler \& Dentzau; 2013). Teachers have not generally been given the opportunity to help determine what should be addressed during PD (Burbank \& Kauchak, 2003; Guskey \& Yoon, 2009; Lewis, 2015; “Teachers Know Best,” 2014; TNTP, 2015; Van Tessell, 2014). Having little to no influence in the design of PD elevates teachers' frustration levels and decreases their buy-in; they feel their expertise is disregarded by a bureaucratic structure resistant to change (Bolman \& Deal, 2013; Roseler \& Dentzau, 2013). A current nationwide survey conducted by Corwin, Learning Forward, and NEA shows of 6,300 teacher respondents, only 4\% indicated PD is designed by teachers while $20 \%$ of teachers noted they had limited input in the content of PD offerings (NEA, 2018). When they are so often shut-out, teachers' motivation to attend PD and expectations for the usefulness of PD diminish and the gap increases between "what we know and what we do" (Reeves, 2010, p. 23). Mizell (2009) offers insight into expectations of PD:

Expectations are at the heart of professional development. Many educators don't expect much because they have often been the victims of poorly conceived and executed professional development... Each day, for thousands of educators, this 
syndrome of low expectations jeopardizes the quality and results of professional development (p. 1).

A study conducted by the Bill and Melinda Gates foundation found "nearly one in five (18 percent) [of teachers] never have a say in their professional development" ("Teachers Know Best," 2014, p. 10). This study concluded the more choices teachers' have in determining PD, the more satisfied they were (Lewis, 2015; "Teachers Know Best," 2015; TNTP, 2015). Ann Lieberman (2000) offers this insight:

Decisions about curriculum and instruction are often made without reference to real problems of classroom life. Teachers are 'developed' by outside 'experts,' rather than participating in their own development... (p. 221)

In addition, $\mathrm{PD}$ often allows teachers to take a passive role in gaining new knowledge rather than working actively or collaboratively (Burbank \& Kauchak, 2003; Ettling, 2012; Haug \& Sands, 2013; Hill, 2009; Roseler \& Dentzau, 2013). Professional development is an opportunity for teachers to once again become the recipient of new knowledge; therefore, PD should engage participants using diverse and differentiated methods to meet their varying needs and learning styles while demonstrating how to transfer and modify newly acquired information for classroom use (Hill, 2009).

\section{Transformative Learning}

Personal experience and self-reflection are the top aspects needed for transformative learning to occur (Kitchenham, 2008; MacKeracher, 2012; Mezirow, 2012; Nonaka, 1991; Taylor, 2009; Troop, 2017). Adult learning theory (ALT) emphasizes the domains of reflective practices and experience; therefore, Mezirow's $(1990,1991,1997,2012)$ transformative learning theory syncs with ALT because the common goals encourage learners" "autonomous thinking" (Bouchard, 2015, p. 1). While Mezirow's transformative learning theory is made of 11 phases (Kitchenham, 
2008; Mezirow, 1990, 1991, 1997, 2012), for the purposes of this study, the phases which link to ALT and PD will be the main areas of focus along with types of transformative knowledge.

\section{Process of Transformation.}

Transformative learning is a process where adult learners "transferring current frames of reference (meaning, perspectives, habits of minds, and mind sets) to make them more inclusive, discriminating, open, emotionally capable of change, and reflective" (Mezirow, 2012, p. 76). In essence, new experiences and situations push learners to question past perspectives and previously established biases in order to build mindful learning (Langer, 2000) and critical assessment of changing expectations and perspectives (Bouchard, 2015; Merriam \& Bierma, 2014; Mezirow, 2012). Learners transform their learning when they put aside ingrained habits of mind, entertain alternatives while remaining open and reflective, and change their actions and reactions to the world around them (Bruffee, 1999; Cranton \& King, 2003; Emslie, 2016; Kitchenham, 2008; Merriam \& Bierma, 2014; Mezirow, 1990, 1991, 1997, 2012; Preskill \& Brookfield, 2009). Simply put, when lived experiences create new meaning through self-reflection, transformative learning has occurred (Taylor, 2009; Troop, 2017).

\section{Transformative Reflection.}

Recognizing diverse perspectives is a fundamental component to changing learning and converting conversation into reflective discourse - a cognitive process and a key catalyst for transformative learning (Bouchard, 2015; Bruffee, 1999; Emslie, 2016; Gill, 2010; Merriam \& Bierma, 2014; Merriam, Caffarella, \& Baumgartner, 2007; Mezirow, 2012). "The goal is to open up alternatives, introduce new ways of thinking 
about teaching - a goal that is potentially transformative" (Cranton \& King, 2003, p. 34). Mezirow (1991) delineated types of reflection into three categories: content reflection, process reflection, and premise reflection. Content reflection focuses on "what we perceive, think, feel or act upon; process reflection is an examination of how we perform these functions of perceiving, thinking, feeling, or acting" (Mezirow, 1991, pp.107-108, emphasis in original). Premise reflection focuses on "why we perceive, think, feel or act" (p. 108). Adults learn by using discourse to share experiences and come to common understandings of concepts or areas of change (Bouchard, 2015). In fact, the use of dialogue through discussion provides learners with a way to "weave connections among ideas" (Gill, 2010, p. 87) in order to learn from each other (Bruffee, 1999; Preskill \& Brookfield, 2009). All three types of reflection can illicit straightforward transformation of (meaning schemes) beliefs and attitudes or (habits of mind) perspectives (Kitchenham, 2008; Merriam et al., 2007). However, Merriam and Bierma (2014) note the only type of reflection which leads to profound perspective transformation is premise reflection, "questioning the problem itself" (Cranton \& King, 2003, p. 350). Reflection alone does not cause learners to transform their perspectives, the reflection must induce "critical reappraisal of the person's frame of reference [to] become more open and critically osmotic" (Emslie, 2016, p. 49).

\section{Obtaining Knowledge.}

Transformative learning cannot occur in isolation (Merriam et al., 2007; RossGordon, Gordon, Alston, Dawson, \& Van Aacken, 2015); instead, it must be approached from a community of practice approach or a collegial culture (Bruffee, 1999; DragoSeverson, 2008). While some learners are able to individually make quick changes in 
their thinking, others need support from peers, family, or superiors in order to apply new knowledge and skills (Bruffee, 1999; Caffarella \& Daffron, 2013; Merriam et al., 2007). As a way to increase motivation during learning, collaborative groups composed of learners who share common goals and outlooks on learning "often generates a discourse and an energy that encourages reflection and can bring about transformation" (Bouchard, 2015, p. 3). Therefore, experience is essential to learning and the role of experience is a key element of learning and transformation of ideas (Caffarella \& Daffron, 2013; Merriam et al., 2007; Mezirow, 1990, 1991, 1997, 2012).

Like children, adults learn and obtain knowledge in different ways which impact our ability to learn and transform tacit knowledge into explicit knowledge which is "the critical steps in the spiral of knowledge" (Nonaka, 1991, p. 99). There are two forms of knowing: tacit and explicit; tacit knowledge is ingrained through life experiences and is difficult to explain, yet explicit knowledge is easily transferred from a multitude of sources (Bennett \& Jessani, 2011; Gill, 2010; Merriam \& Bierema, 2014; Nonaka, 1991). Furthermore, tacit knowledge does not become explicit until reflection and dialogue with other learners has occurred in regards to "thoughts and experiences" (Gill, 2010, p. 170). Habermas $(1971,1984)$ acknowledged and separated different types of knowledge into three separate domains each with its own purpose (Cranton \& King, 2003; DragoSeverson, 2008; Mezirow, 2012). The domains of knowledge are identified as instrumental, communicative, and emancipatory (Cranton \& King, 2003; Mezirow, 2012). Drago-Severson (2008) makes notes of the same domains but labels communicative learning as socializing and emancipatory learning as self-authority (p.61). 
Instrumental learning is valued to a greater degree in society due to learners' ability to "control and manipulate the environment or other people, as in task-oriented, problem solving to improve performance" (Mezirow, 2012, p. 77) and see the world in concrete terms (Drago-Severson, 2008). However, it is communicative learning which encompasses the premise of teaching in order to "[understand] ourselves, others, and the norms of the organization" (Cranton \& King, 2003, p. 1) with greater self-refection by focusing on mindsets, principles, and ethics (Drago-Severson, 2008). While transformation can occur in either instrumental or communicative learning styles, most learning combines domains creating a new domain, emancipation (Mezirow, 2012, p. 78).

\section{Conclusion}

In this section, literature was explored in the foundational areas of adult learning theory, characteristics and barriers to high impact professional development, the rise of English Language Arts education, and transformative learning. The literature selected relates to the conceptual framework of adult learning theory through andragogy, selfdirected learning, reflective practice, as well as teacher self-efficacy and motivation. By focusing on these factors, teaches can address the main components of how adults learn from personal experience and daily knowledge "as learning events" (Merrian \& Bierema, 2014, p. 17). Figure 5 identifies the overlap of key elements found in the study's theoretical framework and conceptual underpinnings.

Public education across America has progressed from an opportunity only for the wealthy (Baines, 2006) and boys headed into a clerical vocation (Mondale \& Patton, 2002) to a requirement for all children in 1918 through the creation of the common school (Baines, 2006; Campbell, 2001; Education News, 2013; Singer, 2016; Watson, 
2008). While common schools intended to provide an equitable education for all by eliminating socioeconomic bias (Cremin, 1957), local and state funding as well as political mandates have kept public schools across the country from true equality (Barone \& Morrell, 2007; Mondale \& Patton, 2002). One attempt to level the playing field of education was the inclusion of English and the study of literature as a mandatory subject for all students (Applebee, 1974; Applebee et al., 2003; NCTE, 1996). However, the debate of who is responsible for teaching the nuances of literacy has landed squarely on the backs of English teachers (Lester, 2000; Wilson et al., 2009). Instead, with the creation of the Common Core State Standards, every teacher has become an "English" teacher (Applebee, 2013; NGABP \& CCSSO, 2010; Wilson et al., 2009).

By defining professional development as promoting change in teachers' practices, attitudes toward implementing new knowledge, and increased student performance (Guskey, 2000, 2002), characteristics of and barriers to high impact PD were investigated. While teachers often find PD does not provide "opportunities for application, practice, reflection, or reinforcement" (Reeves, 2010, p. 23) to enhance their teaching, there are key elements such as collaboration, active/hands-on learning experiences, sustained learning over time, attitude toward learning, and assessment (Bruffee, 1999; Darling-Hammond \& Richardson, 2009; DESE, 2013; Desimone, 2011; Gill, 2010; Guskey, 2002; Killinger, 2004; Reeves, 2010; Strickland, 2009). However, barriers such as top-down directives (Guskey \& Yoon, 2009; Reeves, 2010; Roseler \& Dentzau, 2013), limited teacher voice in selecting PD (Bolman \& Deal, 2013; Burbank \& Kauchak, 2003; Lewis, 2015; Van Tessell, 2014), and limited time for new learning (Couros, 2015; Gulamhussier, 2013) were explored. By using the knowledge teachers 
already possess (Greenwell \& Zygouris-Coe, 2012) and focusing on subject specific content knowledge (Garet et al., 1999; Minor et al., 2016) teachers can gain more confidence in their practices and pedagogy.

Transformative learning aligns to adult learning theory because "transferring current frames of reference (meaning, perspectives, habits of minds, and mind sets) to make them more inclusive, discriminating, open, emotionally capable of change, and reflective" (Mezirow, 2012, p. 76). Through two types of knowledge, tacit and explicit (Bennett \& Jessani, 2011; Gill, 2010; Merriam \& Bierema, 2014; Nonaka, 1991), the importance of collaboration and dialogue to create change was emphasized (Bruffee, 1999; Gill, 2010). Three types of reflection, content reflection, process reflection, and premise reflection, (Mezirow, 1991) are key to changing learning and knowledge acquisition. And while all three types can provide direct changes in knowledge, Merriam and Bierma (2014) note only premise reflection leads to intense learning transformation. Deep reflection alone cannot cause learning transformation; however, by shifting perceived beliefs, adult learners open themselves to deep changes in knowing and learning (Bruffee, 1999; Drago-Severson, 2008; Mezirow, 1991). 


\title{
SECTION FOUR
}

\section{CONTRIBUTION TO PRACTICE}

\section{Plan for Dissemination of Practitioner Contribution}

Who: Attendees of the Missouri Write to Learn 2019 conference including pre-service teachers, current English Language Arts (ELA) teachers, ELA curriculum advisors, curriculum directors, administrators, National Council of Teachers of English members, and university instructors.

When: 2019 Write to Learn Conference, proposal submitted by September of 2018 to Willy Wood.

How: Through a 30 minute Gallery-Walk session at the Missouri Write to Learn Conference at Osage Beach, Missouri at the Tan-Tar-A Resort. This conference is usually held in late February. The presentation will be an interactive poster presentation.

\section{Type of Document(s)}

Document type will be an interactive poster presentation which will be presented at the 2019 Missouri Write to Learn conference which is held annually to serve the needs of current English Language Arts (ELA) teachers in the K-12 to university settings. The poster will facilitate discussions and inform the audience on how to better meet ELA teachers' needs when designing professional development at secondary and postsecondary levels.

\section{Rationale for this Contribution Type}

The Write to Learn Conference is the annual statewide conference structured specifically for the ELA teacher. The conference is supported by the National Council of Teachers of English, the Missouri Association of Teachers of English, the Missouri Writing Projects Network, the Missouri Reading Initiative, Missouri State Council - IRA, Educational Solutions International, and the University of Missouri Conference Office. This is the largest state gathering of teachers of English and has been held for the past X years.

\section{Outline of Proposed Contents}

\author{
Abstract \\ Objectives \& Research Questions \\ Theoretical Frameworks \\ Design of Study \\ Findings and Results \\ Conclusions \\ References
}




\title{
TEACHERS AS AGENTS OF CHANGE: \\ HOW KNOWLEDGE GAINED FROM SECONDARY ENGLISH LANGUAGE ARTS PROFESSIONAL DEVELOPMENT IMPACTS CLASSROOM PRACTICES
}

\author{
Executive Summary for Poster Presentation \\ Write to Learn - Missouri ELA Annual Conference \\ Lake of the Ozarks, Osage Beach, Missouri \\ February 2019
}

By Vicky L. Bryan

\begin{abstract}
Gathering information about how secondary English Language Arts (ELA) teachers use pedagogical content knowledge gained from professional development (PD) to change their classroom practices in one Midwest Missouri school district has the potential to change how future ELA PD is delivered. The researcher examined teachers' perceptions through 21 individual interviews and a focus group as well as district archival surveys administered after three ELA content PD days during the 2017-18 school year. Participants shared their thoughts on effective elements of PD, how teachers implement classroom change and how those changes influence student learning, as well as how teachers know they are growing. This research is qualitative in nature utilizing purposeful sampling, open coding, and an hermeneutic method to identify themes and interpret responses. Data discovered the use of teacher experts, time for collaboration, and participating in reflective practices as the most important elements in gaining new knowledge and impacting classroom practices.
\end{abstract}

Keywords: ELA teachers, effective professional development, teacher experts 


\section{Executive Summary for Research Poster Presentation}

\begin{tabular}{|c|c|}
\hline $\begin{array}{l}\text { Staten } \\
\text { A gap exists in research pertaining to investiga } \\
\text { development (PD) on teacher knowledge and c } \\
\text { 2010). While there is little empirical research } \\
\text { PD on teacher practice (Garet, Porter, Desimon } \\
\text { Supovitz \& Turner, 2000), a review of literatur } \\
\text { and quality to change classroom practices whic } \\
\text { Hammond, 2000; Garritz, 2012; Guskey, 2002, }\end{array}$ & $\begin{array}{l}\text { ent of the Problem } \\
\text { ions of ELA teachers on the impact of professional } \\
\text { langes made in classroom practices (Goldschmidt \& Phelps, } \\
\text { PD literature centered on personal effects or perceptions of } \\
\text {, Birman \& Yoon, 2001; Guskey, 2016; Mouza, 2006; } \\
\text { supports the need for teachers' perspectives on performance } \\
\text { act as a catalyst for increased student achievement (Darling } \\
\text { 2009; Guskey \& Yoon, 2009). }\end{array}$ \\
\hline $\begin{array}{l}\text { Purpose of the Study } \\
\text { The purpose of this study addressed a gap in } \\
\text { the current research focusing on the lack of } \\
\text { ELA teachers' perspective in regards to } \\
\text { professional development and its impact on } \\
\text { transforming classroom practice. Little } \\
\text { research has been devoted to the learning } \\
\text { styles and ways ELA teachers use } \\
\text { pedagogical content knowledge and reflection } \\
\text { to improve their craft (Ajayi, 2016; Desimone } \\
\text { et al., 2005; Garet et al., 2001; Thacker, } \\
\text { 2017). }\end{array}$ & $\begin{array}{l}\text { Theoretical Framework } \\
\text { This study is guided by adult learning theory (ALT). } \\
\text { Gibb (1960) emphasized adult learning opportunities must } \\
\text { be problem-centered, experience-centered, hands-on, and } \\
\text { meaningful to the learner in order to be effective (Fogarty \& } \\
\text { Peete, 2009; Knowles et al., 2015). Teachers need the } \\
\text { freedom to self-direct their inquiries to meet their individual } \\
\text { needs as learners; then, as Trotter (2006) states, their } \\
\text { professional development will become learner-centered and } \\
\text { meaningful. The pillars of public education's introduction } \\
\text { of English courses, professional development, and } \\
\text { transformative learning were explored as to how they } \\
\text { support ALT. }\end{array}$ \\
\hline
\end{tabular}

Qualitative Case Study: Perceptions of professional growth based on experiences where "the research describes the lived experiences of the individuals about a phenomenon as described by participants" (Creswell, 2016, p. 14; Creswell, 2014; Seidman, 2012).

Data Collection: Individual interviews and focus groups were conducted with secondary ELA teachers. Archival survey results from district and departmental professional development reflections were also collected.

Analyses: An hermeneutic method (Goodrick \& Rogers, 2015) and Creswell's (2016) concept of planning backwards to find emergent themes along with open coding was used on all interview and focus group transcripts and then recoded using axial coding; emergent themes were then grouped (Creswell, 2016; Gallicano, 2013; Goodrick \& Rogers, 2015; Krueger \& Casey, 2016; Merriam \& Tisdell, 2016).

Participant Sample: The researcher used purposeful sampling by selecting maximum variation and theoretical sampling as defined by Merriam and Tisdell (2016, pp. 97-99). The researcher balanced ethical issues in terms of relationships with colleagues as participants and critical, qualitative research by doing good work (Drake \& Heath, 2011, Seidman, 2012).

\section{Research Questions}

How have secondary English Language Arts (ELA) teachers, from one Midwest Missouri school district, used pedagogical content knowledge gained from ELA professional development to change their individual classroom practices?

\section{Sub Questions:}

- How do secondary ELA teachers define effective professional development?

- How do secondary ELA teachers implement change in their classroom practices due to newly gained pedagogical content knowledge?

- How do secondary ELA teachers know when classroom practice changes have influenced student learning?

- How do secondary ELA teachers know they are growing and/or transforming professionally? 


\section{Implications}

Analysis of the collected responses from secondary ELA teachers in the Heartland district provided valuable information into how the learning opportunities presented to teachers through content and pedagogical PD impact their daily classroom practices and ultimately their students' learning. This research provided the Heartland School District and other large districts like Heartland with the opportunity to see how PD influences the most important job of schools: teaching students. With the goal of providing teachers with effective opportunities to gain new knowledge to transform their teaching practices, the ELA teacher's voice must be heard. Teachers, district administration, and other district leaders will benefit from the in-depth look into how PD provides classroom change and student learning. In addition, the feedback from ELA teachers can be used to influence the approach to PD and the content other departments may wish to emulate.

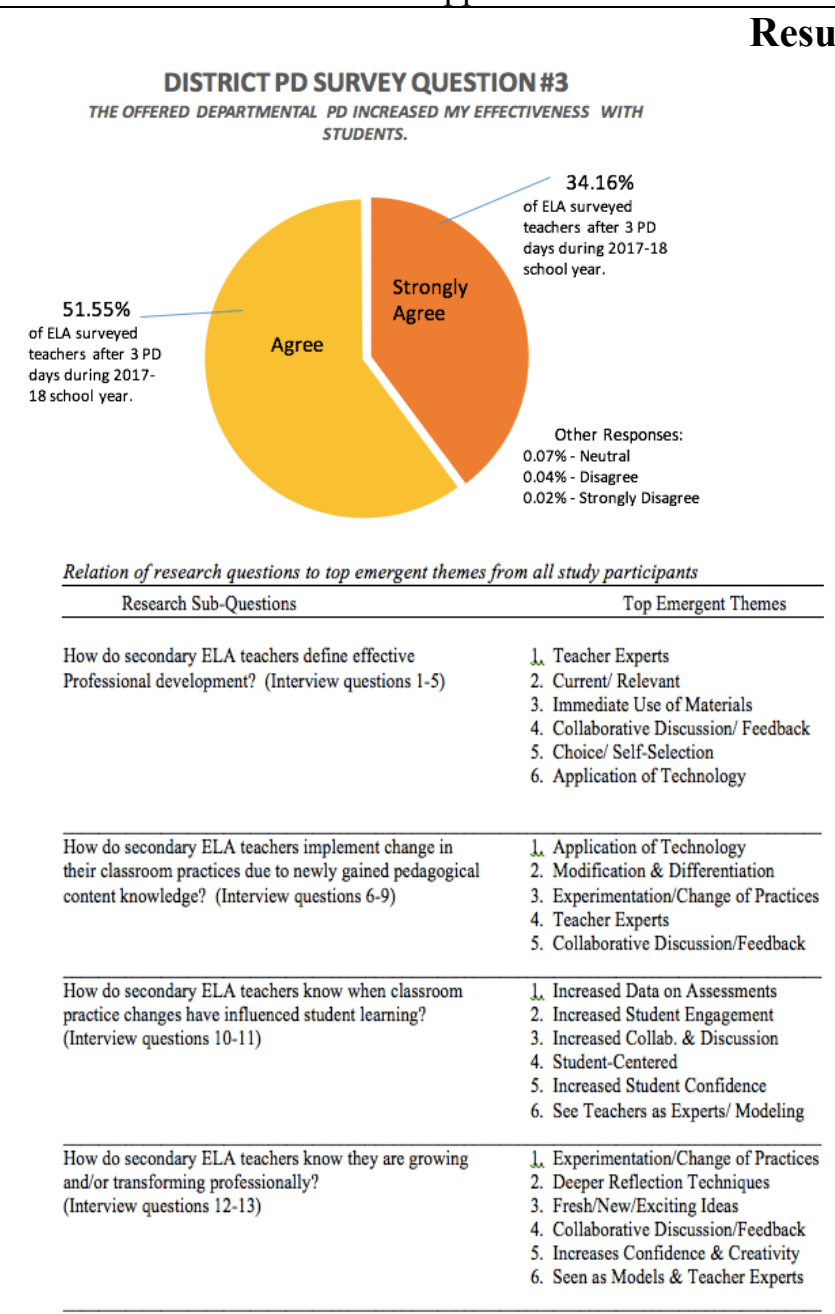

Main Emergent Theme:

Utilizing Teacher Experts

Other Themes:

* Collaborative Discussion

* Reflective Practice

Emergent Sub-Themes:

* experimentation

* application of technology

* individual student increases

* reflective feedback

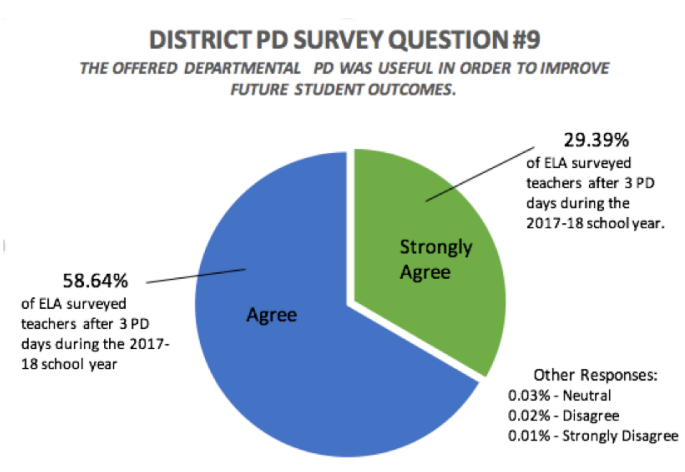

\section{Future Research}

* Using Teacher Experts

$>$ How are teacher leaders able to help peers transform their teaching practices?

$>$ What roles do teacher leaders take within their buildings?

$>$ Does a district need to develop and implement a specific PD presenter training model to use teacher

\section{Conclusion}

The overall views of teacher participants were positive in regards to the quality, acquired knowledge, and ability to increase student learning practices. Findings showed positive ways PD changed classroom practices as well as high levels of using teacher experts, peer collaboration, and reflective techniques. In fact, using teacher experts was the largest emergent theme and was evident the coding of all four research sub-questions and in when 


\begin{tabular}{|c|l|}
\hline $\begin{array}{c}\text { experts to their fullest potential? } \\
\text { Reflective Practices }\end{array}$ & $\begin{array}{l}\text { collected data were grouped into categories depicting } \\
\text { specific years of teaching experience. Additionally, }\end{array}$ \\
experience effect a teacher's professional growth? & the participants revealed experimentation, \\
application of technology, individual student \\
methodologies in their classroom practices? \\
increases in learning, and reflective feedback as \\
possible areas of focus for all future ELA PD \\
presentations. Overall, participants felt the current \\
structure of departmental PD at Heartland has \\
provided growth opportunities for teachers and \\
students alike. However, the breakdown of teacher \\
responses grouped into categories depicting specific \\
years of teaching experience may point to the need \\
for future differentiation of departmental content to \\
better meet all novice to veteran teachers' specific \\
learning needs.
\end{tabular}

\section{Contact Information}

Vicky L. Bryan, Ed. D., is an English Language Arts teacher and Curriculum Advisor for the Saint Joseph School District in northwest Missouri. 


\section{Poster for Research Presentation}
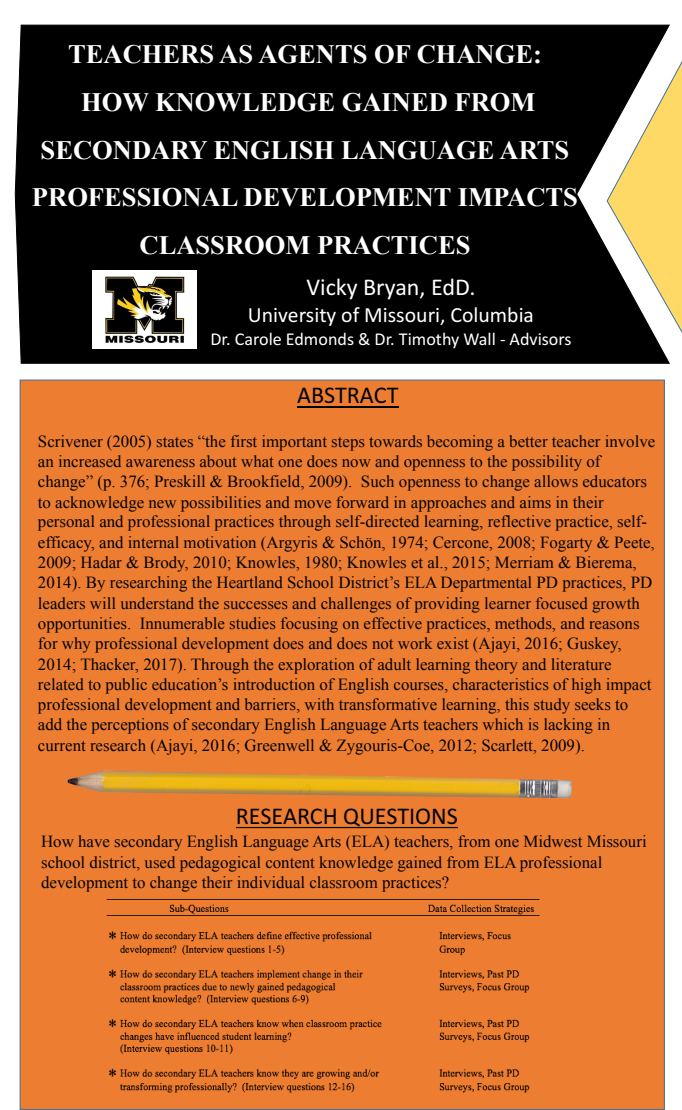

IMPLICATIONS FOR PRACTICE

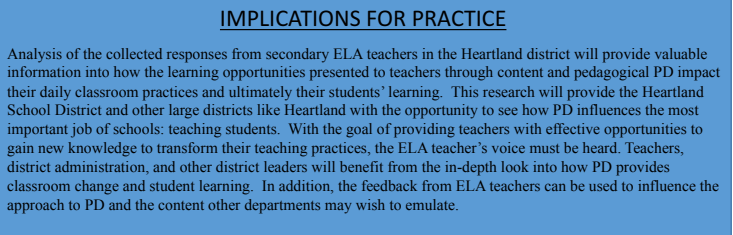

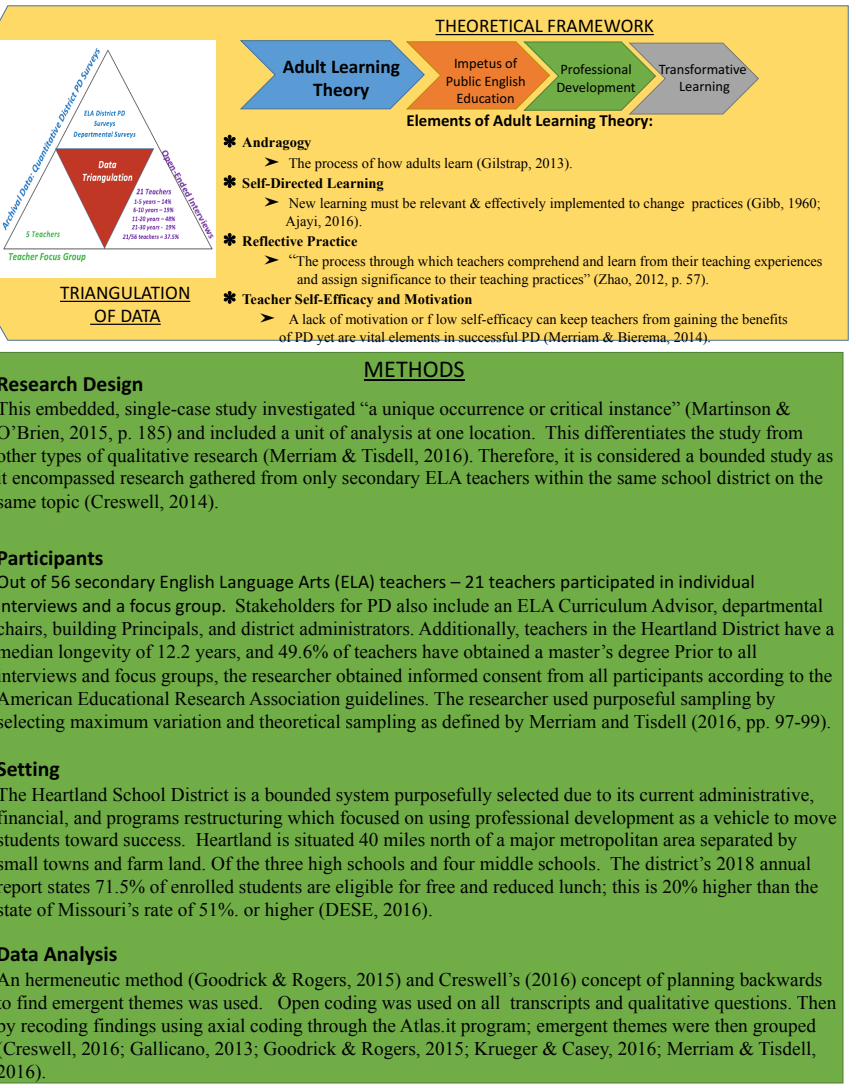

*Using Teacher Expert

\section{FUTURE RESEARCH}

$>$ How are teacher leaders able to help peers transform their teaching practices?

What roles do teacher leaders take within their buildings?
Does a district need to develop and implement a specific PD presenter training model to use teach

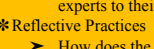

$>$ How does the number of years of teaching experience effect a teacher's professional growth? What keeps teachers from trying new methodologies in th?
What do teachers need to learn about reflective practices?
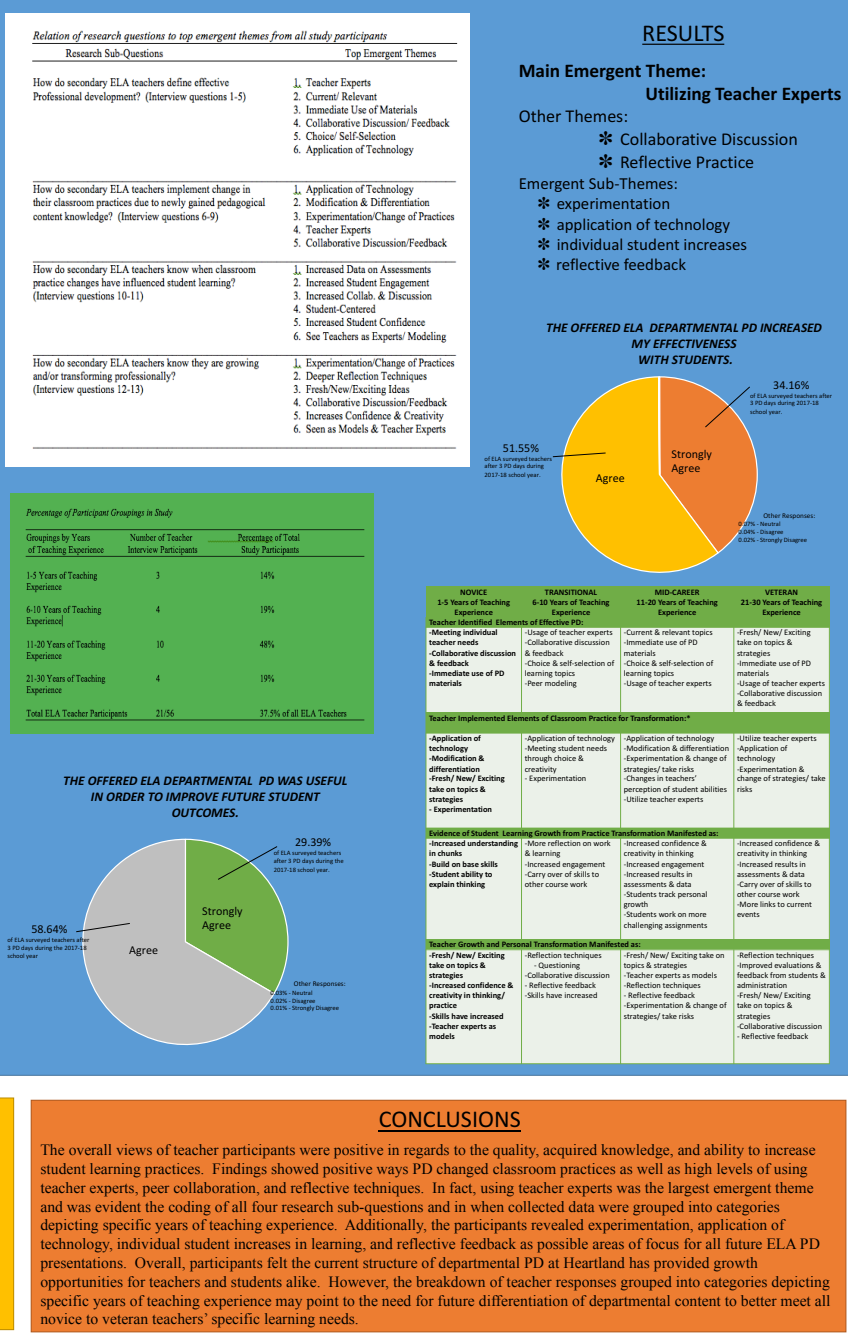


\section{References}

Ajayi, L. (2016). High school teachers' perspectives on the English language arts Common Core State Standards: An exploratory study. Educational Research for Policy and Practice, 15(1), 1-25. doi: 10.1007/s10671-015-9174

Argyris, C., \& Schön, D. A. (1974). Theory in practice: Increasing professional effectiveness. San Francisco, CA: Jossey-Bass.

Cercone, K. (2008). Characteristics of adult learners with implications for online learning design. AACE Journal, 16(2), 137-159.

Creswell, J. W. (2014). Research design: Quantitative, qualitative, and mixed methods approaches (4th ed.). Thousand Oaks, CA: Sage.

Creswell, J. W. (2016). 30 essential skills for the qualitative researcher. Thousand Oaks, CA: Sage.

Darling-Hammond, L. (2000). Teacher quality and student achievement: A review Of state policy evidence. Education Policy Analysis Archives, 8,

DESE, Missouri Department of Elementary \& Secondary Education. (2016). Statistics report. Retrieved from www.dese.mo.gov

Desimone, L. M., Porter, A. C., Garet, M. S., Yoon, K. S., \& Birman, B. F. (2002). Effects of professional development on teachers' instruction: Results from a three-year longitudinal study. Educational Evaluation and Policy Analysis, 24(2), 81-112.

Drake, P., \& Heath, L. (2011). Practitioner research at doctoral level developing coherent research methodologies. (First ed., pp. 46-58). London, New York: Routledge

Fogarty, R., \& Pete, B. (2009). Professional learning 101: A syllabus of seven protocols. Phi Delta Kappan, 91(4), 32-34.

Gallicano, T. D. (2013, July 22). An example of how to perform open coding, axial coding and Selective coding [Web log post]. Retrieved from https://prpost.wordpress.com/2013/07/22/ an-example-of-how-to-perform-openoding-axial-coding-and-selective-coding/

Garet, M. S., Porter, A. C., Desimone, L., Birman, B. F., \& Yoon, K. S. (2001). What makes professional development effective? Results from a national sample of teachers. American Educational Research Journal, 38(4), 915-945 
Garritz, A. (2013). PCK for dummies. Educación Química, 24(2), 462-465.

Gibb, R. J. (1960). Learning theory in adult education. In M. S. Knowles (Ed.), Handbook of Adult Education in the United States. Washington, DC: Adult Education Association of the United States of America.

Gilstrap, D. L. (2013). Why do we teach? Adult learning theory in professional standards as a basis for curriculum development. Library Literature \& Informational Science, 74(5), 501-518.

Goldschmidt, P., \& Phelps, G. (2010). Does teacher professional development affect content and pedagogical knowledge: How much and for how long? Economics of Education Review, 29, 432-439. doi: 10.1016/j.econedurev.2009.10.002

Goodrick, D., \& Rogers, P. J. (2015). Qualitative data analysis. In K. Newcomer, H. Hatry, \& J. Wholey (Eds.), Handbook of practical program evaluation (4th ed., pp. 561-595). Hoboken, New Jersey: Jossey-Bass.

Greenwell, S., \& Zygouris-Coe, V. (2012). Exploring high school English Language Arts teachers' responses to professional development in reading instruction. Journal of Reading Education, 37(2), 21-26.

Guskey, T. R. (2002). Professional development and teacher change. Teachers and Teaching: Theory and Practice, 8(3/4), 381-391. doi: $10.1080 / 13540600210000512$

Guskey, T. R. (2009). Closing the knowledge gap on effective professional development. Educational Horizons, 87(4), 224-233.

Guskey, T. R. (2016). Gauge impact with 5 levels of data. Journal of Staff Development, $37(1), 32-37$.

Guskey, T. R \& Yoon, K. S. (2009). What works in professional development? Phi Delta Kappan, 90(7), 495-500.

Hadar, L., \& Brody, D. (2010). From isolation to symphonic harmony: Building a professional

Development community among teacher educators. Teaching and Teacher Education, 26(8), 1641-1651. doi: 10.1016/j.tate.2010.06.015

Knowles, M. S. (1980). The modern practice of adult education: From pedagogy to andragogy (2nd ed.). Chicago, IL: Follett.

Knowles, M. S., Holton, E. F., \& Swanson, R. A. (2015). The adult learner: The definitive classic in adult education and human resource development (8th ed.). San Francisco, CA: Jossey-Bass. 
Krueger, R. A., \& Casey, M. A. (2016). Focus groups: A practical guide for applied research (5th ed.). Thousand Oaks, CA: Sage.

Martinson, K., \& O’Brien, C. (2015). Conducting case studies. In K. Newcomer, H. Hatry, \& J. Wholey (Eds.), Handbook of practical program evaluation (4th ed., pp. 177-196). Hoboken, New Jersey: Jossey-Bass.

Merriam, S. B., \& Bierema, L. L. (2014). Adult learning: Linking theory and practice. San Francisco, CA: Jossey-Bass.

Merriam, S. B., \& Tisdell, E. J. (2016). Qualitative research: A guide to design and implementation (4th ed.). San Francisco, CA: Jossey-Bass.

Mouza, C. (2006). Linking professional development to teacher learning and practice: A multiple-case study analysis of urban teachers. Journal of Educational Computing Research, 34(4), 405-440.

Preskill, S., \& Brookfield, S. D. (2009). Learning as a way of leading: Lessons from the struggle for social justice. San Francisco, CA: Jossey-Bass. (Selected readings)

Scarlett, D. H. (2009). High school English Language Arts teachers' conceptualizations of pedagogical content knowledge. (Doctoral dissertation).

Scrivener, J. (2005). Learning Teaching (2nd ed.). Oxford: Macmillan Education.

Seidman, I. (2012). Interviewing as qualitative research: A guide for researchers in education and the social sciences (4th ed.). New York, NY: Teachers College Press.

Supovitz, J. A., \& Turner, H. M. (2000). The effects of professional development on science teaching practices and classroom culture. Journal of Research in Science Teaching, 37(9), 963-980.

Thacker, E. S. (2017). “PD is where teachers are learning!” High school social studies teachers' Formal and informal professional learning. The Journal of Social Studies Research, 41, 37-52.

Trotter, Y. (2006, Winter). Adult learning theories: Impacting professional development programs. The Delta Kappa Gamma Bulletin, 72(2), 8-13.

Zhao, M. (2012). Teachers' professional development from the perspective of teaching reflection levels. Chinese Education \& Society, 45(4), 56-67. 


\section{SECTION FIVE \\ CONTRIBUTION TO SCHOLARSHIP}

\section{Target Journal}

The target journal for publication is Research in the Teaching of English (RTE). This journal is a part of the publication suite from the National Council of Teachers of English (NCTE) and considered their flagship research journal.

\section{Rationale for this Target}

This journal specifically focuses on teachers of English language and literacy in K-12 schools and at the university level and beyond including surrounding communities and institutions beyond the traditional classroom. They focus on previously unpublished scholarly research. This journal accepts articles focused on all aspects and topics of teaching English in the United States and around the world and specifically lists professional development as a desired topic.

\section{Outline for Proposed Contents}

An article of no more than 45 pages of content in length and should be written to appeal to a wide variety of readers on a topic relatable to areas inside and outside of English education classrooms. The article will include the following sections:

Abstract

Significance to the field

Introduction of the Problem

Theoretical Framework

Scholarly Grounding

Methodology

Methods

Participants

Data Collection Analysis

Results and Findings

Discussion

Limitations and Delimitations

Implications for Practice and Future Research

References

Appendices

\section{Plan for Submission}

Who: Research in the Teaching of English through the National Council of Teachers of English

When: Summer of 2018

How: Editorial Management System website https:/www.editorialmanager.com/rte 
TEACHERS AS AGENTS OF CHANGE:

HOW KNOWLEDGE GAINED FROM SECONDARY ENGLISH LANGUAGE

ARTS PROFESSIONAL DEVELOPMENT IMPACTS

CLASSROOM PRACTICES

\begin{abstract}
About the Author
Vicky L. Bryan received her Doctorate in Educational Leadership and Policy Analysis from the University of Missouri - Columbia. Bryan has 22 years of secondary English Language Arts teaching experience, is a National Board Certified Teacher, and currently serves her school district as the Secondary ELA Curriculum Advisor.
\end{abstract}

\begin{abstract}
Gathering information about how secondary English Language Arts (ELA) teachers use pedagogical content knowledge gained from professional development (PD) to change their classroom practices in one Midwest Missouri school district has the potential to change how future ELA PD is delivered. The researcher examined teachers' perceptions through 21 individual interviews and a focus group as well as district archival surveys administered after three ELA content PD days during the 2017-18 school year. Participants shared their thoughts on effective elements of PD, how teachers implement classroom change and how those changes influence student learning, as well as how teachers know they are growing. This research is qualitative in nature utilizing purposeful sampling, open coding, and an hermeneutic method to identify themes and interpret responses. Data discovered the use of teacher experts, time for collaboration, and participating in reflective practices as the most important elements in gaining new knowledge and impacting classroom practices.
\end{abstract}

Keywords: ELA teachers, effective professional development, teacher experts 


\section{Significance to the Field}

The voice of the English Language Arts teacher seems to be missing from contributions to research, and teacher professional development studies are rare (Greenwell \& Zygouris-Coe, 2012; Wilson, Grisham, \& Smetana, 2009). Anders, Hoffman, and Duffy (2000) discovered less than 1\% of research since 1965 has addressed topics surrounding teacher professional development (PD). Additionally, investigations on the impact of PD on teacher knowledge and changes made in classroom practices have been limited in scope (Goldschmidt \& Phelps, 2010). There is little empirical research in professional development literature centered on personal effects or perceptions of PD on teacher practice (Garet, Porter, Desimone, Birman \& Yoon, 2001; Guskey, 2016; Mouza, 2006; Supovitz \& Turner, 2000). This study focused on how secondary English Language Arts (ELA) teachers use pedagogical content knowledge (PCK) gained from PD to change their individual classroom practices and influence student learning. This researcher's inquiry attempts to fill gaps where more research is needed. Methods of what works for various groups of teachers is hit and miss, "few if any professional development strategies, techniques, or activities work equally well in all [contexts]" (Guskey, 2009, p. 229).

\section{Introduction of the Problem}

Research has shown professional development (PD) and reflection are considered key components in improving teacher pedagogy and student achievement (DarlingHammond \& McLaughlin, 2011; Gulamhussein, 2013; Guskey, 2000; Guskey \& Yoon, 2009; Schieb \& Karabenick, 2011; Thacker, 2017; TNTP, 2015). Equally important is the factor of teacher performance and quality in classroom practices which act as the 
primary catalyst for increased student achievement (Bucynski \& Hansen, 2010; DarlingHammond, 2000; Garritz, 2012; Guskey, 2002, 2009; Guskey \& Yoon, 2009; Park \& Oliver, 2008). There are many different ways teachers acquire knowledge including "interest in the subject matter; general pedagogical knowledge: and interest in pedagogy; contextual knowledge: an interest in students and their communities" (Diaz-Maggioli, 2004, p. 7). Educational studies abound offering effective practices, possible methods, and reasons for what does not promote effective PD (Garet et al., 2001; Greenwell \& Zygouris-Coe, 2012; Guskey, 2016). Guskey (2014) explains how the lack of strong evidence of effective PD may "stem from a general absence of purpose" (p. 12). Without a clear purpose, the ultimate outcomes of PD often fall flat for many school districts and fail to change classroom practices because the PD is planned "for process, not for results" (Guskey, 2014, p. 12).

\section{Research Questions}

The guiding research question for this study is: How have secondary English Language Arts (ELA) teachers, from one Midwest Missouri school district, used pedagogical content knowledge gained from ELA professional development to change their individual classroom practices? Sub-questions guiding this study include:

- (a) How do secondary ELA teachers define effective professional development?

- (b) How do secondary ELA teachers implement change in their classroom practices due to newly gained pedagogical content knowledge?

- (c) How do secondary ELA teachers know when classroom practice changes have influenced student learning?

- (d) How do secondary ELA teachers know they are growing and/or transforming professionally? 


\section{Theoretical Framework}

This study is guided by adult learning theory (ALT). For educators, learning and growing are at the epicenter of the teaching profession: "New knowledge always begins with the individual" (Nonaka, 1991, p. 97). Adults learn differently than children, and one dimension separating the types of learning focuses on adults' previous learning experiences (Merriam \& Bierema, 2014). Adults need a "process design" in order to relate new information gained to life-long and self-directed learning (Gilstrap, 2013). Additionally, Gibb (1960) emphasized adult learning opportunities must be problemcentered, experience-centered, hands-on, and meaningful to the learner in order to be effective (Fogarty \& Peete, 2009; Knowles, Holton, \& Swanson, 2015). In fact, adults need to understand how new knowledge will impact their daily lives; therefore, Gibb (1960) stresses how new learning must be relevant in order to be effectively implemented and change established practices (Ajayi, 2016).

This premise is especially true to classroom teachers: "Because professional development often presents information that teachers see as irrelevant to student learning in their specific school settings, teachers often don't learn and apply what professional development programs offer" (King \& Newmann, 2000, p. 576). Trotter (2006) furthers this premise by outlining a second key theme for effective adult learning through experience-centered choices: "adults [need] to plan their own educational paths based on their interests and their classrooms" (p. 12). Without these connections of relevancy which promote the internalization of new ideas, changes in teaching practices will not evolve. In fact, prior experiences can impede new learning or alternative thought from 
occurring due to learned biases and prejudicial mental habits or blind spots (Knowles, 1980; Knowles et al., 2015; Merriam \& Bierema, 2014).

Since adults learn by talking and collaborating to share experiences and come to common understandings (Bouchard, 2015), the inclination to obtain new knowledge comes from the essential element of intrinsic motivation combined with engagement in reflective practices. As simplistic as the concept seems, reflecting on personal performance or practice is not a process taught to learners, but in order to grow professionally, teachers must learn to learn (Chalikandy, 2014). Teachers must be willing to experiment with strategies and techniques to stimulate direct change, test these changes, modify them, and then test them again.

Finally, teacher self-efficacy and motivation to gain new knowledge and implement what has been learned is an important component of ALT. Motivational factors such as program content, time duration, activities, and where the PD takes place can be beneficial to those determining and delivering a learning event, yet such factors are rarely considered during program planning or studied in research (Merriam, Caffarella, \& Baumgartner, 2007). However, motivation is about more than just getting teachers to attend PD; it is about pushing them to participate and be active in the learning opportunity though collaboration or engaging in discussion (Bruffee, 1999). Therefore, teachers who are highly motivated stay in the profession longer, participate actively in district and personal developmental pursuits.

\section{Scholarly Grounding}

By defining professional development as promoting change in teachers' practices, 
attitudes toward implementing new knowledge, and increased student performance (Guskey, 2000, 2002), characteristics of and barriers to high impact PD were investigated. While teachers often find PD does not provide "opportunities for application, practice, reflection, or reinforcement" (Reeves, 2010, p. 23) to enhance their teaching, there are key elements such as collaboration, active/hands-on learning experiences, sustained learning over time, attitude toward learning, and assessment (Bruffee, 1999; Darling-Hammond \& Richardson, 2009; DESE, 2013; Desimone, 2011; Gill, 2010; Guskey, 2002; Reeves, 2010). However, barriers such as top-down directives (Guskey \& Yoon, 2009), limited teacher voice in selecting PD (Bolman \& Deal, 2013, 2003; Van Tessell, 2014), and limited time for new learning (Couros, 2015; Gulamhussier, 2013) were explored. By using the knowledge teachers already possess (Greenwell \& Zygouris-Coe, 2012) and focusing on subject specific content knowledge (Garet, Birman, Porter, Desimone, \& Harman, 1999) teachers can gain more confidence in their practices and pedagogy.

Transformative learning aligns to adult learning theory because "transferring current frames of reference (meaning, perspectives, habits of minds, and mind sets) to make them more inclusive, discriminating, open, emotionally capable of change, and reflective" (Mezirow, 2012, p. 76). Through two types of knowledge, tacit and explicit (Bennett \& Jessani, 2011; Gill, 2010; Merriam \& Bierema, 2014; Nonaka, 1991), the importance of collaboration and dialogue to create change was emphasized (Bruffee, 1999; Gill, 2010). Three types of reflection, content reflection, process reflection, and premise reflection, (Mezirow, 1991) are key to changing learning and knowledge acquisition. And while all three types can provide direct changes in knowledge, Merriam 
and Bierma (2014) note only premise reflection leads to intense learning transformation. Deep reflection alone cannot cause learning transformation; however, by shifting perceived beliefs, adult learners open themselves to deep changes in knowing and learning (Bruffee, 1999; Drago-Severson, 2008; Mezirow, 1991).

\section{Methodology}

In order to understand the ways in which teachers grow professionally and perceive professional development, the researcher used a qualitative method from a pragmatic view of reality, wherein "a worldview arises out of actions, situations, and consequences rather than antecedent conditions" (Creswell, 2016, p. 10). A qualitative methodology builds "from particulars to general themes" allowing for "interpretations of the meaning of the data" (Creswell, 2014, p. 4). This was a bounded study as it encompassed research gathered from only secondary ELA teachers within the same school district on the same topic (Creswell, 2014; Yin, 2009, 2012).

\section{Participants}

The Heartland School District employs 56 secondary English Language Arts (ELA) teachers. Stakeholders for PD also include an ELA Curriculum Advisor, departmental chairs, building principals, and district administrators. The researcher used purposeful sampling by selecting maximum variation and theoretical sampling as defined by Merriam and Tisdell (2016, pp. 97-99). The researcher balanced ethical issues in terms of relationships with colleagues as participants and critical, qualitative research by doing good work (Drake \& Heath, 2011, Seidman, 2012). A total of 21 teachers participated in interviews and a focus group; this is $37.5 \%$ of the ELA district teacher 
population. Table 3 provides a breakdown of each participant and his/her obtained degree, gender, years of experience, and current course level taught.

\section{Data Collection and Analysis}

This research study collected data from multiple sources in order to form a triangulation of data (Merriam \& Tisdell, 2016) which ensured internal validity and gained multiple perspectives on the topic (p. 245). The researcher used archival district departmental surveys launched in 2017; the surveys were open to all secondary ELA teachers in the district in order to determine PD interests and ensure all teachers had a voice in the research findings. Individual interviews were then conducted using a purposeful sampling technique allowing the researcher to select interviews from those educators whom the most can be learned (Merriam \& Tisdell, 2016). The interviews were conducted face-to-face and recorded using www.Rev.com for transcription. 
Table 3

Teacher Participant Demographics

\begin{tabular}{|c|c|c|c|c|}
\hline Teacher Name & Degree Obtained & Gender & $\begin{array}{l}\text { Years of } \\
\text { Teaching }\end{array}$ & $\begin{array}{l}\text { Course Level } \\
\text { Taught }\end{array}$ \\
\hline Marissa & Masters & $\bar{F}$ & 3 & High School \\
\hline Celeste & Bachelors & $\mathrm{F}$ & 5 & Middle School \\
\hline Sue & Bachelors & $\mathrm{F}$ & 5 & High School \\
\hline Natasha & Masters & $\mathrm{F}$ & 6 & High School \\
\hline Raquelle & Specialist & $\mathrm{F}$ & 10 & High School \\
\hline Robert & Masters & M & 10 & High School \\
\hline Pheobe & Bachelors & $\mathrm{F}$ & 10 & High School \\
\hline Bonnie & Bachelors & $\mathrm{F}$ & 11 & Middle School \\
\hline Blake & Masters & M & 15 & High School \\
\hline Hallie & Masters & $\mathrm{F}$ & 16 & Middle School \\
\hline *Lucy & Masters & $\mathrm{F}$ & 16 & High School \\
\hline *Sherri & Bachelors & $\mathrm{F}$ & 17 & High School \\
\hline *Nikki & Masters & $\mathrm{F}$ & 17 & High School \\
\hline *Samantha & Masters & $\mathrm{F}$ & 18 & High School \\
\hline *Renee & Bachelors & $\mathrm{F}$ & 18 & High School \\
\hline Penelope & Masters & $\mathrm{F}$ & 19 & High School \\
\hline William & Masters & M & 20 & High School \\
\hline Lori & Bachelors & $\mathrm{F}$ & 21 & Middle School \\
\hline Tammy Lynn & Masters & $\mathrm{F}$ & 23 & Middle School \\
\hline *Ruth & Bachelors & $\mathrm{F}$ & 30 & High School \\
\hline Melanie & Masters & $\mathrm{F}$ & 30 & Middle School \\
\hline
\end{tabular}

Note. *Lucy, Sherri, Nikki, Samantha, Renee, and Ruth participated in a Focus Group discussion; all other teachers participated in individual interviews. 
Interviews were semistructured in design (Merriam \& Tisdell, 2016, p. 110), and used a neo-positivist framework (Merriam \& Tisdell, 2016, p. 112) in which the interviewer was able to "[ask] good questions, [minimize] bias... [generate] quality data and [produce] valid findings" (Roulston, 2010, p. 52). The researcher utilized an hermeneutic method (Goodrick \& Rogers, 2015) and Creswell's (2016) concept of planning backwards to find emergent themes. Open coding was used on all interview transcripts, focus group transcripts, and qualitative questions on district and departmental archival surveys. Then by recoding findings using axial coding through the online www.Atlas.it program; emergent themes were then grouped (Creswell, 2016; Gallicano, 2013; Goodrick \& Rogers, 2015; Krueger \& Casey, 2016; Merriam \& Tisdell, 2016). Archival district and department surveys were used to validate participant data. The use of multiple methods (Caffarella \& Daffron, 2013) open process showed how "multiple sources of data helps build the codes, and in turn, the evidence for the theme[s]" (Creswell, 2016, p. 157). Through this process the researcher was able to eliminate any redundancy and overlap of categories. Further interviews were conducted as needed based on initial findings from coding.

\section{Results and Findings}

Scrivener (2005) states "the first important steps towards becoming a better teacher involve an increased awareness about what you do now and openness to the possibility of change" (p. 376). Such openness to change allows educators to acknowledge new possibilities and move forward in approaches and aims in their personal and professional practices. Discovering how English Language Arts teachers use gained knowledge from professional development to change their classroom practices 
is the compelling principle guiding this study. After triangulating the collected data, the study uncovered three overarching themes within professional development (PD) of the secondary English Language Arts (ELA) teachers at the Heartland School District. The main overarching themes discovered in this research are presented in Table 4 and are as follows:

- Utilizing teacher experts

- Collaboration with peer teachers to discuss classroom topics and gain feedback

- Using reflective strategies and practices

These three main themes were threaded throughout interviews, the focus group, and survey responses. These themes echo the overlap found when the theoretical framework and underpinnings of this study were compared and contrasted. These overlapping areas include collaboration, reflection, motivation, and prior experiences (Appendix A). Four sub-themes also emerged during the coding process when data was grouped into years of teaching experience by research sub-question:

- Experimentation

- Application of technology

- Individual student increases

- Reflective feedback

The data is presented in participants' direct quotations; however, the identity of the participants is kept confidential, and pseudonyms are used in order to maintain anonymity. 
Table 4

Relation of Research Questions to Top Emergent Themes from all Participants

\begin{tabular}{ll}
\hline \multicolumn{1}{c}{ Research Sub-Questions } & \multicolumn{1}{c}{ Top Emergent Themes } \\
\hline How do secondary ELA teachers define effective & 1. Teacher Experts \\
Professional development? & 2. Current/ Relevant \\
(Interview questions 1-5) & 3. Immediate Use of Materials \\
& 4. Collaborative Discussion/ Feedback \\
& 5. Choice/ Self-Selection \\
& 6. Application of Technology \\
\hline How do secondary ELA teachers implement change & \\
in their classroom practices due to newly gained & 1. Application of Technology \\
pedagogical content knowledge? & 2. Modification \& Differentiation \\
(Interview questions 6-9) & 3. Experimentation/Change of Practices \\
& 4. Teacher Experts \\
& 5. Collaborative Discussion/Feedback \\
\hline How do secondary ELA teachers know when classroom & 1. Increased Data on Assessments \\
practice changes have influenced student learning? & 2. Increased Student Engagement \\
(Interview questions 10-11) & 3. Increased Collab. \& Discussion \\
& 4. Student-Centered \\
& 5. Increased Student Confidence \\
& 6. See Teachers as Experts/ Modeling \\
\hline How do secondary ELA teachers know they are & 1. Deeper Reflection Techniques \\
growing and/or transforming professionally? & 2. Experimentation/Change of Practices \\
(Interview questions 12-13) & 3. Fresh/New/Exciting Ideas \\
& 4. Collaborative Discussions \\
& 5. Increases Confidence \& Creativity \\
& 6. Utilizing Content Teacher Experts \\
\hline
\end{tabular}

\section{Teachers' Feelings about Professional Development}

When asked about their immediate visceral reaction to professional development,

three teachers of 21 participating in the study interviews and focus group confessed a less than glowing reaction. With 10 years of teaching experience, Robert stated PD was "a meeting I'm going to have to go to," and Natasha confessed, "Unfortunately, the first thing that comes to mind is a long day that mostly is unproductive followed immediately by the hope that it won't be." Tammy Lynn who has taught for 23 years expressed a closed mind to gaining new knowledge makes her feel like "I am my biggest obstacle." 
After 30 years in the field of education, Melanie feels she may know from where teacher's wariness of PD's effectiveness stems:

I feel that [teachers] do not regard themselves as professionals. If [teachers] regarded [them]selves on the same level as doctors or lawyers or someone at that level of what's considered professional, they would know that they need to constantly update and that they constantly need to be looking at what are the latest trends, what's the latest research. Many teachers just [take] what's offered at the district level and that's it. (Melanie, personal communication, May 14, 2018)

However, a few feelings of negativity were far outweighed by a positive outlook when 18 of the 21 participants provided strong and specific reasoning for favorable attitudes when attending ELA PD. From comments about learning particular or new strategies to make classroom instruction better to time to "collaborate with colleagues on the most recent and most effective ways of getting information to our students and helping them learn" (William, personal communication, May 21, 2018), Heartland teachers find ELA PD to be worth the days taken out of instructional time. Hallie has taught for 16 years within the district and states, "What really comes to mind is growing myself and my craft of teaching. So I'm being developed as a professional in education."

\section{Defining Effective Professional Development}

Experts and research agrees on the elements of effective PD to include ways to gain and process content and pedagogical knowledge, apply best practice strategies, positively impact student learning and teacher effectiveness, offer hands-on/ active learning, collaborative learning, sustained learning, and time to reflect on practice (DESE, 2013; Darling-Hammond, Wei, Andree, Richardson, \& Orphanos, 2009; DarlingHammond \& Richardson, 2009). Additionally, PD in teachers' content areas has a greater impact on teacher and student performance (Garet et al., 1999). Secondary ELA teachers in the Heartland District supported the research in their top responses to this 
study's sub-question (a): How do secondary ELA teachers define effective professional

development? The top six themes which emerged from interview questions one to five

(which appear in Appendix B) and district surveys were:

1. Use of teacher experts

2. Provide current and relevant topics

3. The ability to immediately use PD materials and ideas in the classroom

4. Collaborate with peer teachers to discuss PD topics and gain feedback

5. The ability to self-select PD sessions and topics

6. Apply the newest technology

In addition to these themes, various specific teacher needs emerged when the data were broken down into groups based on teachers' years of teaching experience. These findings are provided in Table 5. A full table of these findings can be found in Appendix B.

Table 5

Theme Emergence by Years of Teaching Experience for Sub-question (a)

Teacher Identified Elements of Effective PD:

\begin{tabular}{llll}
\hline $\begin{array}{c}\text { NOVICE } \\
\text { 1-5 Years of Teaching } \\
\text { Experience }\end{array}$ & $\begin{array}{c}\text { TRANSITIONAL } \\
\text { 6-10 Years of Teaching } \\
\text { Experience }\end{array}$ & $\begin{array}{c}\text { MID-CAREER } \\
\mathbf{1 1 - 2 0} \text { Years of Teaching } \\
\text { Experience }\end{array}$ & $\begin{array}{c}\text { VETERAN } \\
\text { 21-30 Years of Teaching } \\
\text { Experience }\end{array}$ \\
\hline $\begin{array}{l}\text {-Meeting individual } \\
\text { teacher needs }\end{array}$ & -Usage of teacher experts & -Current \& relevant topics & $\begin{array}{l}\text {-Fresh/ New/ Exciting take } \\
\text { on topics \& strategies }\end{array}$ \\
$\begin{array}{l}\text {-Collaborative discussion } \\
\text { \& feedback }\end{array}$ & $\begin{array}{l}\text {-Collaborative discussion } \\
\text { \& feedback }\end{array}$ & -Immediate use of PD materials & $\begin{array}{l}\text {-Immediate use of PD } \\
\text { materials }\end{array}$ \\
-Immediate use of PD & $\begin{array}{l}\text {-Choice \& self-selection of } \\
\text { materials }\end{array}$ & $\begin{array}{l}\text {-Choice \& self-selection of } \\
\text { learning topics }\end{array}$ & $\begin{array}{l}\text {-Usage of teacher experts } \\
\text {-Usage of teacher experts }\end{array}$ \\
\hline
\end{tabular}

Note. This table represents the main themes and sub-themes which emerged from participant responses for this study's sub-question (a) which includes interview questions 1-5. Items in bold link to the main themes found within this study. 


\section{Theme: Collaboration and Discussion}

It stands to reason a veteran teacher of 21-30 years of teaching experience requires different knowledge or strategies than a teacher in her first five years of the profession. Novice teachers at Heartland echoed this sentiment. All three of the novice teacher participants in this study noted they had specific learning needs as new teachers including talking with their peers and being able to immediately use the knowledge gained. Sue, a fifth year teacher said, "I think we should learn off each other. What's the point if you have a really good idea and it works in your room; why not share that wealth? Why not share that knowledge?" Another fifth year teacher, Marissa, also saw collaboration as an important element of effective PD, "I think usually departmental PD, where you're working with people who are in your own subject and talking about things that have worked and things that don't work, that's usually the most helpful for me."

Additionally, mid-career and veteran teachers also expressed the ability to take new knowledge and directly apply it to their classroom practices as a vital element of effective PD along with more time to collaborate and the use of more teacher experts. Mid-career and veteran teachers also noted the need for relevant as well as new and fresh perspectives on strategies.

PD is effective when I can take what I learn and transfer it immediately into my classroom. When I can take what I learn at a PD and see how that's going to work in my classroom with my students and how I incorporate that into my lessons and into the plan I have for my students. (Tammy Lynn, personal communication, May 15, 2018)

Hallie has provided ELA PD inside and outside the Heartland District many times in her 16 years of experience, and she is often a teacher others visit to see her classroom 
practices in action thus securing herself as a teacher expert in the district. Her view on delivering PD echoes the need to plan with effective elements in mind.

When I deliver [PD], I want it to be useful. I need to be useful for the teachers, that they can take right back in and use. Sometimes, I don't know if that's good PD or not, but I try to model it for how I would conduct with my students. (Hallie, personal communication, May 17, 2018)

Phoebe, a teacher of 10 years noted the knowledge gained during PD must "actually [be] something that we can quickly implement in the classroom and that it's something that there's going to be takeaways right away."

\section{Theme: Utilizing Teacher Experts}

By utilizing the skills and knowledge of teacher experts like Hallie, Heartland has been able to influence classroom practices. The PD provided by a product the district purchased, www.NoRedInk.com, was mentioned by 19 of the 21 teacher participants. The presenters from www.NoRedInk.com are former ELA teachers; this provides credibility to their insights and has inspired change within Heartland ELA classrooms. Sherri, a mid-career teacher of 17 years stated: "I always find that teachers give the best professional development because they know how important it is, they know how to present it, they know what's worthwhile." Sherri went on to explain what made PD so successful when www.NoRedInk.com presenters came, "I'm not very tech savvy so anything that has to do with tech and if they can explain it to me in a way that I can really understand and give me the opportunity to do some hands on practice, that is helpful." Blake has also taught for 17 years. He discussed not only the importance of using other teachers' expertise but the benefits of peer collaboration and reflection:

You know, we can sit at my building during the collaboration and say man, iReady is hard to use. We don't understand it. We need some help. So, we find one of the districts who's having success with it, sit down and talk to them, find out 
what they did and then maybe problem solve some more because we have different classrooms or something like that and then that helps us. (Blake, personal communication, May 16, 2018)

Such comments support how transformative learning cannot happen in isolation (Meriam et al., 2007), but should be approached from a community of practice approach or a collegial culture (Bruffee, 1999; Drago-Severson, 2008). Communicative learning also allows teachers to socialize (Drago-Severson, 2008) and look to veteran teachers as mentors with a wellspring of ideas. Such conversations and modeling help blend teachers' experience and knowledge which "often generates a discourse and an energy that encourages reflection and can bring about transformation" (Bouchard, 2015, p. 3).

\section{Implementation of Change from Gained Pedagogical Knowledge}

Rolfe (2001) feels teachers must be willing to experiment with strategies and techniques to stimulate direct change to fully activate reflective practices within Adult Learning Theory (ALT). Additionally, teachers' motivation to gain new teaching strategies and implement what has been learned (Merriam \& Bierema, 2014) is also a driving force in ALT. Such motivation can be seen in teachers' responses to interview and focus group questions six through nine which appear in Appendix B. Secondary ELA teachers in the Heartland District supported the research in their top responses to this study's sub-question (b): How do secondary ELA teachers implement change into their classroom practices due to newly gained pedagogical content knowledge? The top five themes which emerged from interviews, a focus group, and surveys were:

1. Application of technology

2. Modification of strategies and ability to differentiate

3. Experimentation and risk taking with instructive practices

4. Use of teacher experts

5. Collaborate with peer teachers to discuss PD topics and gain feedback 
The theme of utilizing teacher experts continues to be supported in the overall data. In addition, a new sub-theme of experimentation and changes to teaching strategies emerged along with the application of technology when data were grouped into categories depicting specific years of teaching experience. These findings are provided in Table 6 .

Table 6

Theme Emergence by Years of Teaching Experience for Sub-question (b)

Teacher Implemented Elements of Classroom Practice for Transformation:

\begin{tabular}{|c|c|c|c|}
\hline $\begin{array}{c}\text { NOVICE } \\
\text { 1-5 Years of Teaching } \\
\text { Experience }\end{array}$ & $\begin{array}{c}\text { TRANSITIONAL } \\
\text { 6-10 Years of Teaching } \\
\text { Experience }\end{array}$ & $\begin{array}{c}\text { MID-CAREER } \\
\text { 11-20 Years of Teaching } \\
\text { Experience }\end{array}$ & $\begin{array}{c}\text { VETERAN } \\
\text { 21-30 Years of Teaching } \\
\text { Experience }\end{array}$ \\
\hline -Application of technology & -Application of technology & -Application of technology & -Utilize teacher experts \\
\hline $\begin{array}{l}\text {-Fresh/New/ Exciting take } \\
\text { on topics \& strategies }\end{array}$ & - Experimentation & $\begin{array}{l}\text {-Experimentation \& change of } \\
\underline{\text { strategies/ take risks }}\end{array}$ & $\begin{array}{l}\text {-Experimentation \& } \\
\underline{\text { change of strategies / take }} \\
\underline{\text { risks }}\end{array}$ \\
\hline - Experimentation & & $\begin{array}{l}\text {-Changes in teachers' perception } \\
\text { of student abilities }\end{array}$ & \\
\hline
\end{tabular}

Note. This table represents the main themes and sub-themes which emerged from participant responses for this study's sub-question (b) which includes interview questions 6-9. Items in bold link to the main themes found within this study.

\section{Theme: Utilizing Teacher Experts}

The need for teacher experts remained particularly important for teacher participants with 11-30 years of teaching experience. Perhaps such willingness to seek expert opinions on teaching strategies and techniques gives teachers the ability to be selfdirected learners (Gibb, 1960) in order to find the relevancy of new knowledge in order to change established practices (Ajayi, 2016). The use of teacher experts may provide adult learners with a peer-like collaborative experience and ease the concerns which may 
emerge when new ideas or concepts are introduced. Tammy Lynn, Hallie, and four more teachers supported this theory when they explained how transformation is most likely to occur when a current teacher is leading the PD. By acknowledging the expertise available within a department or district, teachers are able to become teacher leaders. By giving teachers recognition for sharing their experiences and knowledge, transformative practices can emerge from within.

I have to have PD, or I would lose my passion as an educator. Professional development is what makes the environment positive. Without PD, I couldn't do it. I wouldn't know what to do. That's why I'm on the quest to talk to leaders. I'm on the quest to read books. I'm on a quest to go visit other schools and do peer observations (Hallie, personal communication, May 17, 2018)

Teachers can be skeptical of learning or implementing new techniques. They want to know the time they are spending in learning a new strategy will positively impact their students when implemented into their classroom practices. Providing teachers with student work samples and real classroom situations can provide the credibility needed to change practices district wide.

I want to know that it's gonna be worth my effort to learn how to do something new, and I want to see that it's gonna give me results before I really say I'm gonna just throw myself into this and change what I'm doing in the classroom. I want to see that it's actually gonna give me something before I really invest in it. (Marissa, personal communication, May 19, 2018)

But there have been multiple times where I've had great P.D. that really has transformed my classroom practice. Specifically, we've had some great P.D. in the English department over the last few years here in the district. Primarily I think because the teachers who were organizing it are very conscious of not wasting anyone's time and making sure that teachers leave with something they can use. (Penelope, personal communication, May 21, 2018)

When you put teachers in charge [of PD], then it's much more likely that I'm going to come out of there ... I'm at least going to approach it with a more open mind because I know this is a person who struggles every day in the classroom just like me. And this is what works for this person. So, I at least have an open mind. (Tammy Lynn, May 16, 2018) 
In order to get teachers to grow, their interest has to be piqued. They have to possess a desire to gain new knowledge even if what is presented to them does not directly apply to their course content. Bartlett (1990) states that posing "what and why questions gives us [teachers] a certain power over our teaching" (p. 267). Showing teachers how to implement changes of practice into their classrooms is more important than providing them new strategies, and the more complex the skill, the more time teachers will need to practice it (Gulamhussein, 2013). Teachers need ongoing support to implement change. By providing modeling or peer classroom visits by other teachers within the district, change can be implemented quicker and more effectively (Gulamhussein, 2013).

\section{Sub-theme: Application of Technology}

Teachers mentioned the application of technology as a change agent of classroom practices 16 times. While most of the discussion on technology focused on the district purchased programs such as NoRedInk or i-Ready, teacher participants in all experience categories mentioned technology as a way to increase student participation and engagement. Raquelle has taught for 10 years and feels technology helps show students they are accountable for their learning: "I think in terms of [technology], there are things that could be more effective, but NoRedInk, even Turnitin, helps kids know that they are going to be held accountable." Knowing they are essentially in charge of their learning gives students a greater sense of ownership in how they learn and can change the entire culture of a classroom. Renee a teacher of 18 years had this to say about the technology of NoRedInk when providing grammar instruction:

[Technology] was that extra level of accountability that you actually had to look at that lesson so now you're not going to sit there and struggle and click 176 times instead of asking me for help. So I saw, with a lot of kids, it empowered them a 
little bit more to lay off the click and use that resource that's readily available to them. (Renee, focus group, May 21, 2018)

Through the adaptive differentiation provided through technology, many participants responded similarly to Phoebe and Renee. The change in student accountability has allowed students to ease into emancipatory learning (Drago-Severson, 2008).

Two teachers who work primarily with senior students attended PD led by a Heartland teacher expert, Blake, discussing Adobe Spark. After collaborating, Sherri, who has taught for 17 years, and Ruth, who has taught for 30 years, realized by incorporating technology into their senior exhibitions projects they could reduce problems with student presentations, time constraints, and lack of creativity during presentations.

Several of the students, they didn't want to present in front of the class but they were able to do that and take themselves and then present it, the students could give feedback and then they could still be part of the experience that they could get the feedback from their presentation even though, they really, they would have been ones to not do it. Had it been in front of the classroom. They would have chosen to take the zero. (Ruth, focus group, May 21, 2018)

Sherri stated: "It was a nice way for all of the students to share their work and comment on one another and watch each other in a way that was engaging for them." Marissa, a teacher with three years of experience, used the same technology PD to change a practice in her classroom.

Marissa primarily works with freshman students and wanted to increase their communication and presentation skills. Knowing her students' abilities, she felt a traditional formal presentation in front of the class was not the practice students needed and would not meet the listening and speaking standards she wanted to address. She also attended Blake's PD. 
I've used the Flipgrid where I gave students a question that they had to address in their assignment and then they had to get on and talk about it for a certain amount of time. And it worked pretty well, except the students seemed a little bit shy. Which is kind of funny, as much as they use social media; that just doing an assignment for a class. But I thought that was really useful and I want to try to use more, especially of the Adobe Spark and, you know, have them create more innovative presentations. Because it's more interesting for me and them. I actually have some students who have difficulty expressing themselves in writing, and they found it ... like particularly, I had an ELL student and she felt more comfortable speaking than writing. And so she really liked [Flipgrid] because she was able to do the assignment and she felt like she did better than if she had to just write it down. [Students are] not terrific with public speaking and they need to practice it, and so that's one way that they can do it. ... a way they can kind of become more comfortable with it. (Marissa, personal communication, May 19, 2018)

By purposefully trying new techniques students find engaging through technology, students can find success beyond traditional assignments preparing them for more $21^{\text {st }}$ Century work skills.

\section{Sub-theme: Experimentation}

Taking a risk in classroom practice may be scary for some teachers. They may face poor administrative feedback, lower standardized test scores, or pushback from students who also fear taking learning risks. Therefore, willingness to face the possible failure which may follow taking a risk, requires teachers to be highly motivated to make changes within their practice. By experimenting with what they have learned, teachers can not only transform their thinking but can change the way they think about teaching (Cranton \& King, 2003). Taking the risk to experiment with strategies and techniques in the classroom allows for teacher learning to grow and transform into emancipatory learning through self-authority (Drago-Severson, 2003). When the teacher is given or takes the authority to make significant changes in classroom practice, true transformation is triggered. Phoebe, a teacher of 10 years stated: "I feel like every year I do things 
differently. I feel like every year I revamp what I'm doing. I've not ever had one year where I've done the exact same thing all year, ever, or even the same units." William, a teacher with 20 years of experience noted how experimentation in the classroom keeps him on his toes:

[Experimentation] makes sure that I'm not stagnant water. Make sure I'm always changing and adapting to the best ways of teaching the kids who are currently in my classroom. Just because it worked in the past doesn't mean that it's the best practice for today. (William, personal communication, May 22, 2018)

Robert, another teacher of 10 years expressed: "When I know I'm in a place where I'm allowed to experiment, I feel safe to grow. Growth, for me, requires that feeling of safety." Three more Heartland participants also stated experimentation as a key way to transform their classroom practices. Effort to experiment or take risks must be put forth in order to improve practice, improve depth of knowledge, and improve professionalism.

\section{When Classroom Practice Influences Student Learning}

Schools are in place so students can learn. And students learn within classrooms led by teachers. Furthermore, in order to move students' forward in their learning, teachers must be a catalyst for change in the classroom. In order for teachers to learn how to be a catalyst of learning change, they need training. Therefore, PD offered to teachers provides the greatest chance of changing classroom practice and ultimately what and how students learn (Johnson, 2014). The link between teacher learning and student learning can be seen in teacher participants' responses to interview and focus group questions 10 and 11 which appear in Appendix B. Secondary ELA teachers in the Heartland District supported the research in their top responses to this study's subquestion (c): How do secondary ELA teachers know when classroom practice changes 
have influenced student learning? The top six themes which emerged from interviews, a focus group, and surveys were:

1. Increased improvement of data on assessment results

2. Increased student engagement

3. Increased collaboration \& discussion

4. Student centered approaches

5. Increased confidence and creativity in thinking

6. See teachers as modeling experts

A new sub-theme centered on student increases emerged when data were grouped into categories depicting specific years of teaching experience. Increases fell into distinct categories of confidence, engagement, understanding, and assessment results as well as carry over of skills from one course to another. The main themes of collaboration, reflection, and teachers as experts do not appear within participant responses about student learning. This stands to reason as these themes are more aligned with the ways teachers learn rather than specific classroom practices created for students. This is not to say collaboration and reflection are not essential elements of the increases teachers have seen in student learning. In fact, participants indicated through new learning acquired during PD, their students are more reflective of their own learning, engage in deeper conversations with peers, and see their teachers as modeling experts. These findings are provided in Table 7. 
Table 7

Theme Emergence by Years of Teaching Experience for Sub-question (c)

Evidence of Student Learning Growth from Practice Transformation Manifested as: NOVICE

1-5 Years of Teaching

Experience
TRANSITIONAL 6-10 Years of Teaching

Experience
MID-CAREER

11-20 Years of Teaching

Experience
VETERAN

21-30 Years of Teaching

Experience

-Increased understanding
in chunks
-Build on base skills
-Student ability to
explain thinking

\section{-More reflection on work \& learning}

-Increased engagement

-Carry over of skills to other course work

\section{-Increased confidence \& creativity in thinking}

-Increased engagement

-Increased results in assessments \& data

-Students track personal growth

-Students work on more challenging assignments
-Increased confidence \& creativity in thinking

-Increased results in assessments \& data

-Carry over of skills to other course work

-More links to current events

Note. This table represents the main themes and sub-themes which emerged from participant responses for this study's sub-question (c) which includes interview questions 10-11. Items in bold link to the main themes found within this study.

\section{Sub-theme: Increases in Learning}

Under Missouri Revised Statute $\S 161.092$ goal three, updated in January of 2016, the state will "prepare, develop, and support effective educators" (p. 2) in addition to retaining highly qualified teachers. The process seems simple: institutions of higher learning will prepare new teachers to be highly effective in the classroom, and in turn, teachers will strengthen and grow their craft over many years preparing students for academic success. Therefore, schools must "invest in either finding the best teachers or providing exceptional professional development to help [students]" (Johnson, 2014, p.1) learn at their highest potentials. The teachers in Heartland overwhelmingly feel ELA PD is providing them with tools to help students learn. In district archived surveys, the cumulative results of three surveys from each of the three specific ELA PD days during the $2017-18$ school year indicated $34.16 \%$ of teachers surveyed strongly agreed and 
$51.55 \%$ agreed the offered PD increased their effectiveness with students. District surveys also indicated $29.39 \%$ of participating teachers strongly agreed and $51.64 \%$ agreed the ELA PD they received over the course of the 2017-18 school year would help them to improve future student outcomes. Samantha, a teacher with 18 years' experience, stated ELA PD "gave me some focus on how to really raise the rigor." Another teacher noted ELA PD "gave me a chance to differentiate and individualize instruction" (Lucy, focus group, May 21, 2018). Participants in this study provided positive data when describing how ELA PD impacted students' learning. Participants were most eager to discuss the increases in confidence, engagement, and transferred understanding shown in student work because of the new pedagogical content knowledge gained during PD. Figures 6 and Figure 7 present these findings.

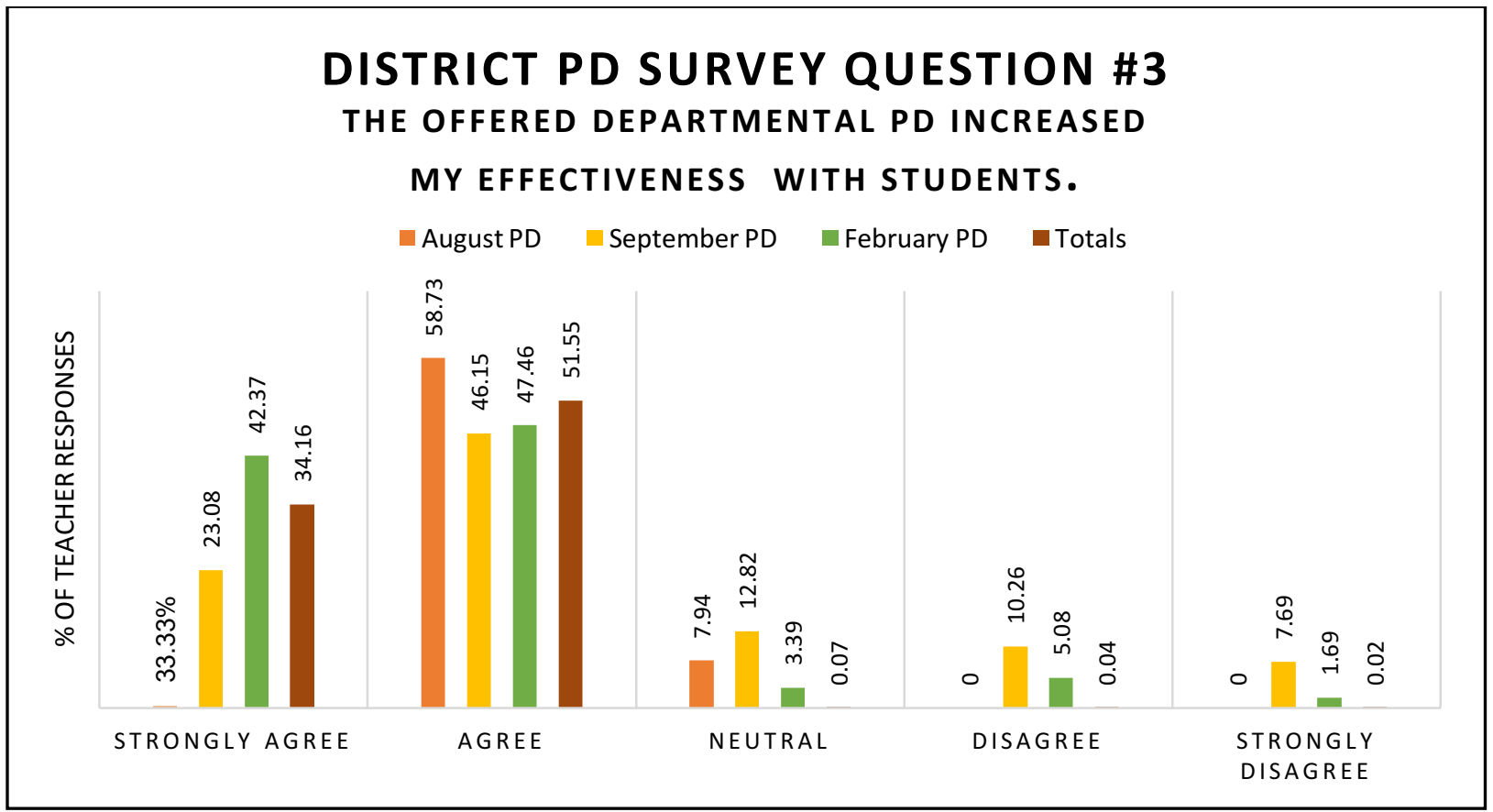

Figure 6. District PD Survey Question \#3. This figure represents the Likert scale type responses of ELA teacher participants over three post-PD surveys in August 2017, September 2017, and February 2018. A total of 161 responses are recorded. 


\section{DISTRICT PD SURVEY QUESTION \#9 THE OFFERED DEPARTMENTAL PD WAS USEFUL IN ORDER TO IMPROVE FUTURE STUDENT OUTCOMES.}

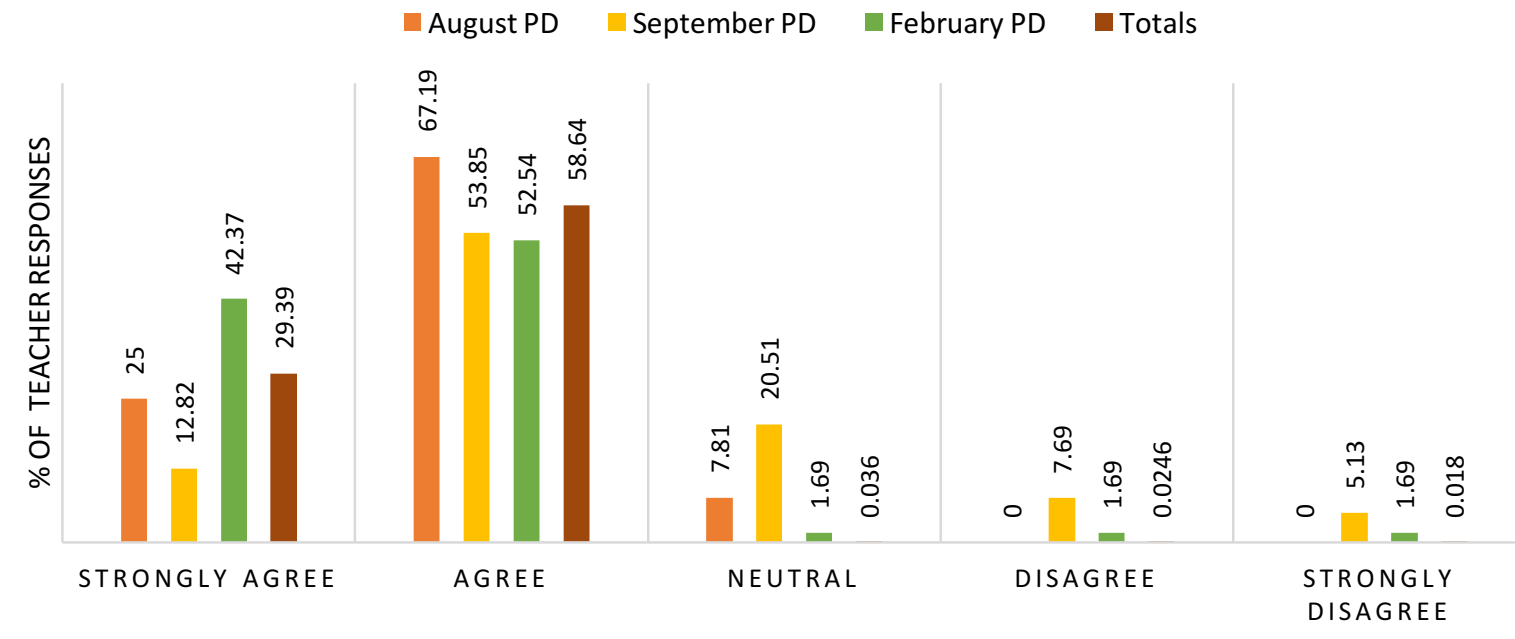

Figure 7. District PD Survey Question \#9. This figure represents the Likert scale type responses of ELA teacher participants over three post-PD surveys in August 2017, September 2017, and February 2018. A total of 162 responses are recorded.

\section{Increases in Student Confidence.}

Sue, a teacher with five years' experience had students track their own learning on a simple chart she created after attending a PD session on visual learning.

It was like they were proud because I don't think they've ever been shown growth like that. 'Cause they could see actual, "Wow. I actually am learning something." And that was the group that I just graduated out, and they were better writers from doing that, I feel like. In the time I started with them until now. (Sue, personal communication, May 17, 2018)

Melanie, a 30 year veteran teacher expressed how ELA PD gave her the skills of increasing student accountability for their own learning when students moved toward increased learning self-confidence through tracking their own growth.

Going back again to having students graph their own progress in ways that maybe they hadn't done it before. And to break that down into smaller things, not just graph a district test, not just graph testing, but to graph how ... For example, if your focus is on introductions to essays ... They have to keep copies of that and then determine if you're looking at elements of the introduction, and they have to 
graph how many of these elements have I hit, and by the end of the year, can I get all five elements, let's say. Incorporate it smoothly into a great introduction. Or am I still missing pieces or floundering with this ... So that they could really look at what they're doing? Or conclusions or that type of thing. I think that becomes the key that I've taken away from professional development in the last couple of years, has been more responsibility and accountability on the student for progress and for determination of have I done what's expected, have I improved. (Melanie, personal communication, May 14, 2018)

Hallie found similar increases in student learning self-confidence when she worked one-

on-one with students to view their learning progress on district benchmark tests in reading and working with decoding skills and comprehension strategies.

We had conversations about it, and I would pull us their SRI test, and I would print out the test they took, and we would analyze each question. So then we would say ... They would kind of see their mistakes, and, "Did you see that you were inferring here?" It was, again, focused on those comp strategies that you had to infer this, or this was really what was important, so we had to determine what's important here. So when they started to tackle those small things, when they saw those small things happen, then they were like, "I can do this!" And it was just a natural ... I'd call it a flow of learning. They were just in that flow of, "We're here to think and to communicate." They started to believe in themselves. (Hallie, personal communication, May 17, 2018)

Increases in student learning confidence was also shown when students became willing to use their work as examples for the whole class to discuss. This allowed them to gain specific and detailed feedback from all learners. Phoebe began using current student work samples as a way to more effectively provide students with models.

I rely much more on like, "Okay who's willing to show me their example? Let's break down that one person's example." I rely much more on their peers. So instead of me maybe giving them feedback all the time, I have them work with their peers a lot or switch stuff with their peers and have their peers give them feedback a lot more with bigger class sizes. (Phoebe, personal communication, May 11, 2018)

The above data show Heartland teachers understand the importance of student selfconfidence as a factor in overall educational success and preparing students to be lifelong learners. 


\section{Increases in Student Engagement.}

With increased student learning confidence, all 21 teacher participants in this study found an increase in students' classroom engagement, willingness to put forth more effort and deepen critical thinking through creativity on assignments, as well as increased depth of scholarly practice when participating in conversations with other students. Like Sue, Melanie, and Hallie, William found when students felt they were growing, their increased self-confidence pushed them to do more and try harder to reach new levels of learning through greater learning engagement.

I found, success breeds more success and so when they were able to ... if I was able to say, "Your A in this class is these five objectives ... mastering these five objectives," then they were not beat down all the time because they weren't getting the best grades on everything. They were able to just focus on those things. Really made a big difference in the class, especially for the kids with special needs, but even for the students that tend to get lost a little bit, which is our average students. (William, personal communication, May 22, 2018)

With 17 years of teaching experience, 10 of which were working with English as a Second Language (ESL) students, Sherri expressed similar findings as William. When students experienced feelings of success, their willingness to push themselves further also increased, and they engaged more in class activities such as large group conversations.

It [large group discussion] was very inclusive. It was not just for Spanish speakers; it was all the other countries that are reflected in our classroom as well. So there was greater engagement, more excitement. The kids felt like they wanted to share so they wanted to talk more, which was really important for them. Engagement [increased] and you could see the excitement and a lot of the ... even the shy kids that didn't like to talk very much opened up and really participated in the class. There was a lot of back and forth, a lot of conversation; group conversation, whole group conversation, and then a lot of sharing with me as well. (Sherri, individual communication, May 21, 2018)

Greater engagement in the classroom produced a side effect teacher participants noticed instantly. When students were fully engaged in their learning, they were able to take 
ownership of their work and were willing to take some risks in exhibiting proficiency.

Lori, a teacher with 21 years' of experience noted greater student interaction with technology in her seventh grade classroom after attending Blake's PD on Adobe Spark.

Their fear of failure while using technology began to decline, and their confidence level rose. Students began feeling comfortable experimenting with components of new programs and taking risks. Even reluctant learners were engaging in new technologies. Further, students began assisting one another. They didn't rely solely on the teacher as a resource. Their attitudes improved and their end products, for the most part, were a source of pride for them. (Lori, personal communication, May 12, 2018)

When Robert implemented new pedagogical content knowledge gained from content specific PD about the Four Cs, he could see a change in student creativity. He knew learning was impacted because he made changes in his classroom practice which pushed students to increase the quality of their work to produce an end product showing evidence of greater critical thinking and creativity.

Without question student creativity soared. Students were pushed in new ways. It created students with more well-rounded work and helped push emphasis away from grades and toward genuine learning. The quality of their work changed. With some exception, most students were now actively deciding to create something unique for projects rather than do what they thought I "wanted". (Robert, personal communication, May 15, 2018)

Increased engagement in the classroom is paramount not only to high school graduation but to retaining the skills necessary to remain a life-long learner (Hobson, 2015). Student engagement has also been linked to increased student achievement (Lee \& Shute, 2009.) Additionally, a survey of students conducted by Willms, Fiesen, and Milton (2009) found "students want their teachers to establish learning environments that build interdependent relationships and that promote and create a strong culture of learning" (p. 36). The above data show teachers in Heartland are taking their new knowledge from ELA PD and using it to fully engage students across the district. 


\section{Sub-theme: Transfer of Understanding}

Through increased self-confidence and increased engagement in lessons and activities, the collected data show an increase in student understanding of objectives, skills used to complete assignments, the ability to explain their growth, as well as which learning strategies they utilized. Such depth of critical thinking and application to other content areas and assignments identifies clear student growth within Heartland's ELA classrooms due to teachers' acquisition of effective PD. 12 out of 21 teacher participants in this study expressed they witnessed students applying strategies and skills learned in the ELA classroom to other subject areas and assignments.

Bonnie, a teacher with 11 years of experience in education, noted she knew her students were truly growing as learners because they were able to articulate their growth process, discuss the steps of their growth, and present her with past and present work samples to prove increased performance in writing skills.

But to hear them talk through it minimally shows me that they know that they're growing because they can see a difference and they have to put language to that; that's not simple, "I did it," right? "It got better because...," there has to be something after that. When you just let them say, "I just did it," it never gets to that point. But when they have to show you something, they can at least point to it and say, "This thing right here is better because ... " Whatever they come up with might not really be the most sophisticated response for what they actually did, but the point is that they can talk you through it in a more sophisticated way than what they originally [did], which is just praying that it was better. (Bonnie, personal communication, May 23, 2018)

When asked if she saw students' carry-over the revision strategy of lining a text she learned from ELA PD, Raquelle noted her tenth grade students were in fact transferring their knowledge.

Oh yeah, definitely. Especially in World History, I felt like that was something that they did. Maybe not necessarily with the lining, but more of like the analysis process that we went through like TIQA paragraphs. Making sure that you quoted 
from something, you pulled your textual evidence but then answering those questions about why it mattered and what difference it made. Rather than just paraphrasing the whole time, actually getting to that level of analysis, I think was something that definitely transferred into their other classes. (Raquelle, personal communication, May 18, 2018)

Melanie began to see her seventh grade students use writing techniques and show attention to literary analysis devices in other courses because of the PD she received from www.NoRedInk.

What I see more at [my] level is they carry over techniques from the ELA classes to the writing and history more so than coming back to us. I think that they do. They say, "Oh, I used that on my history paper. Or on a lab report in science, that type of thing. "Oh, I knew I had to really look at my word choice," a student said that once about a lab report that they realized in order for them to demonstrate that they had done this correctly and come up with the right result, that they really had to make sure the word choice reflected that. (Melanie, personal communication, May 14, 2018)

Phoebe also noted her tenth grade students were transferring their knowledge to other subject areas: "I had some students talking about how they maybe took something and applied it in a different class. So I would say yes, I saw [them thinking] how can I use this thinking in other ways?" (personal communication, May 11, 2018).

The application of such rigorous metacognitive skills proves Heartland teachers have adapted important strategies from ELA PD into their classroom practices, and students are applying the critical thinking skills necessary to apply acquired knowledge to various course contents and assignments. Offered ELA PD has helped teachers and students alike develop the ability to transform tacit knowledge into explicit knowledge in what Nonaka (1991) claims is "the critical steps in the spiral of knowledge" (p. 99). By transferring knowledge from one course context to another, students have proved their knowledge has become explicit through reflective discussion with teachers and their peers (Gill, 2010). Such examples show true transformative learning has taken place. 


\section{How ELA Teachers Know They Are Transforming Professionally}

The profession of teaching requires constant growth because it is a field marked with unsolved problems and changing needs including the challenge of covering a growing expanse of content while teaching specific skills at an in-depth level. Stated in the National Boards Professional Teaching Standards (NBPTS), proposition four focuses on how teachers use reflection, collaboration, and research to make difficult decisions about teaching strategies. NBPTS summarizes proposition four with the following statement:

Striving to strengthen their teaching, accomplished teachers critically examine their practice, seek to expand their repertoire, deepen their knowledge, sharpen their judgment and adapt their teaching to new findings, ideas and theories. ("What Teachers Should Know," 2002, p. 4)

Furthermore, NBPTS emphasizes how masterful teachers stay abreast of current research through conferences, workshops and articles. Learning should be their passion, and they should foster inquiry and teach their students to deeply question the world around them. Individual teacher growth can be seen in teacher participants' responses to interview and focus group questions 12 and 13 which appear in Appendix C. Secondary ELA teachers in the Heartland District continue to support the research in their top responses to this study's sub-question (d): How do secondary ELA teachers know they are growing and/or transforming professionally? The top six themes emerged from interviews, a focus group, and surveys were:

1. Deeper reflection practices

2. Experimentation and change of practices

3. Fresh, new, exciting ideas

4. Collaborative discussions

5. Increased confidence and creativity

6. Utilizing content teacher experts 
A new theme of reflection emerged from teacher participant responses about how teachers know they are growing. As this theme has been present in responses to other sub-questions, the researcher felt reflection is the third main theme to emerge from this study. Within the theme of reflection, a sub-theme of reflective feedback emerged when data were grouped into categories depicting specific years of teaching experience. The main theme of utilizing teacher experts continued to be the main theme present in teacher participant responses to this final sub-question. These findings are provided in Table 8 .

Table 8

Theme Emergence by Years of Teaching Experience for Sub-question (d)

Teacher Growth and Personal Transformation Manifested as:

\begin{tabular}{lccc}
\hline \multicolumn{1}{c}{$\begin{array}{c}\text { NOVICE } \\
\text { 1-5 Years of Teaching } \\
\text { Experience }\end{array}$} & $\begin{array}{c}\text { TRANSITIONAL } \\
\text { 6-10 Years of Teaching } \\
\text { Experience }\end{array}$ & $\begin{array}{c}\text { MID-CAREER } \\
\mathbf{1 1 - 2 0} \text { Years of Teaching } \\
\text { Experience }\end{array}$ & $\begin{array}{c}\text { VETERAN } \\
\text { 21-30 Years of Teaching } \\
\text { Experience }\end{array}$ \\
\hline $\begin{array}{l}\text {-Fresh/ New/ Exciting take } \\
\text { on topics \& strategies }\end{array}$ & $\begin{array}{c}\text {-Reflection techniques } \\
\text { - Questioning }\end{array}$ & $\begin{array}{l}\text {-Fresh/ New/ Exciting take on } \\
\text { topics \& strategies }\end{array}$ & -Reflection techniques \\
$\begin{array}{l}\text {-Increased confidence \& } \\
\text { creativity in thinking/ } \\
\text { practice }\end{array}$ & -Collaborative discussion & -Teacher experts as models & $\begin{array}{l}\text {-Improved evaluations \& } \\
\text { feedback from students \& } \\
\text { administration }\end{array}$ \\
-Skills have increased & -Reflective feedback & -Reflection techniques & -Fresh/ New/ Exciting take \\
-Skills have increased & -Reflective feedback & on topics \& strategies \\
$\begin{array}{l}\text {-Teacher experts as } \\
\text { models }\end{array}$ & & -Experimentation \& change of & -Collaborative discussion \\
& & strategies/ take risks & -Reflective feedback
\end{tabular}

Note. This table represents the main themes and sub-themes which emerged from participant responses for this study's sub-question (d) which includes interview questions 12-13. Items in bold link to the main themes found within this study.

\section{Theme: Reflection}

Innovation is a byproduct of the reflective process (Messmann \& Mulder, 2015) which can push educators to discover solutions to complex problems. Breaking through 
the routine of everyday teaching approaches and reactions can guide teachers to discover new methods and resources which may improve their professional performance.

Additionally, reflection is a conscious byproduct of group collaboration (Brufee, 1999;

Gill, 2010; Hadar \& Brody, 2010; Merriam \& Bierema, 2014). Combined with

discussion, reflection is enhanced so that "individual motivation and clarity of thought...

generates thinking which in turn supports a reflective stance towards teaching" (Hadar \&

Brody, 2010, p. 1647).

I can absolutely see a difference if I go for any extended period of time with no reflection. I can tell a difference. I can tell that nothing is improving in the room. There's no energy in the classroom because I'm not changing anything. I'm not thinking about anything, I'm not changing anything. (Melanie, personal communication, May 14, 2018)

I know that I'm growing professionally when I can see a difference in my thinking, and I'll give you an example. Last week, I was thinking to myself ... because of professional development, I was saying to myself, "What things do I need to start working on for next year? What do I want to be better at?" And that's one of the professional developments that we had was being able to reflect on your own teaching. I want to start implementing more not letting the students just turn in average things. I want to be able to say, "No, we're not moving on. I want you to do this again." (William, personal communication, May 22, 2018)

Zhao's (2012) study stated, “Only through reflection can she see clearly whether or not her methods are valid and lay a proper foundation for her own practice..." (p. 64).

In general, teachers aren't given much time to think about how or what to implement from reflective practices. It is usually done too quickly, class hour by class hour, or it is considered done when one question on a post-PD survey asks what teachers learned during the session.

To get people to do [reflective practices], I think we need to encourage it within planning time. I think that it needs to be one of our goals, building goals. I think young teachers need to see older teachers doing it and they need to be told, "This is why it's important." The older teachers, if they're not currently doing it, it's 
harder to get them to change their ways. (William, personal communication, May $22,2018)$

Teacher participants feel time should be built into PD for the process of reflection. Camburn and Han's (2015) recent study echoes this restraint "professional development rarely provides teachers with opportunities to try out and reflect on their teaching in the context of their day-to-day work" (p. 512). Celeste, a novice teacher with five years of experience stated: "You cannot grow if you do not self-reflect." If time is built in for collaboration, teacher participants want to know why not include time for reflection after collaboration or after district PD? Veteran teacher Melanie stated the importance of reflection in professional growth: "But I think that reflection has to be weekly, it has to be quarterly, it has to be by semester. And I think you're not progressing as a professional if you don't do that." Reflection takes time for teachers to "critically examine their actions, intention, motives, and attitudes towards learning and learners" (Chalikandy, 2014, p. 117). Reflection takes time for teachers to research new ideas and try new methods. Reflection is not a quick or easy process.

I think [reflection] has a huge role [in personal growth] because if you aren't reflecting on how it worked and what worked and what didn't work, then you're just doing the same thing again the next class period. And you're not helping your kids. So I think that has, it has a huge role to play and I think that we do it subconsciously, but I also think it's easy to fall into that rut of not doing it. (Penelope, personal communication, May 21, 2018)

Time specified for introspective and retrospective personal critique is required for continued personal growth. Messmann and Mulder (2015) stress organizational recognition for reflection as a "crucial component...that enhances employees' [capabilities]" (p. 136). 


\section{Sub-theme: Reflective Feedback}

Reflective feedback emerged as a sub-theme and as a way for teachers to know they have grown professionally. Many pressures are on teachers to internalize and positively change their professional practice to meet new pedagogical techniques as well as state and local mandates. Aside from crunching the data from the standardized tests students take at the end of the year, teachers must periodically self-assess to ensure they are progressing in their profession. Through collected reflective feedback, teachers can not only process what occurred in their classroom, they can also make decisions on how to differentiate or modify future instructional practice for maximum student success.

Several years ago [through] the IB program we get feedback...on one of their assessments that was discouraging to me. Because as a teacher who has been doing this awhile, I think I'm pretty good at what I do. And the feedback that I got told me that I was not as good as I thought I was. So after I hollered and clenched my fists and pouted about it for a couple of days, I actually read it and went oh, well how can I change it? And I made some huge changes in how I had the kids approach the analysis and organize their analysis. And not only did I learn from that but the kid's scores went up and they learned from that. (Penelope, personal communication, May 21, 2018)

At the end of the year I have my students give me, fill out a feedback, a reflection form. I really use that. I have them tell me like, What do they think I should be doing differently, or more? So, that's helped me, you know see myself growing professionally. Because I'll notice that things will pop up, they'll say things that I'm doing well, that I've worked on that year. Then also it gives me a focus for the following year. (Phoebe, personal communication, May 11, 2018)

I have a pretty good relationship with my administrator. She comes in, and she gives me lots of feedback. She doesn't know ELA. But she does know strategies. So if it's a strategy that I'm trying to hone in on, like the questioning I do, or my wait time, she can pinpoint that. (Hallie, personal communication, May 17, 2018)

Teachers tend to be life-long learners. It can be seen from the teacher participant responses above; teachers crave improvement. In order help students improve, teachers 
need to know how they can improve their professional practice. Effective advice leads to teacher development, and stronger teachers lead to improved student success.

Heartland School District's assessment of the effectiveness of delivered ELA PD has stalled at what Guskey (2016) describes as level one because participants' reactions are only garnered through a survey or questionnaire given at the end of a PD session for “measuring participants' initial satisfaction" (p. 33). Instead, effective PD aspires to move learners to Guskey's (2016) level four which delves into examining how new knowledge changes teachers' professional and individual classroom practices (DarlingHammond \& Richardon, 2009; Desimone, Porter, Garet, Yoon, \& Birman, 2002; Hill, 2009; Goldschmidt \& Phelps, 2010; Guskey, 2000, 2002; Kilinger, 2004; Strickland, 2009; Reeves, 2010). By changing how teachers learn and present ELA content knowledge, students will be better prepared for finding success in all content areas.

\section{Theme: Utilizing Teacher Experts}

The theme of using knowledgeable teachers to teach other teachers has remained a key theme throughout all sub-questions of this study. Educational research has found teacher leaders to be a vital piece of the school reform puzzle (Margolis, 2009; Katzemneyer \& Moller, 2001). An "outside expert" often tells teachers to change what and how they teach causing resentment and closemindedness (Margolis, 2009) to new knowledge, and they also feel "outside" presenters are disconnected from the practice of teaching or have been too far removed from the everyday classroom (Royce, 2010). Raquelle commented: "I think a lot of times we're like, 'Oh, let's pay some outside consultant,' or do whatever without acknowledging the expertise that we have in our own district, department" (personal communication, May 18, 2018). While many teacher 
participants noted exceptional PD from the www.NoRedInk product, teachers interviewed did not view those presenters as outside consultants. Instead, since these presenters have all been former ELA teachers, have presented within the district for the past five years, and are seen as experts in the NoRedInk product, HSD teachers have come to regard them as teacher experts and not as outside consultants.

The ELA teachers at Heartland support study findings conducted by Campbell (2014) which specifies instructional practices such as peer observation and teacher led workshops as the best way to help teachers learn. During the focus group, Samantha stated: "I know that I have grown so much as an educator because of the expertise down in my department." And Tammy Lynn expressed: "[The most effective PD] is when I'm taught by teachers. Any time I have a PD that is run by teachers for teachers and taught by teachers to teachers, that's always the best." She goes on to say:

[True] transformation, like I said, comes when I talk with teachers and I'm being taught by teachers and I'm getting ideas from other teachers and jumping from there to how I'm going to put that into my classroom. Very rarely have experts been able to teach me. I can't remember a time when an expert, curricular expert, curriculum expert, transformed by classroom. (Tammy Lynn, personal communication, May 16, 2018)

Additionally, Penelope stated: “[PD should] be presented by a master teacher and a master entertainer. Not only someone who is really knowledgeable but somebody who is also really passionate about what they were talking about and super excited to be there."

By modeling instructional processes in a differentiated manner during PD, teachers' needs can be better met (Royce, 2010). Blake, who led PD sessions twice during the 2017-18 school year to fellow Heartland ELA teachers, expressed what works for him as a teacher leader: "[P]eople come to me with questions and things like that. I get to be a leader on stuff like PD and technology and reading and choosing our resources 
and stuff like that." Likewise, Hallie has also presented PD during the school year and feels:

[W]e've been blessed that we've had good leaders that have developed our professional development, and they have listened to us. They brought in outside people, too, like the Holt Company. And we've collaborated within ourselves like through, across middle schools and across high school. (Hallie, personal communication, May 17, 2018)

Teachers learn best from other teachers! A fellow teacher expert peer can understand the nuances of district needs, can provide a teacher-audience with emotional and instructional support as a fellow learner, can support theory through real-world, student work examples, as well as build on previous and current district learning initiatives (Margolis, 2009). Providing teachers with more opportunities to take on leadership roles may not only be cost effective (Ingersoll, 2001) but "have been shown to improve student achievement in more lasting ways" (Margolis, 2008, p. 307). Dubliner (2001) notes expert teachers impact student learning through initiating elevated motivation to learn, deeper understanding of subject matter, and advanced levels of learning success (p. 479). Heartland teachers have instinctively embraced the learning growth available to teachers and ultimately students through PD led by fellow teacher experts.

\section{Discussion}

This study was designed to gather information on how Heartland School Districts' secondary English Language Arts teachers use pedagogical content knowledge gained through ELA PD to change their individual classroom practices. This study also examined how teachers implement changes of practice, how teachers know these changes are influencing student learning, and how teachers themselves, know they are growing. 
The purpose of this qualitative study (Creswell, 2016) was to extend the knowledge base of how ELA teachers learn and transform acquired knowledge.

\section{Summary of Findings}

The overall views of teacher participants were positive in regards to the quality, acquired knowledge, and ability to increase student learning practices. Findings showed positive ways PD changed classroom practices as well as high levels of using teacher experts, peer collaboration, and reflective techniques. In fact, using teacher experts was the largest emergent theme and was evident in the coding of all four research subquestions and more evident when collected data were grouped into categories depicting specific years of teaching experience. Additionally, the participants revealed experimentation, application of technology, individual student increases in learning, and reflective feedback as possible areas of focus for all future ELA PD presentations. Overall, participants felt the current structure of departmental PD at Heartland has provided growth opportunities for teachers and students alike. However, the breakdown of teacher responses grouped into categories depicting specific years of teaching experience may point to the need for future differentiation of departmental content to better meet all novice to veteran teachers' specific learning needs.

\section{Inclusion of New Key Terms}

Teacher Expert: While a lack of experience can clearly denote being a novice in a subject, having experience does not directly transition into a position as an expert (Berliner, 2001). Instead, experts are seen to have an equal distribution of talent and practice as well as other propositions such as these from Glaser (1996):

- Expertise is specific to a learning domain 
- Experts solve problems in different ways which are deeper and richer in experience

- Experts are more flexible

- Experts are not sidetracked by ambiguity

- Development of expertise is not linear

- Experts are faster problem solvers

- Expertise includes a deep passion for subject matter

Additionally, expert teachers are seen to be those who are able to provide varied explanations of instruction in multiple ways to meet specific learner needs in addition to having deep content knowledge in core-practices of teaching (Forzani, 2014). While teaching expertise has traditionally been linked to student test scores, this is not an accurate way to measure expertise; however, Dubliner (2001) has determine three hypothesized features of an expert teacher's impact on students:

- Higher motivation to learn and higher feelings of self-efficacy

- Deeper understanding of subject matter

- Higher levels of achievement (p. 470)

Teacher-Led Professional Development: Unlike traditional teacher professional development which tends to be prescribed and delivered using a top-down approach from district or building administration, teacher led PD assumes a "boots on the ground", bottom-up structure of learning (Macias, 2017). There is currently little research on bottom-up structures of delivering PD; however, there is an expressed need for the shift to teacher-led PD for increased collegial collaboration and more focus on "teachers' empowerment and learning... originat[ing] from schools' and teaches' own concerns" (Vangrieken, Meredith, Packer, \& Kyndt, 2017, p. 5.2.1). In addition to increasing the use of teacher experts, Macias's (2017) study on teacher-led PD found this style of PD: treats teachers as active learners, enhances content knowledge, focuses on learning outcomes, and provides sustainability for teachers and districts (p. 86-87). 


\section{Limitations and Delimitations}

\section{Limitations}

This study focused on the perception of secondary English teachers from one school district; therefore, the researcher must monitor generalizability of findings as representation of all secondary English teachers (Merriam \& Tisdell, 2016). Qualitative case studies are limited by what and how much information participants are willing to share, their perceived truth of an event or idea, and the researcher's interpretation of gathered data (Merriam \& Tisdell, 2016). Participants were assured their responses would only be used for investigative purposes and would not impact their job performance in any way. Some teacher participants may be intimidated by the researcher's recent promotion to English Language Arts secondary professional development and curriculum advisor within the district. While the researcher's new role is not evaluatory, some teachers may view the position as authoritative or administrative in nature and therefore may be less inclined to be candid or completely open in their responses. However, for the 2018-2019 school year, the ELA curriculum advisor position along with 11 other content area advisors have been condensed to two generalist advisor positions for the district. A further limitation may be based on teacher participants' perception of actual classroom practice change from learning gained at ELA PD. Beyond accepting participant stories collected during interviews to be true accounts of personal and classroom changes, the research is limited in ability to verify specific changes. 


\section{Delimitations}

Case studies have natural boundaries and parameters (Merriam \& Tisdell, 2016). The geography of the district's location may not be a true representation of the feelings of all secondary English Language Arts teachers across the state or nation. No data is included in this study about participants' lives or how their life experiences have impacted their teaching practices or perceptions of professional development provided by the district.

\section{Implications for Practice and Future Research}

Given the findings of this research study and the limited number of studies which discuss PD with English Language Arts teachers specifically, it seems important to use these findings for future PD planning for all secondary teachers within the Heartland district and other districts with the same demographics. PD leaders, administration, and teachers themselves can use these results to train for future PD presentations. These findings also provide a basis for continued research focused on teacher transformation in their classroom practices. The amount of classroom transformation could be impacted by the way PD is delivered. Therefore, it would be beneficial to study the impact of teacher learning when the same PD content is delivered through various structures. Through research focused on teacher perceptions and transformative practices, districts and leaders can guide changes to PD in innovative ways in order to further impact student improvement.

\section{Recommendations for Future Practice}

Based on the analysis of collected data from this study and in order to continue providing the best PD to meet ELA teachers' needs, the researcher has determined and 
recommends the following five suggestions for the Heartland School District in regards to planning future ELA PD. These suggestions are based on data gathered from 21 individual interviews, a focus group, and archival district PD surveys.

1. Heartland should reinstate the positions of the four core content secondary curriculum advisors: Mathematics, Science, Social Studies, and English Language Arts. In order to provide PD which meets specific content needs, the researcher's data reveals teachers of the HSD understand the importance of using content expert teachers to plan, deliver PD, and guide adult learners to transformational classroom changes which support the District and Departmental Improvement Plans. To further validate the need for core curriculum advisors, 19 out of 21 interviewed teacher participants indicated the direct importance of this position on PD, teacher growth and resources, district communication, departmental improvement, and student learning.

2. Heartland teachers need more job embedded time for peer collaboration. This need is validated through 52 separate interview responses from teacher participants expressing the need for more job embedded time for peer collaboration. Such collaboration could be in the form of content PD days with sessions in the morning and team collaboration time in the afternoon or the inclusion of an additional content specific PD day to the district calendar. Ideally, one collaborative day at the end of each quarter would provide time for teachers to reflect, view collected student data, and make plans for future instruction. Additionally, 21\% of respondents to the ELA February 2018 post-PD survey 
indicated the need for more collaborative time as an important district PD improvement which needs to be made.

3. $100 \%$ of interviewed teacher participants indicated the importance of content teacher experts when presenting PD. Heartland should strongly consider providing specified PD for teachers who are seen as content teacher experts. In order to ensure best practices for adult learners are met, teacher experts may need to learn how to deliver PD. Such training for co-teachers was held in the past and was followed up with a classroom visit from a presenter to provide individualized feedback to co-teachers. Such a program would benefit teacher leaders within their buildings, departments, and the district as a whole.

4. Heartland should provide more opportunities for teachers to obtain or attend individualized PD based on their levels of knowledge and/or expertise of specific subjects central to the ELA Departmental Improvement Plan and the District Improvement Plan. As the researcher's collected data reveals, Heartland teachers expressed they learn best and show the most growth when working with content on the level which best supports their background knowledge and pushes them to try new strategies and techniques as well as take risks. Furthermore, collected archival data indicated $43 \%$ of respondents to the ELA February 2018 post-PD survey specified personalization and choice as the top improvement which needs to be made to future content and district PD.

5. Heartland should provide teachers with more opportunities to voice their ideas and needs about the content and presentation of PD topics. $47 \%$ of interviewed teacher participants indicated the need for teachers to have a stronger voice in 
determining PD topics. Initiating a survey of staff before the district and/or content PD committees meet to plan, determine topics, and delivery methods may provide the opportunity to offer more differentiated sessions to increase the knowledge base for adult learners.

\section{Future Research}

A suggestion for future studies would be to further the conversation of how teachers use reflection and feedback to transform their classroom practices to help students grow. This may include discovering what teachers need to learn about reflective practices to lead to transformation or how districts provide time or strategies for reflection and peer or administrative feedback. It may also be worthwhile to study how teachers use collected data during their reflective practices to influence changes of classroom practices and if the use of this data improves student performance.

Future research may also surround the use of teacher experts and how teachers emerge as leaders within their districts and communities. Additionally, administrators may wish to know how teacher leaders are able to help their peers transform teaching practices and strategies and what roles they take within their own buildings. District may find a need to develop a specific PD presenter training model to use teacher experts to their fullest potential.

A final area in which there should be further research is the effect of teachers' years of experience in their professional growth. The NBPTS stated years of experience should not be considered as or in professional growth:

The formal knowledge teachers rely on accumulates steadily, yet provides insufficient guidance in many situations. Teaching ultimately requires judgment, improvisation, and conversation about means and ends ("What Teachers Should Know," 2002, p. 2). 
However, the common belief held by teachers is that they grow as they gain experience (Chalikandy, 2014). Ten teachers in this study indicated years of experience should count and should be considered as a factor in determining professional growth. From this data, districts and administrators may find value in investigating how and what motives teachers to continue to grow professionally as well as what keeps educators from trying new methodologies in their classroom practices. 


\section{References}

Ajayi, L. (2016). High school teachers' perspectives on the English language arts Common Core State Standards: An exploratory study. Educational Research for Policy and Practice, 15(1), 1-25. doi: 10.1007/s10671-015-9174-3

Anders, P., Hoffman, J., \& Duffy, G. (2000). Teaching teachers to teach reading: Paradigm shifts, persistent problems, and challenges. In M. L. Kamil, P. B. Mosenthal, P. D. Pearson, \& R. Barr (Eds.), Handbook of reading research (Vol. 3, pp. 719-742). Mahwah, NJ: Erlbaum.

Bartlett, L. (1990). Teacher development through reflective teaching. In J. C. Richards and D.Nunan (Eds.), Second Language Teacher Education (pp.215-226). New York: Cambridge University Press.

Bennett, G., \& Jessani, N. (2011). The knowledge translation toolkit: Bridging the knowdo gap. Thousand Oaks, CA: Sage.

Berliner, D. (2001). Learning about and learning from expert teachers. International Journal of Educational Research, 35(5), 463-482. doi:10.1016/S08830355(02)00004-6

Bolman, L. G., \& Deal, T. E. (2013). Reframing organizations: Artistry, choice and leadership (5th ed.). San Francisco, CA: Jossey-Bass.

Bouchard, J. (2015). Transformative learning. Research Starters: Education, Online.

Bruffee, K. A. (1999). Collaborative learning: Higher education, interdependence and the authority of knowledge (2nd ed.). Baltimore, MD: Johns Hopkins University Press.

Buczynski, S., \& Hansen, C. B. (2010). Impact of professional development on teacher practice: Uncovering connections. Teaching and Teacher Education, 26, 599-607. doi: 10.1016/j.tate.2009.09.006

Caffarella, R. S., \& Daffron, S. R. (2013). Planning programs for adult learners: A practical guide (3rd ed.). San Francisco, CA: Jossey-Bass.

Camburn, E. M., \& Han, S. W. (2015). Infrastructure for teacher reflection and instructional change: An exploratory study. Journal of Educational Change, 16(4), 511-533. doi: 10.1007/s10833-015-9252-6

Campbell, C. L. (2014). Teachers Teaching Teachers: A Sustainable and Inexpensive Professional Development Program to Improve Instruction (Doctoral dissertation). Portland State University, Oregon. Retrieved from https://pdxscholar.library.pdx.edu/open_access_etds/2072 
Chalikandy, M. A. (2014). Reflection: A tool for professional development. Researchers World, 4(3), 117-124.

Couros, G. (2015). The innovator's mindset: Empowering learning, unleash talent, and lead a culture of creativity. San Diego, CA: Dave Burgess Consulting, Inc.

Cranton, P., \& King, K. P. (2003). Transformative learning as a professional development goal. New Directions for Adult Continuing Education, 98, 31-37.

Creswell, J. W. (2014). Research design: Quantitative, qualitative, and mixed methods approaches (4th ed.). Thousand Oaks, CA: Sage.

Creswell, J. W. (2016). 30 essential skills for the qualitative researcher. Thousand Oaks, CA: Sage.

Darling-Hammond, L. (2000). Teacher quality and student achievement: A review Of state policy evidence. Education Policy Analysis Archives, 8, 1.

Darling-Hammond, L., \& McLaughlin, W. (2011). Policies that support professional development in an era of reform. Phi Delta Kappan, 92(6), 81-92.

Darling-Hammond, L., \& Richardson, N. (2009). Teacher learning: What matters? Educational Leadership, 66(5), 46-53.

Darling-Hammond, L., Wei, R. C., Andree, A., Richardson, N., \& Orphanos, S. (2009). State of the profession: Study measures status of professional development. National Staff Development Council, 30(2), 42-50.

DESE, Missouri Department of Elementary \& Secondary Education. (2013). Professional learning guidelines for student success. Retrieved from www.dese.mo.gov

Desimone, L. M. (2011). A primer on effective professional development. Phi Delta Kappan, 92(6), 68-71.

Desimone, L. M., Porter, A. C., Garet, M. S., Yoon, K. S., \& Birman, B. F. (2002). Effects of professional development on teachers' instruction: Results from a three-year longitudinal study. Educational Evaluation and Policy Analysis, 24(2), 81-112.

Diaz-Maggioli, G. (2004). Teacher centered professional development. Alexandria, VA: ASCD.

Drago-Severson, E. (2008). 4 practices serve as pillars for adult learning. JSD The Learning Forward Journal, 29(4), 60-63. 
Drake, P., \& Heath, L. (2011). Practitioner research at doctoral level developing coherent research methodologies. (First ed., pp. 46-58). London, New York: Routledge

Fogarty, R., \& Pete, B. (2009). Professional learning 101: A syllabus of seven protocols. Phi Delta Kappan, 91(4), 32-34.

Forzani, F. M. (2014). Understanding "Core Practices" and "Practice-Based" teacher education learning from the past. Journal of Teacher Education, 65(4), 357-368. doi: $10.1177 / 0022487114533800$.

Gallicano, T. D. (2013, July 22). An example of how to perform open coding, axial coding and Selective coding [Web log post]. Retrieved from https://prpost.wordpress.com/2013/07/22/ an-example-of-how-to-perform-opencoding-axial-coding-and-selective-coding/

Garet, M. S., Birman, B. F., Porter, A. C., Desimone, L. M., \& Herman, R. (1999). Designing effective professional development lessons from the Eisenhower program [and] technical appendices (pp. 532). Washington, DC: American Institutes of Research.

Garet, M. S., Porter, A. C., Desimone, L., Birman, B. F., \& Yoon, K. S. (2001). What makes professional development effective? Results from a national sample of teachers. American Educational Research Journal, 38(4), 915-945.

Garritz, A. (2013). PCK for dummies. Educación Química, 24(2), 462-465.

Gibb, R. J. (1960). Learning theory in adult education. In M. S. Knowles (Ed.), Handbook of Adult Education in the United States. Washington, DC: Adult Education Association of the United States of America.

Gill, S. J. (2010). Developing a learning culture in nonprofit organizations. Los Angeles, CA: Sage.

Gilstrap, D. L. (2013). Why do we teach? Adult learning theory in professional standards as a basis for curriculum development. Library Literature \& Informational Science, 74(5), 501-518.

Glaser, R. (1996). Changing the agency for learning: Acquiring expert performance. In K. A. Ericsson (Ed.), The Road to Excellence: The Acquisition of Expert Performance in the Arts and Sciences, Sports, and Games (pp. 303-311). Lawrence Erlbaum Associates, Mahwah, NJ.

Goldschmidt, P., \& Phelps, G. (2010). Does teacher professional development affect content and pedagogical knowledge: How much and for how long? Economics of Education Review, 29, 432-439. doi: 10.1016/j.econedurev.2009.10.002 
Goodrick, D., \& Rogers, P. J. (2015). Qualitative data analysis. In K. Newcomer, H. Hatry, \& J. Wholey (Eds.), Handbook of practical program evaluation (4th ed., pp. 561-595). Hoboken, New Jersey: Jossey-Bass.

Greenwell, S., \& Zygouris-Coe, V. (2012). Exploring high school English Language Arts teachers' responses to professional development in reading instruction. Journal of Reading Education, 37(2), 21-26.

Gulamhussein, A. (2013). Teaching the teachers: Effective professional development in an era of High stakes accountability. Center for Public Education. [Case study]. Retrieved from http://www.centerforpubliceducation.org/teachingtheteachers

Guskey, T. R. (2000). Evaluating professional development. Thousand Oaks, CA: Sage.

Guskey, T. R. (2002). Professional development and teacher change. Teachers and Teaching: Theory and Practice, 8(3/4), 381-391.

Guskey, T. R. (2009). Closing the knowledge gap on effective professional development. Educational Horizons, 87(4), 224-233.

Guskey, T. R. (2014). Planning professional learning. Educational Leadership, 71(8), 1016.

Guskey, T. R. (2016). Gauge impact with 5 levels of data. Journal of Staff Development, $37(1), 32-37$.

Guskey, T. R \& Yoon, K. S. (2009). What works in professional development? Phi Delta Kappan, 90(7), 495-500.

Hadar, L., \& Brody, D. (2010). From isolation to symphonic harmony: Building a professional Development community among teacher educators. Teaching and Teacher Education, 26(8), 1641-1651. doi: 10.1016/j.tate.2010.06.015

Hill, H. C. (2009). Fixing teacher professional development. Phi Delta Kappan, 90(7), 470-476.

Hobson. (2015). How to increase student engagement at your school [White paper]. Retrieved from https://www.naviance.com/resources/entry/

Ingersoll, R. (2001). Teacher turnover and teacher shortages: An organizational analysis. American Education Research Journal, 38(3), 499-534.

Johnson, B. (2014, September 16). Why quality professional development for teachers matters. [Web log post]. Retrieved from www.Edutopia.org

Katzenmeyer, M., \& Moller, G. (2001). Awakening the sleeping giant: Helping teachers develop as leaders (2nd ed.). Thousand Oaks, CA: Sage. 
Klinger, J. K. (2004). The science of professional development. Journal of Learning Disabilities, 37(3), 248-255.

King, M. B., \& Newmann, F. M. (2000). Will teacher learning advance school goals. Phi Delta Kappan, 81, 576.

Knowles, M. S. (1980). The modern practice of adult education: From pedagogy to andragogy (2nd ed.). Chicago, IL: Follett.

Knowles, M. S., Holton, E. F., \& Swanson, R. A. (2015). The adult learner: The definitive classic in adult education and human resource development (8th ed.). San Francisco, CA: Jossey-Bass.

Krueger, R. A., \& Casey, M. A. (2016). Focus groups: A practical guide for applied research (5th ed.). Thousand Oaks, CA: Sage.

Lee, J., \& Shute, V. (2009). The influence of noncognitive domains on academic achievement in K-12 (ETS Research Rep. No. RR-09-34). Princeton, NJ: ETS

Macias, A. (2017). Teacher-led professional development: A proposal for a bottom-up structure approach. International Journal of Teacher Leadership, 8(1), 76-91.

Margolis, J. (2008) When teachers face teachers: listening to the resource "right down the hall". Teaching Education, 19(4), 293-310. doi: 10.1080/10476210802425628

Margolis, J. (2009). How teachers lead teachers. Educational Leadership, 66(5). Retrieved from http://www.ascd.org/publications/educationalleadership/feb09/vol66/num05

Merriam, S. B., \& Bierema, L. L. (2014). Adult learning: Linking theory and practice. San Francisco, CA: Jossey-Bass.

Merriam, S. B., Caffarella, R. S., \& Baumgartner, L. M. (2007). Learning in adulthood: A comprehensive guide (3rd ed.). San Francisco, CA: Jossey-Bass

Merriam, S. B., \& Tisdell, E. J. (2015). Qualitative research: A guide to design and implementation (4th ed.). San Francisco, CA: Jossey-Bass.

Merriam, S. B., \& Tisdell, E. J. (2016). Qualitative research: A guide to design and implementation (4th ed.). San Francisco, CA: Jossey-Bass.

Messmann, G., \& Mulder, R. H. (2015). Reflection as a facilitator of teachers' innovative work behavior. International Journal of Training and Development, 19(2), 125137. doi: $10.1111 /$ ijtd.12052 
Mezirow, J. (1991). Transformative dimensions of adult learning. San Francisco, CA: Jossey-Bass.

Mezirow, J. (2012). Learning to think like an adult. In E. W. Taylor, \& P. Cranton (Eds.), Handbook of transformative learning: Theory, research, and practice (pp. 73-96). San Fransisco, CA: Jossey-Bass.

Missouri Revised Statute $§ 161.092$ (2016).

Mouza, C. (2006). Linking professional development to teacher learning and practice: A multiple-case study analysis of urban teachers. Journal of Educational Computing Research, 34(4), 405-440.

Nonaka, I. (1991). The knowledge-creating company. Harvard Business Review, 69(6), 96-104.

Park, S., \& Oliver, J. S. (2008). National board certification (NBC) as a catalyst for teachers' learning about teaching: The effects of the NBC process on candidate teachers' PCK development. Journal of Research in Science Teaching, 45(7), 812-834. doi: 10.1002/tea.20234

Reeves, D. B. (2010). Transforming professional development into student results. Alexandria, VA: ASCD.

Roulston, K. (2010). Reflective interviewing: A guide to theory and practice. London and Thousand Oaks, CA: Sage.

Royce, C. A. (2010). A revolutionary model of professional development. Science Scope, 34(3), 6-9.

Schieb, L. J. \& Karabenick, S. A. (2011). Teacher motivation and professional development: A guide to resources. Math and Science Partnership - Motivation Assessment Program [Research study]. Ann Arbor, MI: University of Michigan.

Scrivener, J. (2005). Learning Teaching (2nd ed.). Oxford: Macmillan Education.

Seidman, I. (2012). Interviewing as qualitative research: A guide for researchers in education and the social sciences (4th ed.). New York, NY: Teachers College Press.

Strickland, C. A. (2009). Professional development for differentiating instruction. Alexandria, VA: ASCD.

Supovitz, J. A., \& Turner, H. M. (2000). The effects of professional development on science teaching practices and classroom culture. Journal of Research in Science Teaching, 37(9), 963-980. 
Teachers Know Best: Teachers' Views on Professional Development. (2014, December). [Case study]. Bill \& Melinda Gates Foundation \& The Boston Consulting Group. Retrieved from http://www.teachersknowbest.org/reports

Thacker, E. S. (2017). "PD is where teachers are learning!" High school social studies teachers' Formal and informal professional learning. The Journal of Social Studies Research, 41, 37-52.

TNTP. (2015). The Mirage: Confronting the hard truth about our quest for teacher development. [Case study]. Brooklyn, NY: Author. www. The Mirage.org

Trotter, Y. (2006, Winter). Adult learning theories: Impacting professional development programs. The Delta Kappa Gamma Bulletin, 72(2), 8-13.

Vangrieken, K., Meredith, C., Packer, T., \& Kyndt, E. (2017). Teacher communities as a context for professional development: A systematic review. Teaching and Teacher Education, 61, 47-59.

Van Tessell, R. (2014). The trouble with top-down. Educational Leadership, 71(8), 7678.

What teachers should know and be able to do. (2002). National Board for Professional Teaching Standards. Retrieved from http://www.nbpts.org/sites/default/files/what teachers should know.pdf

Willms, J. D., Friesen, S. \& Milton, P. (2009). What did you do in school today?

Transforming classrooms through social, academic and intellectual engagement. (First National Report) Toronto: Canadian Education Association.

Wilson, N. S., Grisham, D. L., \& Smetana, L. (2009). Investigating content area teachers' understanding of a content literacy framework: A yearlong professional development initiative. Journal of Adolescent \& Adult Literacy, 52(8), 708-718.

Yin, R. K. (2009). Case study research: Design and methods (4th ed.). Thousand Oaks, CA: Sage.

Yin, R. K. (2012). Application of case study research (3rd ed.). Thousand Oaks, CA: Sage.

Zhao, M. (2012). Teachers' professional development from the perspective of teaching reflection levels. Chinese Education \& Society, 45(4), 56-67. 


\section{APPENDIXES}

APPENDIX A

The Compare and Contrast of this Study's Theoretical Framework and Conceptual Underpinnings

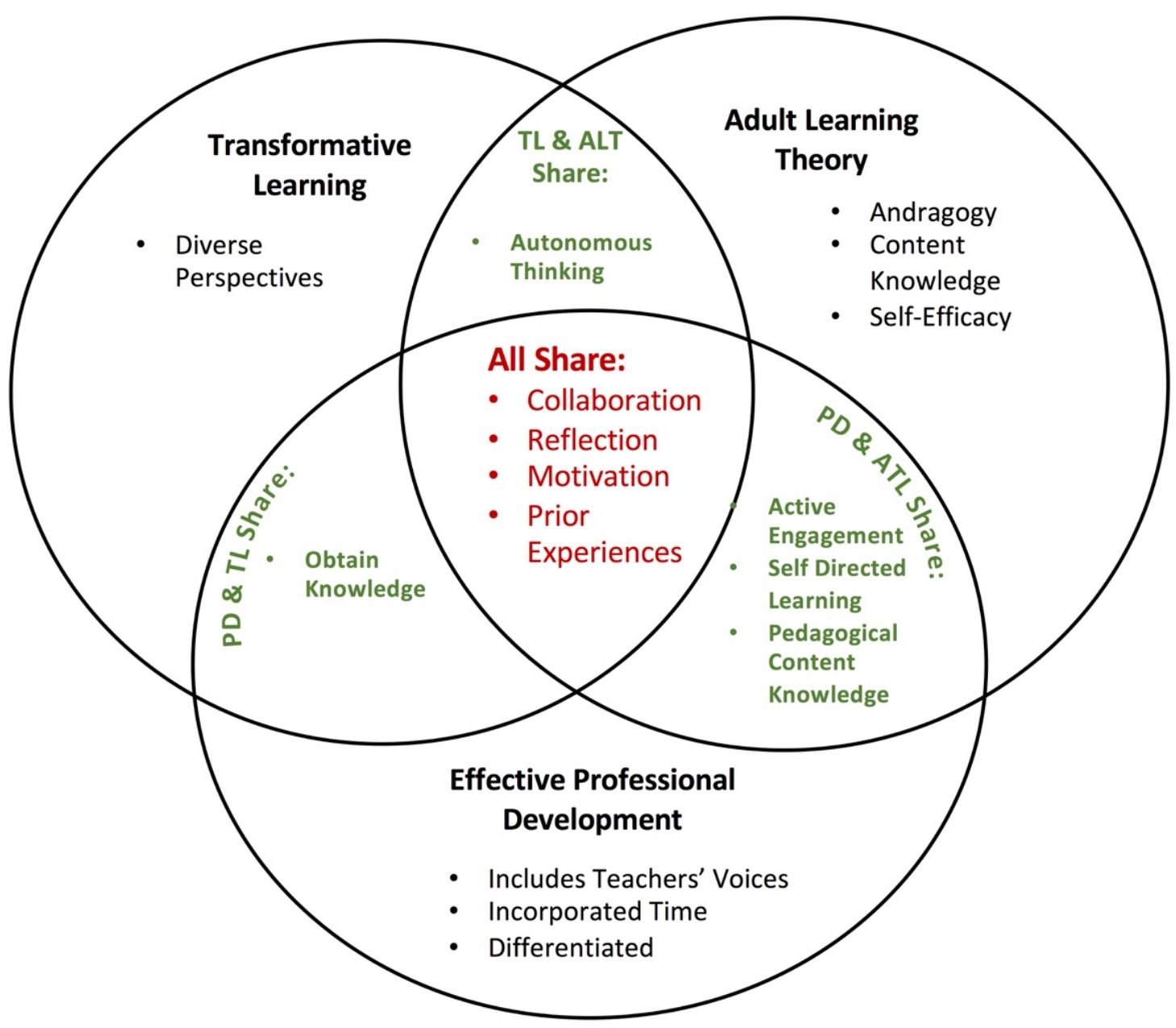

This figure represents the interconnection of the Theoretical Framework and Underpinnings of this study. The areas in green and black compare and contrast the essential components shared by the study's pillars. The area in red denotes the similarities all pillars within the study share. This figure should serve to further explain the interconnection within each area of the framework and presents the cyclical nature of the underlying concepts surrounding the main theoretical framework of Adult Learning Theory. 


\section{APPENDIX B \\ Interview \& Focus Group Questions}

How have secondary ELA teachers, from one Midwest Missouri school district, used pedagogical content knowledge gained from ELA PD to change their individual classroom practices?

- How do secondary ELA teachers define effective professional development?

- How do secondary ELA teachers implement change in their classroom practices due to newly gained pedagogical content knowledge?

- How do secondary ELA teachers know when classroom practice changes have influenced student learning?

- How do secondary ELA teachers know they are growing and/or transforming professionally?

Interview Content Questions:

SECTION 1: DEFINITION OF EFFECTIVE PROFESSIONAL DEVELOPMENT

1. How long have you been teaching?

2. What comes to mind when someone says "Professional Development"?

3. What makes PD "effective" for you?

4. What avenues have helped you to grow professionally?

5. What is your belief in the role PD plays in transformation of classroom practices?

\section{SECTION 2: TRANSFORMATION IN CLASSROOM PRACTICE}

6. Describe one instance when knowledge gained from PD (internal or external) influenced you to question past classroom practices.

7. What classroom practices have you changed due to the impact of this professional learning?

8. Focusing on one practice, describe how your classroom changed due to implementation.

9. What are the challenges or obstacles to transforming classroom practice?

\section{SECTION 3: CULTIVATING STUDENT LEARNING THROUGH TRANSFORMATION}

IN CLASSROOM PRACTICE

10. How did students' learning change with the implementation of new pedagogical knowledge?

11. How do you know their learning changed?

\section{SECTION 4: TRANSFORMATION IN PERSONAL GROWTH}

12. How do you know you are growing professionally?

13. What is your belief about the role reflection plays in professional development? 


\section{APPENDIX C}

\section{Sub-Themes of the Study by Years of Experience}

Table 9

Top Emergent Sub-Themes of Research Sub-Questions Divided into Years of Teaching Experience Groupings

\begin{tabular}{|c|c|c|c|}
\hline $\begin{array}{c}\text { NOVICE } \\
\text { 1-5 Years of Teaching } \\
\text { Experience }\end{array}$ & $\begin{array}{c}\text { TRANSITIONAL } \\
\text { 6-10 Years of Teaching } \\
\text { Experience }\end{array}$ & $\begin{array}{l}\text { MID-CAREER } \\
\text { 11-20 Years of Teaching } \\
\text { Experience }\end{array}$ & $\begin{array}{c}\text { VETERAN } \\
\text { 21-30 } \begin{array}{l}\text { Years of Teaching } \\
\text { Experience }\end{array}\end{array}$ \\
\hline \multicolumn{4}{|c|}{ Teacher Identified Elements of Effective PD: } \\
\hline $\begin{array}{l}\text {-Meeting individual } \\
\text { teacher needs } \\
\text {-Collaborative discussion } \\
\& \text { feedback } \\
\text {-Immediate use of PD } \\
\text { materials }\end{array}$ & $\begin{array}{l}\text {-Usage of teacher experts } \\
\text {-Collaborative discussion \& } \\
\text { feedback } \\
\text {-Choice \& self-selection of } \\
\text { learning topics } \\
\text {-Peer modeling }\end{array}$ & $\begin{array}{l}\text {-Current \& relevant topics } \\
\text {-Immediate use of PD materials } \\
\text {-Choice \& self-selection of } \\
\text { learning topics } \\
\text {-Usage of teacher experts }\end{array}$ & $\begin{array}{l}\text {-Fresh/ New/ Exciting take } \\
\text { on topics \& strategies } \\
\text {-Immediate use of PD } \\
\text { materials } \\
\text {-Usage of teacher experts } \\
\text {-Collaborative discussion } \\
\text { \& feedback }\end{array}$ \\
\hline \multicolumn{4}{|c|}{ Teacher Implemented Elements of Classroom Practice for Transformation:* } \\
\hline $\begin{array}{l}\text {-Application of technology } \\
\text {-Modification \& } \\
\text { differentiation } \\
\text {-Fresh/ New/ Exciting take } \\
\text { on topics \& strategies } \\
\text { - Experimentation }\end{array}$ & $\begin{array}{l}\text {-Application of technology } \\
\text {-Meeting student needs } \\
\text { through choice \& creativity } \\
\text { - Experimentation }\end{array}$ & $\begin{array}{l}\text {-Application of technology } \\
\text {-Modification \& differentiation } \\
\text {-Experimentation \& change of } \\
\text { strategies/ take risks } \\
\text {-Changes in teachers' perception } \\
\text { of student abilities } \\
\text {-Utilize teacher experts }\end{array}$ & $\begin{array}{l}\text {-Utilize teacher experts } \\
\text {-Application of technology } \\
\text {-Experimentation \& } \\
\text { change of strategies/ take } \\
\text { risks }\end{array}$ \\
\hline \multicolumn{4}{|c|}{ Evidence of Student Learning Growth from Practice Transformation Manifested as: } \\
\hline $\begin{array}{l}\text {-Increased understanding } \\
\text { in chunks } \\
\text {-Build on base skills } \\
\text {-Student ability to } \\
\text { explain thinking }\end{array}$ & $\begin{array}{l}\text {-More reflection on work \& } \\
\text { learning } \\
\text {-Increased engagement } \\
\text {-Carry over of skills to other } \\
\text { course work }\end{array}$ & $\begin{array}{l}\text {-Increased confidence \& } \\
\text { creativity in thinking } \\
\text {-Increased engagement } \\
\text {-Increased results in assessments } \\
\text { \& data } \\
\text {-Students track personal growth } \\
\text {-Students work on more } \\
\text { challenging assignments }\end{array}$ & $\begin{array}{l}\text {-Increased confidence \& } \\
\text { creativity in thinking } \\
\text {-Increased results in } \\
\text { assessments \& data } \\
\text {-Carry over of skills to } \\
\text { other course work } \\
\text {-More links to current } \\
\text { events }\end{array}$ \\
\hline \multicolumn{4}{|c|}{ Teacher Growth and Personal Transformation Manifested as: } \\
\hline $\begin{array}{l}\text {-Fresh/ New/ Exciting take } \\
\text { on topics \& strategies } \\
\text {-Increased confidence \& } \\
\text { creativity in thinking/ } \\
\text { practice } \\
\text {-Skills have increased } \\
\text {-Teacher experts as models }\end{array}$ & $\begin{array}{l}\text {-Reflection techniques } \\
\text { - Questioning } \\
\text {-Collaborative discussion } \\
\text { - Reflective feedback } \\
\text {-Skills have increased }\end{array}$ & $\begin{array}{l}\text {-Fresh/ New/ Exciting take on } \\
\text { topics \& strategies } \\
\text {-Teacher experts as models } \\
\text {-Reflection techniques } \\
\text { - Reflective feedback } \\
\text {-Experimentation \& change of } \\
\text { strategies/ take risks }\end{array}$ & $\begin{array}{l}\text {-Reflection techniques } \\
\text {-Improved evaluations \& } \\
\text { feedback from students \& } \\
\text { administration } \\
\text {-Fresh/ New/ Exciting take } \\
\text { on topics \& strategies } \\
\text {-Collaborative discussion } \\
\text { - Reflective feedback }\end{array}$ \\
\hline
\end{tabular}

Note. Themes are arranged in order of most important to each group of teachers. 


\section{Current Heartland Professional Development Structure}

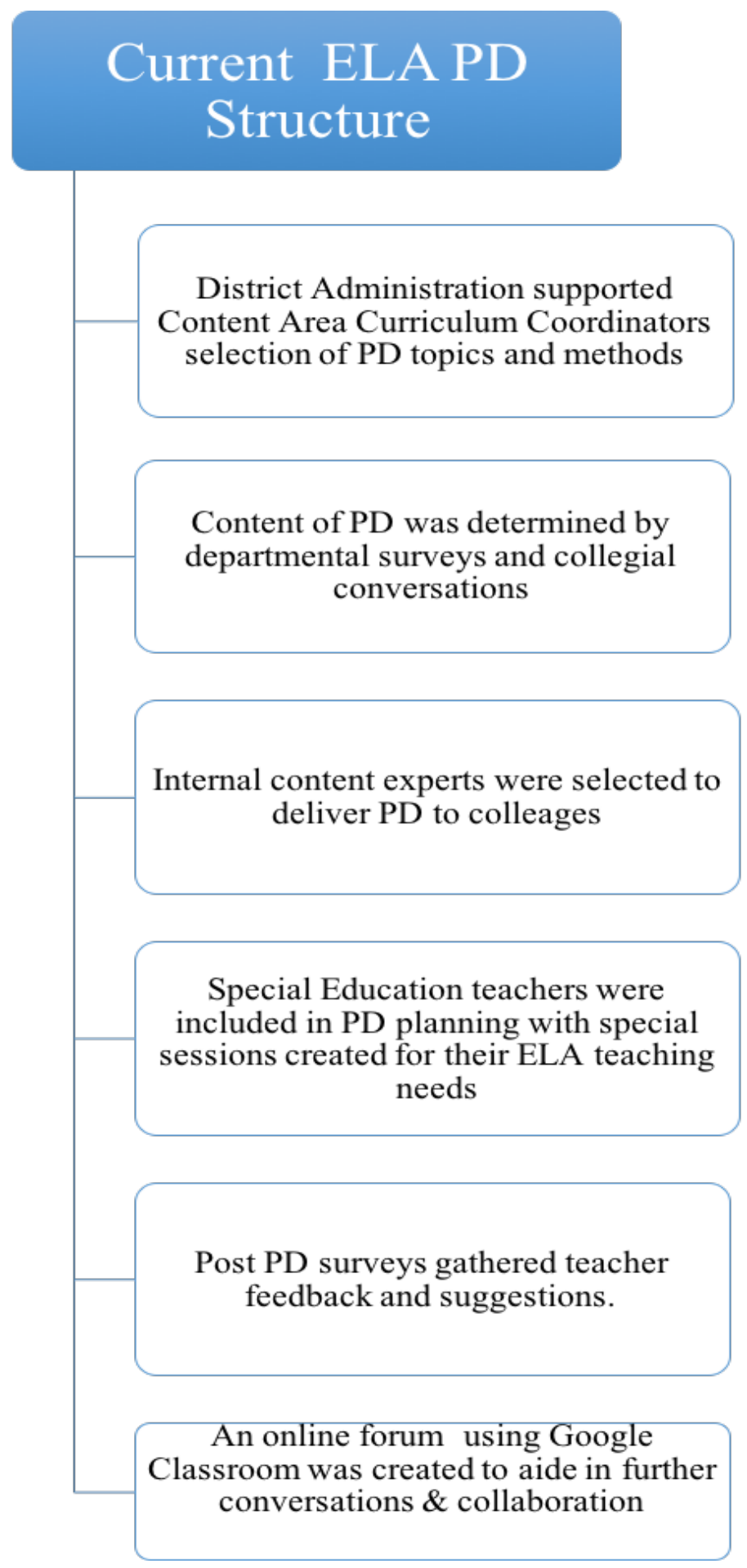




\section{SECTION SIX}

\section{SCHOLARLY PRACTITIONER REFLECTION}

This portion of the dissertation in practice (DIP) provides a place for me to reflect on how the Educational Leadership and Policy Analysis (ELPA) Doctoral Program has influenced my practice as an educational leader and has further influenced me as a scholar. As I have learned in the research finding of this study, reflection is an integral part of the learning process of adult learning theory (ALT), effective professional development (PD), and transformative learning (TL). TL does not happen in isolation, therefore the collaborative structure of the cohort model through group tasks, open discussions, reflective practices, formal and informal presentations, various teambuilding groups, and practical workplace projects, the Ed.D. program has prepared me for multiple leadership positions in my building, district, and community. I look forward to the future leadership doors the Ed.D. will open for gained practice knowledge.

\section{Dissertation Influencing Practice as an Educational Leader}

Kotter (2011) defines leadership as setting direction, aligning people, and providing motivation to cope with change. However, Goleman (2011) believes a great leader is distinguished from a good one by possessing emotional intelligence, "the ability to work with others and effectiveness in leading change" (p. 2). Similarly, Bolman and Deal's (2013) position on human resource leaders advocate characteristics such as a strong belief, visibility and access, as well as empowering others as gifted leaders. While “everyone's intelligence is needed to help [an] organization flex, respond, regroup and retool" (Hargreaves \& Fink, 2006, p. 10), leaders are the grease which enable all working parts of the organizational machine to run smoothly. Leadership "is a reciprocal process 
because leaders affect followers and followers affect leaders" (Northouse, 2016, p. 196).

Through the process of determining my leadership style through seven different questionnaire surveys as a class assignment, I realized I am a servant leader.

\section{Servant Leadership}

Servant leadership is described as a person who chooses to serve first while acknowledging their desire to lead (Northouse, 2016); they also remain attentive to and empower the development of their followers' capabilities. Core to the servant leader's process are seven key behaviors: conceptualizing, emotional healing, putting followers first, helping followers grow and succeed "place the good of the followers over the leaders' self-interest" (Northouse, 2016, p. 253), behaving ethically, empowering, and creating value for the community. "Servant leaders believe that organizations play a moral role in society and make sure to give back to make things better than the way they were found" (Beck, 2014, p. 302). Through knowledge gained during the ELPA program, I applied for the position of my district's Secondary English Language Arts (ELA) Curriculum Advisor. Based on what I had learned from the ELPA program I created a three-year proposal of district departmental changes which I presented during the interview process. The cohort program prepared me to fill this position.

\section{Changes in Personal Practice}

I learned I am an Achiever through the results of the StrengthsQuest questionnaire taken during the first summer of ELPA course work in June of 2015. The results also indicated I am intrinsically motivated to complete tasks correctly while adhering to a selfimposed standard of perfection. In addition, I took a Skills Inventory Questionnaire from Northouse (2016) which indicated my ability to master technical skills to be my preferred 
leadership style. I conducted further research and found the StrengthsQuest findings supported that I am a self-taught learner as well as an authentic and servant leader by highlighting my preference for helping identify and solve problems. Two of the problems I solved within my district involved the current grammar scaffold and assessment planning (Northouse, 2016).

\section{Changes in Leadership Practice}

"Authentic and servant leader[s] all recognize the importance of a positive moral perspective and a focus on the follower's development" (Beck, 2014, p. 300). In the position of a secondary curricular advisor, I drew upon my 20 years of teaching experience and knowledge gained about adult learning and policy analysis to begin instating specific changes which would benefit all ELA teachers in the district: curriculum realignment, instating a grammar scaffold for grades 7-12, and providing teachers with easy access to district and departmental information. Through other questionnaires in Northouse (2016), I verified relationships as a key variable in my leadership personality (p. 93). Through the importance of relationship building, I want to help teachers work smarter and not harder.

Therefore, when the Missouri Grade Level Expectations (Mo GLE) replaced the Common Core State Standards (CCSS) delineation of individual grammar and mechanics skills for every grade level were whittled to one standard, using identical language for grades 7-12, I knew teachers would need more instructional guidance. Thus with my task behavior and technical capabilities as well as the position of secondary curriculum advisor I was able to merge the district purchased online program, www.NoRedInk.com, with what I knew students needed in terms of grammar instruction to meet state testing 
and ACT objectives into a grammar scaffold for each grade level. This showed how as a leader I " provide[ed] structure for followers, and [I] nurture[ed] them" (Northouse, 2016, p. 72) by ensuring the year's PD would support the new grammar curriculum outlined through the www.NoRedInk.com program.

By pulling together a collaborative team of ELA departmental chairs as leaders from all seven district secondary buildings, I was able to gather input from all teachers' reactions of how the grammar scaffold worked in their classrooms; this allowed for a full spectrum of ideas (Gill, 2010). This also ensured a clear spiral of skills to build from one grade level to another. Such diversity of ideas provides a positive team experience for all stakeholders through collaborative conversations (Levi, 2014). Along with credibility and honesty, such willingness for all chairs to share their teams' learning will solidify the unity of the team (Mihelic, Lipicnik, \& Tekavcic, 2010). Thus we can reframe the team's functionality through the Scientific Management method which encourages workers to train each other and thus improve each member's performance (Taylor, 1916/2005). This process of gathering feedback to drive changes in the grammar scaffold helped reduce the resistance that comes with implementing organizational changes (Jansson, 2013).

\section{Dissertation Driven Changes}

Through the dissertation process when reviewing district post-PD surveys, a focus group, and individual interviews with secondary ELA teachers within my district, I realized the presentation of ELA PD needed to meet more specific teacher needs. Additionally, my new role as curriculum advisor provided a positive platform on which to discuss my findings with and gain support from district administration. This allowed me to instate changes in the PD structure for the February 2018 meeting which allowed 
for teacher more choice and more individualization ranging from novice sessions to advanced sessions on various subjects. Through positive feedback from teachers, the structural changes initiated can influence future PD and research. Through the DIP data gathering process, I gleaned three important elements which need to be integrated into future PD planning: (a) the use of teacher experts, (b) more time for collaborative discussions, and (c) time for reflective practice.

\section{Dissertation Process Influencing Scholarship}

"New knowledge always begins with the individual" (Nonaka, 1991, p. 97). However, there are two forms of knowing and gaining knowledge: tacit and explicit (Nonaka, 1991). Tacit knowledge is an ingrained part of learners' upbringing and technical skills while explicit knowledge is easily transferred by discussion or traditional classroom practices (Bennett \& Jessani, 2011; Gill, 2010; Merriam \& Bierema, 2014; Nonaka, 1991). It is important to remember "all educators are learners first" (Merriam \& Bierema, 2014, p. 251). As educators and adult learners, we have different needs and processes which impact our ability to learn and transform tacit knowledge into explicit knowledge which is "the critical steps in the spiral of knowledge" (Nonaka, 1991, p. 99). Additionally, Gill (2010) pinpoints how "tacit knowledge does not come into awareness until people share and discuss their thoughts and experiences with each other" (p. 170).

\section{Transforming Knowledge}

In order to transform knowledge, Taylor (2009) states there are three essential components: "individual experience, critical reflection, and dialogue" (p. 4) with a learner's prior experience as the "primary medium of transformative learning" (p. 5). In fact, learning effectiveness depends on the process of learning "being a collective 
activity" (Gill, 2010, p. 103). Much of a learner's experiences come from collaboration, discussion, and dialogue which Bruffee (1999) touts as one of the powerful forces of adult learning. The use of dialogue through discussion provides learners with a way to "weave connections among ideas" (Gill, 2010, p. 87) in order learn from each other (Bruffee, 1999; Preskill \& Brookfield, 2009), to give feedback, support rational arguments, and build emotional intelligence (Levi, 2014). To emphasize the importance

of emotional intelligence in collaboration, dialogue, and learning, Goleman (2011) believes a great leader is distinguished from a good one by possessing emotional intelligence (EQ), by leading change through the employment of empathy and social skills. To echo EQ, the practice of openness involves suppressing individual "assumptions and preconceptions" (Preskill \& Brookfied, 2009, p. 21) so the value in the contributions made by others can be evaluated and critiqued without bias. The lack of openness within the concept of learning hinders transformation of tacit knowledge, stunts collaboration and critical dialogue from occurring, and critical thinking wanes along with learners' desire to participate in learning activities (Levi, 2014; Merriam \& Bierema, 2014; Preskill \& Brookfield, 2009).

\section{Changes in Personal Scholarship}

As a student and life-long learner, I have always preferred to listen to other's ideas and opinions, allow them to percolate with my own, and then discuss my thoughts in a small group setting. I am self-conscious when participating in dialogue within a large group setting. Through the StrengthsQuest survey, the theme of Intellection succinctly supported my preference for refraining in the participation of large group discussions. For these past actions, the ELPA cohort model "facilitates the forming of 
social ties" (Lei, Gorelick, Short, Smallwood, \& Wright-Porter, 2011, p. 498) due to "intellectual and academic stimulation" (Lei et al., 2011, p. 498) which has allowed my inner Learner to overcome the social weaknesses of Intellection.

Kernis (2003) explains that, "Relational transparency occurs when individuals share their core feelings, motives, and inclinations with others in an appropriate manner" (Northouse, 2016, p. 203). Through my peers' perceptions of my leadership, I was chosen to present several break-out sessions over the past four years during our district's days for professional development. Such opportunities have pushed me to embrace Preskill and Brookfield's (2009) concept of openness and utilize my EQ as a way to listen to what my peers need to facilitate learning over the PD topic I am covering. Through small group discussions and their response to a hands-on activity (Desimone, 2011; Fogarty \& Peete, 2009; Knowles, Holton, \& Swanson, 2015), I have gained more EQ in how to motivate and understand others' learning (Merriam \& Bierema, 2014). In essence, I have transformed because I have moved beyond my comfort zone of simply being a passive learner (Ettling, 2012, p. 541). The cohort program has given me the confidence to support what I instinctively knew was good teaching and leading with a solid foundation through the program's course of study. I can now support my ideas and reasoning with researched knowledge and expert background. I have continued my personal practice of transformative learning through reflective practices as I worked on the renewal components of National Board Certification and my personal improvement plan as a curriculum advisor. My continued learning supports how Merriam and Bierema (2014) describe what makes a growing practitioner, "Reflection in action is what distinguishes the more expert practitioner from the novice" ( p. 116). 


\section{Changes in Practice}

New approaches and creative ideas involve risk (Levi, 2014) and may require support in order to provide innovative problem solving strategies. Teachers can connect with the humanistic viewpoint, which sees the potential and talent in all learners (Bolman \& Deal, 2013; Merriam \& Bierema, 2014) when they "believe their actions will matter and have the resources to act... (Hess \& Lautzenheiser, 2012, p. 3). Both the Strategic and Maximizer themes from the StrengthsQuest survey emphasize how I can envision multiple options for a problem and the consequences for each. In addition, I want my peers to view me as trustworthy, able to maintain open communication, invested in helping my peers become successful problem solvers, and do what is best for the district's English Language Arts (ELA) team. Through the traits of openness, trustworthiness, and diligence identified by my peers' perception of my leadership, I have addressed issues of social justice and equity through advocating for Special Education teachers and students to have a parallel curriculum aligned to support and challenge students at a level which allows them to show learning growth. Additionally, I have been an agent of change in my ability to pilot a leadership team charged with the task of implementing a student intervention program for ESOL students who are falling behind in their ELA courses.

I feel I have gained credibility as a teacher leader and learner by remaining open and willing to share student work samples in order to exhibit the techniques I utilize in my classroom practices. While providing PD on the changes in the ACT Writing subtest, I provided attendees with high, medium, and low scoring student sample essays. I also showed teachers how to dissect the writing prompt just as I showed my students. I provided teachers with three differentiated brainstorming and prewriting handouts they could use with their students. In fact, one teacher participant interviewed during my research data collection specifically addressed the ACT PD session I led. Tammy Lynn said: 
Everything you taught [us] was the same as the way I would teach an essay, but the way that you gave that and delivered it to me turned on the light for me. I felt that day understanding how to get my students to write a good ACT essay. And I remember, I said, you've got to give me everything. I need everything you know. Please. And you sent it all to me and I used it all. And I was able to transform it to fit with students' needs and my needs as a teacher. And I saw great improvement in their writing skills as a result.

Such opportunities to be open with my peers provided a layer of transparency (Northouse, 2016) by offering my teaching practices as a catalyst for concept discussion. In addition, I have become more open to showing my colleagues data tracking, student progress charting, and measured learning growth techniques. For me as a learner, without clear examples of how new content or strategies can improve classroom practices, I tend to tune out. This can cause teacher buy-in to stagnate and teachers resistant to change may languish (Ettling, 2012; Kotter, 2011; Merriam \& Bierema, 2014). I was glad my inner Strategist was able to provide differentiated examples of how teachers could customize the content of my PD presentations to meet the needs of their students as well as assessment changes and curricular updates. As a curriculum advisor, I continue to strive to create a culture which supports Gill's (2010) continuous learning at all levels: individuals, teams, whole organizations, and community levels.

\section{Dissertation Driven Changes}

As the new advisor for the district's secondary ELA departmental PD planning and implementation, I must increase my openness and EQ to better meet the changing learning needs of fellow teachers. Due to the diverse perspective of critical human resource development (Merriam \& Bierema, 2014), the move to ensuring PD provides the opportunity to understand how ELA teachers use PCK to change individual classroom practices would be beneficial to increasing critical thinking and openness of those who 
refrain from participating during discussions. This would create a change in whose voice is heard during PD by varying who takes the lead in guiding PD sessions (Preskill \& Brookfield, 2009). Since we are all members of an "overlapping community of interest and expertise" (Bruffee, 1999, p. 10), I want to learn from my colleagues by giving those who have creative and best practices which would benefit all classrooms but often stay on the sidelines and out of the spotlight by asking them to lead PD sessions. Such action as the PD leader will provide an opportunity for teachers to experience triple-loop learning (Argyris \& Schön, 1974; Bennett \& Jessani, 2011; Gill, 2010; Merriam \& Bierema, 2014) which prompts learning how to learn through personal reflection and deep discussion practices; both of which are key elements to adult learning (Knowles et al., 2015). By tapping others to share their creative ideas, I am modeling the openness I want participants to embrace (Preskill \& Brookfield, 2009) while contributing to collaborate and hold collegial discussions.

Bolman and Deal (2013) state, "Events and processes are often more important for what is experienced than for what is produced" (p. 248). Therefore, the most power teachers possess is the control over knowledge, and with this power comes the capability to disseminate knowledge and the obligation to acquire new ways of obtaining knowledge (Block, 2013). All teachers in the department have the potential to share "knowledge that everyone [possesses] and apply it to new problems and conditions imposed by tasks" (Bruffee, 1999, p. 37). Getting the right teachers to present their skills and best practices is one of my goals as a curricular advisor. As a learning team, ELA teachers can provide targeted, essential, and learner-centered PD for all teachers within the district no matter their experience or knowledge levels, "organizational learning is a 
process of forming and applying collective knowledge to problems and needs" (Gill, 2010, p. 6). 


\section{References}

Abadiano, H. R. \& Turner, J. (2004). Professional staff development: What works? The NERA Journal, 40(2), 87-91.

Ajayi, L. (2016). High school teachers' perspectives on the English language arts Common Core State Standards: An exploratory study. Educational Research for Policy and Practice, 15(1), 1-25. doi: 10.1007/s10671-015-9174-3

Alvermann, D. E. (2001). Effective literacy instruction for adolescents. Executive summary and paper commissioned by the National Reading Conference. Chicago, IL: National Reading Conference.

Alvermann, D. E., Moore, D. W., \& Conley, M. W. (1987). Research within reach: Secondary school reading. Newark, DE: International Reading Association.

Amir, A., \& Kamarudin, M. F. (2009). The impact of path-goal leadership behavior group on group cohesiveness: A Japanese electronic company and Singaporean electronic company in Johor. Journal of Human Capital Development, 2(1), 1-11.

Anders, P., Hoffman, J., \& Duffy, G. (2000). Teaching teachers to teach reading:

Paradigm shifts, persistent problems, and challenges. In M. L. Kamil, P. B. Mosenthal, P. D. Pearson, \& R. Barr (Eds.), Handbook of reading research (Vol. 3, pp. 719-742). Mahwah, NJ: Erlbaum.

Applebee, A. N. (1974). Tradition and reform in the teaching of English: A history. Urbana, IL: National Council of Teachers of English.

Applebee, A. N. (2013). Common core state standards: The promise and the peril in a national palimpsest. The English Journal, 103(1), 25-33. 
Applebee, A. N., Langer, J. A., Mystrand, M., \& Gamoran, A. (2003). Discussion -based approaches to developing understanding: Classroom instruction and student performance in middle and high school English. American Educational Research Journal, 40(3), 685-730.

Argyris, C., \& Schön, D. A. (1974). Theory in practice: Increasing professional effectiveness. San Francisco, CA: Jossey-Bass.

Au, W. \& Gourd, K. (2013). Asinine assessment: Why high-stakes testing is bad for everyone, including English teachers. English Journal, 103(1), 14-19.

Avalos, B. (2011). Teacher professional development in teaching and teacher education over ten years. Teaching and Teacher Education, 27(1), 10-20. doi: $10.1016 /$ j.tate 2010.08 .007

Baines, L. (2006). Does Horace Mann still matter? Educational Horizons, 84(4), 268275.

Ball, D. L., Thames, M. H., \& Phelps, G. (2008). Content knowledge for teaching: What makes it special? Journal of Teacher Education, 59(5), 389-407

Bandura, A. (1995). Self-efficacy in changing societies. Cambridge, UK: Cambridge University Press.

Barone, D., \& Morrell, E. (2007). Multiple perspectives on preparing teachers to teach reading. Reading Research Quarterly, 42(1), 167-180. doi: 10.1598/RRQ.42.1.10

Bartlett, L. (1990). Teacher development through reflective teaching. In J. C. Richards and D. Nunan (Eds.), Second Language Teacher Education (pp.215-226). New York: Cambridge University Press. 
Bean, T. W., \& Harper, H. (2011). The context of English language arts learning: The high school years. In D. Lapp \& D. Fisher (Eds.), Handbook of Research on Teaching the English Language Arts (3rd ed., pp. 60-68). New York, NY:

Routledge.

Beavis, C. (2013). Literary English and the challenge of multimodality. Changing English, 20(3), 241-252.

Beck, C. D. (2014). Antecedents of servant leadership: A mixed methods study. Journal of Leadership \& Organizational Studies, 21(3), 299-314.

Bennett, G., \& Jessani, N. (2011). The knowledge translation toolkit: Bridging the knowdo gap. Thousand Oaks, CA: Sage.

Ben-Peretz, M. (2011). Teacher knowledge: What is it? How do we uncover it? What are its implications for schooling? Teaching and Teacher Education, 27, 3-9. doi: $10.1016 /$ j.tate 2010.07 .015

Berliner, D. (2001). Learning about and learning from expert teachers. International Journal of Educational Research, 35(5), 463-482. doi:10.1016/S08830355(02)00004-6

Bolman, L. G., \& Deal, T. E. (2013). Reframing organizations: Artistry, choice and leadership (5th ed.). San Francisco, CA: Jossey-Bass.

Bolman, L. G. \& Gallos, J. V. (2011). Reframing academic leadership. San Francisco, CA: Jossey-Bass.

Bouchard, J. (2015). Transformative learning. Research Starters: Education, Online. 
Broad, J. H. (2015). So many worlds, so much to do: Identifying barriers to engagement with continued professional development for teachers in the further education and training sector. London Review of Education, 13(1), 16-30.

Bromley, B. D. (1986). The case-study method in psychology and related disciplines. Chichester, Great Britain: Wiley.

Bruffee, K. A. (1999). Collaborative learning: Higher education, interdependence and the authority of knowledge (2nd ed.). Baltimore, MD: Johns Hopkins University Press.

Buczynski, S., \& Hansen, C. B. (2010). Impact of professional development on teacher practice: Uncovering connections. Teaching and Teacher Education, 26, 599-607. doi: $10.1016 /$ j.tate 2009.09 .006

Burbank, M. D. \& Kauchak, D. (2003). An alternative model for professional development: Investigations into effective collaboration. Teaching and Teacher Education, 19(5), 499-514. doi: 10.1016/S0742-051X(03)00048-9

Butler, D. L. \& Schnellert, L. (2012). Collaborative inquiry in teacher professional development. Teaching and Teacher Education, 28(8), 1206-1220. doi: 10.1016/j.tate.2012.07.009

Caffarella, R. S., \& Daffron, S. R. (2013). Planning programs for adult learners: A practical guide (3rd ed.). San Francisco, CA: Jossey-Bass.

Camburn, E. M., \& Han, S. W. (2015). Infrastructure for teacher reflection and instructional change: An exploratory study. Journal of Educational Change, 16(4), 511-533. doi: 10.1007/s10833-015-9252-6 
Campbell, C. L. (2014). Teachers Teaching Teachers: A Sustainable and Inexpensive Professional Development Program to Improve Instruction (Doctoral dissertation). Portland State University, Oregon. Retrieved from https://pdxscholar.library.pdx.edu/open_access_etds/2072

Campbell, P. W. (2001, July/August). The great experiment: A film journey with America's public schools. Humanities, 22(4), 8-11, 42.

Cave, A., \& Mulloy, M. (2010). How do cognitive and motivational factors influence teachers' degree of program implementation? A qualitative examination of teacher perspectives. National Forum of Educational Administration and Supervision Journal, 27(4), 1-26.

Cercone, K. (2008). Characteristics of adult learners with implications for online learning design. AACE Journal, 16(2), 137-159.

Cevero, R. M., \& Wilson, A. L. (1994). Planning responsibly for adult education: A guide to negotiating power and interests. San Francisco, CA: Jossey-Bass.

Chalikandy, M. A. (2014). Reflection: A tool for professional development. Researchers World, 4(3), 117-124.

Chen, J., \& McCray, J. (2012). A conceptual framework for teacher professional Development: The whole teacher approach. National Head Start Association Dialog, 15(1), 8-23. doi: 10.1080/15240754.2011.636491

Clotfelter, C. T., Ladd, H. F., \& Vigdor, J. L. (2006). Teacher-student matching and the assessment of teacher effectiveness. Journal of Human Resources, 41(4), 778820. 
Colquitt, J. A., \& George, G. (2011). From the editors publishing in AMJ - part 1: Topic choice. Academy of Management Journal, 54(3), 432-435. doi: 10.5465/AMJ. 2011.61965960

Cosenza, M. N. (2015). Defining teacher leadership: Affirming the teacher leader model Standards. Issues in Teacher Education, 24(2), 79-99.

Couros, G. (2015). The innovator's mindset: Empowering learning, unleash talent, and lead a culture of creativity. San Diego, CA: Dave Burgess Consulting, Inc.

Cranton, P., \& King, K. P. (2003). Transformative learning as a professional development goal. New Directions for Adult Continuing Education, 98, 31-37.

Cremin, L., ed. (1957). The republic and the school. New York, NY: Teachers College Press.

Creswell, J. W. (2014). Research design: Quantitative, qualitative, and mixed methods approaches (4th ed.). Thousand Oaks, CA: Sage.

Creswell, J. W. (2016). 30 essential skills for the qualitative researcher. Thousand Oaks, CA: Sage.

Danielson, C. (2007). The many faces of leadership. Educational Leadership, 65(1), 1419.

Darling-Hammond, L. (2000). Teacher quality and student achievement: A review Of state policy evidence. Education Policy Analysis Archives, 8, 1.

Darling-Hammond, L. (2003). Keeping good teachers: Why it matters: What leaders can do. Educational Leadership, 60(8), 6-13.

Darling-Hammond, L. (2013). When teachers support and evaluate their peers.

Educational Leadership, 71(2), 24-29. 
Darling-Hammond, L., \& McLaughlin, W. (2011). Policies that support professional development in an era of reform. Phi Delta Kappan, 92(6), 81-92.

Darling-Hammond, L., \& Richardson, N. (2009). Teacher learning: What matters? Educational Leadership, 66(5), 46-53.

Darling-Hammond, L., Wei, R. C., Andree, A., Richardson, N., \& Orphanos, S. (2009). State of the profession: Study measures status of professional development. National Staff Development Council, 30(2), 42-50.

De Kramer, R. M, Masters, J., O’Dwyer, L. M., Dash, S., \& Russell, M. (2012). Relationship of online teacher professional development to seventh-grade teachers' and students' knowledge and practices in English Language Arts. The Teacher Educator, 47, 236-259.

DeFauw, D. L., \& Taylor, J. A. (2015). Art and culture in the English Language Arts: Research findings and educator's perspectives. Journal of Reading Education, 40(2), 3-12.

DESE, Missouri Department of Elementary \& Secondary Education. (2013). Professional learning guidelines for student success. Retrieved from www.dese.mo.gov

DESE, Missouri Department of Elementary \& Secondary Education. (2016). Statistics report. Retrieved from www.dese.mo.gov

Desimone, L. M. (2011). A primer on effective professional development. Phi Delta Kappan, 92(6), 68-71. 
Desimone, L. M., Porter, A. C., Garet, M. S., Yoon, K. S., \& Birman, B. F. (2002). Effects of professional development on teachers' instruction: Results from a three-year longitudinal study. Educational Evaluation and Policy Analysis, 24(2), 81-112.

Diaz-Maggioli, G. (2004). Teacher centered professional development. Alexandria, VA: ASCD.

Drago-Severson, E. (2008). 4 practices serve as pillars for adult learning. JSD The Learning Forward Journal, 29(4), 60-63.

Drake, P., \& Heath, L. (2011). Practitioner research at doctoral level developing coherent research methodologies. (First ed., pp. 46-58). London, New York: Routledge

Education News. (2013, April 16). American public education: An origin story. Retrieved from http://www.educationnews.org/education-policy-and-politics/americanpublic-education-an-origin.story/

Eisenberg, M. (2013, September 23). The importance of studying language arts [Web log post]. Retrieved from http://naturalhealingnews.com (Reprinted from AzNetNews, 24(4), 2005, Arizona: The Sonoran Science Academy)

Emslie, N. (2016). Transformative learning and ministry formation. Journal of Adult Theological Education, 13(1), 48-63.

Ettling, D. (2012). Educator as change agent: Ethics of transformative learning. In E. W. Taylor \& P. Cranton (Eds.), The handbook of transformative learning (pp. 536551). San Francisco, CA: Jossey-Bass. 
Fernandez-Balboa, J. M., \& Stiehl, J. (1995). The generic nature of pedagogical content knowledge among college professors. Teaching and Teacher Education, 11, 293-306.

Fink, A. (2017). How to conduct surveys: A step-by-step guide (6th ed). Thousand Oaks, CA: Sage.

Finkelstein, B. (1990). Perfecting childhood: Horace Man and the origins of public education in the United States. Biography, 13(1), 6-20.

Fogarty, R., \& Pete, B. (2009). Professional learning 101: A syllabus of seven protocols. Phi Delta Kappan, 91(4), 32-34.

Forzani, F. M. (2014). Understanding “Core Practices" and "Practice-Based" teacher education learning from the past. Journal of Teacher Education, 65(4), 357-368. doi: $10.1177 / 0022487114533800$

French, Jr. R. P., \& Raven, B. (2005). The basis of social power. In J. M. Shafritz, J. S. Ott \& Y. S. Jang (Eds.), Classics of organizational theory (6th ed., pp. 311-320). Boston, MA: Wadsworth. (Reprinted from The basis of social power, pp. 150167, 1959, Michigan: University of Michigan)

Gaible, E., \& Burns, M. (2005). Using technology to train teachers: Appropriate uses of ICT for Teacher professional development in developing countries. Washington, DC: infoDev/World Bank. Retrieved from www.infodev.org/en/Publications.13.html 
Gallicano, T. D. (2013, July 22). An example of how to perform open coding, axial coding and Selective coding [Web log post]. Retrieved from https://prpost.wordpress.com/2013/07/22/ an-example-of-how-to-perform-opencoding-axial-coding-and-selective-coding/

Garet, M. S., Birman, B. F., Porter, A. C., Desimone, L. M., \& Herman, R. (1999). Designing effective professional development lessons from the Eisenhower program [and] technical appendices (pp. 532). Washington, DC: American Institutes of Research.

Garet, M. S., Porter, A. C., Desimone, L., Birman, B. F., \& Yoon, K. S. (2001). What makes professional development effective? Results from a national sample of teachers. American Educational Research Journal, 38(4), 915-945.

Garritz, A. (2013). PCK for dummies. Educación Química, 24(2), 462-465.

Gibb, R. J. (1960). Learning theory in adult education. In M. S. Knowles (Ed.), Handbook of Adult Education in the United States. Washington, DC: Adult Education Association of the United States of America.

Gill, S. J. (2010). Developing a learning culture in nonprofit organizations. Los Angeles, CA: Sage.

Gilstrap, D. L. (2013). Why do we teach? Adult learning theory in professional standards as a basis for curriculum development. Library Literature \& Informational Science, 74(5), 501-518. 
Glaser, R. (1996). Changing the agency for learning: Acquiring expert performance. In K. A. Ericsson (Ed.), The Road to Excellence: The Acquisition of Expert Performance in the Arts and Sciences, Sports, and Games (pp. 303-311). Lawrence Erlbaum Associates, Mahwah, NJ.

Goldschmidt, P., \& Phelps, G. (2010). Does teacher professional development affect content and pedagogical knowledge: How much and for how long? Economics of Education Review, 29, 432-439. doi: 10.1016/j.econedurev.2009.10.002

Goleman, D. (2011). What makes a leader? In HBR's 10 must reads on leadership (pp. 121), Boston, MA: Harvard Business Review Press. (Reprint R0401H, Originally published in June 1996)

Goodrick, D., \& Rogers, P. J. (2015). Qualitative data analysis. In K. Newcomer, H. Hatry, \& J. Wholey (Eds.), Handbook of practical program evaluation (4th ed., pp. 561-595). Hoboken, New Jersey: Jossey-Bass.

Gore, J., \& Lubans, D. (2017). Effects of professional development on the quality of teaching: Results from a randomized controlled trial of quality teaching rounds. Teaching and Teacher Education, 68, 99-113. doi: 10.1016/j.tate.2017.08.007

Greenwell, S., \& Zygouris-Coe, V. (2012). Exploring high school English Language Arts teachers' responses to professional development in reading instruction. Journal of Reading Education, 37(2), 21-26.

Gulamhussein, A. (2013). Teaching the teachers: Effective professional development in an era of High stakes accountability. Center for Public Education. [Case study]. Retrieved from http://www.centerforpubliceducation.org/teachingtheteachers 
Guskey, T. R.(1995). Results-oriented professional development: In search of an optimal mix of effective practices. Naperville, IL: North Central Regional Education Laboratory.

Guskey, T. R. (2000). Evaluating professional development. Thousand Oaks, CA: Sage. Guskey, T. R. (2002). Professional development and teacher change. Teachers and Teaching: Theory and Practice, 8(3/4), 381-391. doi: $10.1080 / 13540600210000512$

Guskey, T. R. (2009). Closing the knowledge gap on effective professional development. Educational Horizons, 87(4), 224-233.

Guskey, T. R. (2014). Planning professional learning. Educational Leadership, 71(8), 1016.

Guskey, T. R. (2016). Gauge impact with 5 levels of data. Journal of Staff Development, $37(1), 32-37$.

Guskey, T. R \& Yoon, K. S. (2009). What works in professional development? Phi Delta Kappan, 90(7), 495-500.

Hadar, L., \& Brody, D. (2010). From isolation to symphonic harmony: Building a professional Development community among teacher educators. Teaching and Teacher Education, 26(8), 1641-1651. doi: 10.1016/j.tate.2010.06.015

Hargreaves, A., \& Fink, D. (2006). Sustainable leadership. San Francisco: Jossey-Bass. Haug, C. A. \& Sands, D. I. (2013). Laboratory approach to secondary teacher professional development: Impacting teacher behavior and student engagement. Clearing House, 86(6), 197-206. doi: 10.1080/00098655.2013.826484 
Hess, F. M., \& Lautzenheiser, D. K. (2012). Putting the punch in parent power. American Enterprise Institute for Public Policy Research, 5, 1-7.

Hill, D. M., \& Barth, M. (2004). NCLB and teacher retention: Who will turn out the lights? Education and the Law, 16(2), 173-181.

doi: $10.1080 / 0953996042000291588$

Hill, H. C. (2009). Fixing teacher professional development. Phi Delta Kappan, 90(7), 470-476.

Hirsch, S. (2006). NSDC standards provide a richer definition of professional development. Journal of Staff Development, 27(3), 59-60.

Hobson. (2015). How to increase student engagement at your school [White paper]. Retrieved from https://www.naviance.com/resources/entry/

Howell, G., \& Magazinnik, A. (2017, May). Presidential presriptions for state policy:

Obama's Race to the Top initiative. Journal of Policy Analysis and Management, 36(3), 502-531. doi: 10.1002/pam.21986

Hunefeld, R. (2009). When teachers are the experts: How schools can improve professional development. Education Week, 29, 24-25.

Ingersoll, R. (2001). Teacher turnover and teacher shortages: An organizational analysis. American Education Research Journal, 38(3), 499-534.

Ingersoll, R. M. (2007). Is there really a teacher shortage? In A. R. Sadovnik (Ed.), Sociology of education: A critical reader (pp. 159-176). New York: Routledge Taylor and Francis Group.

Jansson, N. (2013). Organizational change as practice: A critical analysis. Journal of Organizational Change Management, 26(6), 1003-1019. 
Jehlen, A. (2007). Professional development. NEA Today, 26, 36-37.

Jewitt, C., Bezemer, J., \& Kress, G. (2010). Annotation in school English: A social semiotic historical account. The Yearbook of the National Society for the Study of Education, 110(1), 129-152.

Johnson, B. (2014, September 16). Why quality professional development for teachers matters. [Web log post]. Retrieved from www.Edutopia.org

Katzenmeyer, M., \& Moller, G. (2001). Awakening the sleeping giant: Helping teachers develop as leaders (2nd ed.). Thousand Oaks, CA: Sage.

Kazempour, M. (2009). Impact of inquiry-based professional development on core conceptions and teaching practices: A case study. Science Educator, 18(2), 56-68.

Kernis, M. H. (2003). Toward a conceptualization of optimal self-esteem. Psychological Inquiry, 14, 1-26.

Killion, J., \& Roy, P. (2009). Becoming a learning school. Oxford, OH: National Staff Development Council.

Kitchenham, A. (2008). The evolution of John Mezirow's transformative learning theory. Journal of Transformative Education, 6(104), 104-123. doi: $10.1177 / 1541344608322678$

Klein, A. (2017, January). Race to the top. Education Week, 36(17), 18.

Klinger, J. K. (2004). The science of professional development. Journal of Learning Disabilities, 37(3), 248-255.

King, M. B., \& Newmann, F. M. (2000). Will teacher learning advance school goals. Phi Delta Kappan, 81, 576. 
Knowles, M. S. (1980). The modern practice of adult education: From pedagogy to andragogy (2nd ed.). Chicago, IL: Follett.

Knowles, M. S., Holton, E. F., \& Swanson, R. A. (2015). The adult learner: The definitive classic in adult education and human resource development (8th ed.). San Francisco, CA: Jossey-Bass.

Kotter, J. P. (2011). What leaders really do. In HBR's 10 must reads on leadership (pp. 37-55), Boston, MA: Harvard Business Review Press. (Reprint 0111F, Originally published in May 1990)

Kress, G., Jewitt, C., Bourne, J., Franks, A., Hardcastle, J., Jones, K., \& Reid, E. (2005). English in urban classrooms. London: RoutledgeFalmer.

Krueger, R. A., \& Casey, M. A. (2016). Focus groups: A practical guide for applied research (5th ed.). Thousand Oaks, CA: Sage.

Kubitskey, B., Fishman, B. J., \& Marx, R. (2004). Impact of professional development on a Teacher and her students: A case study. American Educational Research Association. Retrieved from http://www.umich.edu/ hiceweb/downloads/Kubitskey_AERA04.pdf

Kyriakides, L, Creemers, B. P. M., \& Antouniou, P. (2009). Teacher behavior and student outcomes: Suggestions for research on teacher training and professional development. Teaching and Teacher Education, 25, 12-23.

doi: $10.1016 /$ j.tate.2008.06.001

Ladd, H. F. (2008, May). Value-added modeling of teacher credentials: Policy implications. Paper presented at the Teacher Quality Conference at Northwestern University, Evanston, IL. 
Langer, J. A. (2000). Excellence in English in middle and high school: How teachers' Professional lives support student achievement. American Educational Research Journal, 37(2), 397-439.

Lee, J., \& Shute, V. (2009). The influence of noncognitive domains on academic achievement in K-12 (ETS Research Rep. No. RR-09-34). Princeton, NJ: ETS

Lei, S., Gorelick, D., Short, K., Smallwood, L., \& Wright-Porter, K. (2011). Academic cohorts: Benefits and drawbacks of being a member of a community of learners. Education, 131(3), 497-504.

Lester, J. H. (2000). Secondary instruction: Does literacy fit in? High School Journal, 83(3), 10-16.

Levi, D.J. (2014). Group dynamics for teams (4 ${ }^{\text {th }}$ ed.). Los Angeles, CA: Sage.

Lewis, V. (2015, October 25). Why most professional development stinks: And how you can make it better [Web log post]. Retrieved from https://www.edsurge.com/news/2015-10-25-why-most-professional-developmentstinks-and-how-you-can-make-it-better

Lieberman, A. (2000). Networks as learning communities. Journal of Teacher Education, $51,221-227$.

Little, J. W. (1987). Teachers as colleagues. In V. Richardson-Koehler (Ed.), Educators' handbook: A research perspective (pp. 491-518). New York: Longman.

Luizzi, P. (2017). Situational Leadership. Fire Engineering, 170(8), 65-66.

Luke, A., \& Woods, A. (2008). Policy and adolescent literacy. In L. Christenbury, R. Boner, \& R. Smagorinsky (Eds.), Handbook of Adolescent Literacy Research (pp. 197-219). New York, NY: The Guilford Press. 
Macias, A. (2017). Teacher-led professional development: A proposal for a bottom-up structure approach. International Journal of Teacher Leadership, 8(1), 76-91.

MacKeracher, D. (2012). The role of experience in transformative learning. In E. W. Taylor, \& P. Cranton (Eds.), Handbook of transformative learning: Theory, research, and practice (pp. 342-354). San Fransisco, CA: Jossey-Bass.

Malm, B. (2008). Authenticity in teachers' lives and work: Some philosophical and empirical considerations, Scandinavian Journal of Educational Research, 52(4), 373-386. doi: 10.1080/00313830802184525

Magnusson, S., Krajcik, J., \& Borko, H. (1999). Nature, sources and development of pedagogical content knowledge for science teaching. In J. Gess-Newsome \& N. G. Lederman (Eds.), Examining pedagogical content knowledge: The construct and its implications for science education (pp. 95-132). Dordrecht, The Netherlands: Kluwer Academic.

Margolis, J. (2008) When teachers face teachers: listening to the resource "right down the hall”. Teaching Education, 19(4), 293-310. doi: 10.1080/10476210802425628

Margolis, J. (2009). How teachers lead teachers. Educational Leadership, 66(5). Retrieved from http://www.ascd.org/publications/educationalleadership/feb09/vol66/num05

Martinson, K., \& O’Brien, C. (2015). Conducting case studies. In K. Newcomer, H. Hatry, \& J. Wholey (Eds.), Handbook of practical program evaluation (4th ed., pp. 177-196). Hoboken, New Jersey: Jossey-Bass.

Meier, D. (2016). Situational leadership theory as a foundation for a blended learning framework. Journal of Education and Practice, 7(10), 25-30. 
Merriam, S. B., \& Bierema, L. L. (2014). Adult learning: Linking theory and practice. San Francisco, CA: Jossey-Bass.

Merriam, S. B., Caffarella, R. S., \& Baumgartner, L. M. (2007). Learning in adulthood: A comprehensive guide (3rd ed.). San Francisco, CA: Jossey-Bass.

Merriam, S. B., \& Tisdell, E. J. (2016). Qualitative research: A guide to design and implementation (4th ed.). San Francisco, CA: Jossey-Bass.

Messmann, G., \& Mulder, R. H. (2015). Reflection as a facilitator of teachers' innovative work behavior. International Journal of Training and Development, 19(2), 125137. doi: $10.1111 /$ ijtd.12052

Mezirow, J. (1990). Fostering critical reflection in adulthood: A guide to transformative and emancipatory learning. San Francisco, CA: Jossey-Bass.

Mezirow, J. (1991). Transformative dimensions of adult learning. San Francisco, CA: Jossey-Bass.

Mezirow, J. (1997). Transformative learning. New Directions for Adult and Continuing Education, 74, 5-12.

Mezirow, J. (2000). Learning as transformation: Critical perspectives on a theory in progress. San Francisco, CA: Jossey-Bass.

Mezirow, J. (2012). Learning to think like an adult. In E. W. Taylor, \& P. Cranton (Eds.), Handbook of transformative learning: Theory, research, and practice (pp. 73-96). San Fransisco, CA: Jossey-Bass.

Mihelic, K. K., Lipicnik, B., \& Tekavcic, M. (2010). Ethical leadership. International Journal of Management \& Information Systems, 14(5), 31-41. 
Minor, E. C., Desimone, L., Lee, J. C., \& Hochberg, E. D. (2016). Insights on how to shape teacher learning policy: The role of teacher content knowledge in explaining differential effects of professional development. Education Policy Analysis Archives, 24(61), 1-30. http://dx.doi.org/10.14507/epaa.24. 2365

Mintzberg, H. (2005). The five basic parts of the organization. In J. M. Shafritz, J. S. Ott \& Y. S. Jang (Eds.), Classics of organizational theory (6th ed., pp. 219-230). Belmont, CA:Wadsworth. (Reprinted from The structure of organizations: A synthesis of the research, pp. 18-34, 1979, New Jersey: Prentice-Hall)

Missouri Revised Statute $§ 161.092$ (2016).

Mizell, H. (2009, June 22). Ineffective PD often part of the problem in low-performing schools. [Web log post]. Retrieved from http://www.nsdc.org/learningBlog/

Mondale, S., \& Patton, S. B. (Eds.), (2002). School: The story of American public education. Boston, MA: Beacon Press.

Mouza, C. (2006). Linking professional development to teacher learning and practice: A multiple-case study analysis of urban teachers. Journal of Educational Computing Research, 34(4), 405-440.

National Council of Teachers of English (1996). NCTE/IRA standards for the English language arts. Retrieved from http://www.NCTE.org/standards/ncte-ira

NEA. (2018, Winter). Quality professional development still out of reach for most educators. NEA Today, 36(3), 13. 
NGABP \& CCSSO. (2010). Common Core State Standards for English Language Arts Literacy in History/Social Studies, Science, and Technical Subjects. Washington, DC. Retrieved from http://www.corestandards.org/assets/CCSSI ELA\%20Standards.pdf

Nonaka, I. (1991). The knowledge-creating company. Harvard Business Review, 69(6), 96-104.

Nonaka, I. (1994). A dynamic theory of organizational knowledge creation. Organization Science, 5(1), 14-37.

Northouse, P. G. (2016). Leadership: Theory and practice (7th ed.). Thousand Oaks, CA: Sage.

Palmer, D. J. (1965). The rise of English Studies. London: Oxford University Press.

Papay, J. P., \& Kraft, M. A. (2016). They myth of the performance plateau. Educational Leadership, 73(8), 36-42.

Park, S., \& Oliver, J. S. (2008). National board certification (NBC) as a catalyst for teachers' learning about teaching: The effects of the NBC process on candidate teachers' PCK development. Journal of Research in Science Teaching, 45(7), 812-834. doi: $10.1002 /$ tea.20234

Popp, J. S., \& Goldman, S. R. (2016). Knowledge building in teacher professional learning communities: Focus of meeting matters. Teaching and Teacher Education, 59, 347-359. doi: 10.1016/j.tate.2016.06.007

Preskill, S., \& Brookfield, S. D. (2009). Learning as a way of leading: Lessons from the struggle for social justice. San Francisco, CA: Jossey-Bass. (Selected readings) 
Ravitch, D. (2014). Reign of error: The hoax of the privatization movement and the danger to America's public schools. New York, NY: Vintage.

Reutzel, D. (2013). Implementation of the Common Core State Standards and the practitioner: Pitfalls and possibilities. In S. Neuman \& L. Gambrell (Eds.), Quality reading instruction in the age of Common Core State Standards (pp. 5974). Newark, DE: IRA.

Reeves, D. B. (2010). Transforming professional development into student results. Alexandria, VA: ASCD.

Rolfe, G. (2001). Reflective practice: Where now? Nurse Education in Practice, 2, 21-29. doi: $10.1054 /$ nepr.2002.0047

Rolfe, G. (2016). Did Schön really say that? A response to Comer. Nurse Education Today, 36, 1-3. doi: 10.1016/jnedt.2015.10.024

Roseler, K. \& Dentzau, M. W. (2013). Teacher professional development: A different perspective. Cultural Studies of Science Education, 8(3), 619-622. doi: $10.1007 / \mathrm{s} 11422-013-9493-8$

Ross-Gordon, J., Gordon, S., Alston, G., Dawson, K., \& Van Aacken, C. (2015). Efforts to transform learning and learners. Journal of Thought, 49(1/2), 52-70.

Roulston, K. (2010). Reflective interviewing: A guide to theory and practice. London and Thousand Oaks, CA: Sage.

Royce, C. A. (2010). A revolutionary model of professional development. Science Scope, 34(3), 6-9.

Scarlett, D. H. (2009). High school English Language Arts teachers' conceptualizations of pedagogical content knowledge. (Doctoral dissertation). 
Schieb, L. J. \& Karabenick, S. A. (2011). Teacher motivation and professional development: A guide to resources. Math and Science Partnership - Motivation Assessment Program [Research study]. Ann Arbor, MI: University of Michigan.

Schön, D. A. (1983). The reflective practitioner: How professionals think in action. Basic Books, USA.

Schön, D. A. (1987). Educating the reflective practitioner. New York, NY: Basic Books.

Scrivener, J. (2005). Learning Teaching (2nd ed.). Oxford: Macmillan Education.

Seidman, I. (2012). Interviewing as qualitative research: A guide for researchers in education and the social sciences (4th ed.). New York, NY: Teachers College Press.

Shulman, L. S. (2013). Those who understand: Knowledge growth in teaching. The Journal of Education, 193(3), 1-11.

Singer, A. (2016, September 7). Welcome back! A brief history of education in the United States. [Web log post] Retrieved from http://www.huffingtonpost.com

Singh, K. (2012). Teacher leadership: Making your voice count. Kappa Delta Pi Record, $47,15-20$.

Smith, J. A., Flowers, P., \& Larkin, M. (2009). Interpretative Phenomenological Analysis: Theory, method, and research. Thousand Oaks, CA: SAGE.

Stoll, L., Bolam, R., McMahon, A., Wallace, M., \& Thomas, A. (2006). Professional learning communities: A review of the literature. Journal of Educational Change, $7,221-258$.

Strickland, C. A. (2009). Professional development for differentiating instruction. Alexandria, VA: ASCD. 
Supovitz, J. A. (2001). Translating teaching practice into improved student performance. In S. H. Fuhrman (Ed.), From the capitol to the classroom; Standards-based reform in the states. $100^{\text {th }}$ Yearbook of the National Society for the Study of Education (Part II) (pp. 81-98). Chicago, IL: University of Chicago Press.

Supovitz, J. A., \& Turner, H. M. (2000). The effects of professional development on science teaching practices and classroom culture. Journal of Research in Science Teaching, 37(9), 963-980.

TALIS. (2009). Creating effective teaching and learning environments. Chapter 4 Teaching practices, teacher's beliefs and attitudes. France: OECD Publications. Retrieved from www.oecd.org/publishing/corrigenda

Taubman, P. (2014). The art of the impossible: Professional study and the making of teachers. English Journal, 103(6), 14-19.

Taylor, F. W. (2005). The principles of scientific management [Abstract]. In J. M. Shafritz, J. S. Ott, \& Y. S. Jang (Eds.). Classics of organization theory (6th ed., pp. 61-72). Belmont, CA: Wadsworth. (Reprinted from Bulletin of the Taylor Society, 1916)

Taylor, E. W. (2009). Fostering transformative learning. In J. Mezirow \& E. W. Taylor (Eds.), Transformative learning in practice: Insights from community, workplace, and higher education (pp. 3-17). San Francisco, CA: Jossey-Bass.

Teachers Know Best: Teachers' Views on Professional Development. (2014, December). [Case study]. Bill \& Melinda Gates Foundation \& The Boston Consulting Group. Retrieved from http://www.teachersknowbest.org/reports 
The Teacher Leadership Competencies. (2014). [Case study]. Center for Teaching Quality. Retrieved from http://www.teachingquality.org/content/teacherleadership-competencies

Thacker, E. S. (2017). “PD is where teachers are learning!" High school social studies teachers' Formal and informal professional learning. The Journal of Social Studies Research, 41, 37-52.

Thomas, P. L. (2011). A respect for the past, a knowledge of the present, and a concern for the future: The role of history in English education. English Education, 43(2), 123-144.

TNTP. (2015). The Mirage: Confronting the hard truth about our quest for teacher development. [Case study]. Brooklyn, NY: Author. www. The Mirage.org

Torraco, R. J. (1997). Theory building research methods. Human resource development research handbook. San Francisco, CA: Berrett-Koehler. (pp. 114-137).

Troop, M. (2017). Creativity as a driver for transformative learning: Portraits of teaching and Learning in a contemporary curriculum course. Journal of Transformative Education, 15(3), 203-222. doi: 10.1177/1541344617692772

Trotter, Y. (2006, Winter). Adult learning theories: Impacting professional development programs. The Delta Kappa Gamma Bulletin, 72(2), 8-13. Retrieved from http://teacherlink.ed.usu.edu/nmsmithpages/irex2012/readings/Susan/Susan\%20T urner\%20Reading\%201.pdf

U.S. Department of Education, National Center for Education Statistics. (1999). Teacher quality: A report on the preparation and qualifications of public school teachers (NCES 1999-080). Washington, DC: Author. 
U.S. Department of Education. (2009). State and local implementation of the No Child Left Behind Act, volume VIII: Teacher quality under NCLB: Final report. Retrieved from http://www.2.ed.gov/rschstat/eval/teaching/nclb-final/index.html

Vangrieken, K., Meredith, C., Packer, T., \& Kyndt, E. (2017). Teacher communities as a context for professional development: A systematic review. Teaching and Teacher Education, 61, 47-59.

Van Tessell, R. (2014). The trouble with top-down. Educational Leadership, 71(8), 7678.

Vartuli, S. (2005). Beliefs: The heart of teaching. Young Children, 60(5), 76-78, 80-86.

Venezky, R. L. (1995). Literacy. In T. L. Harris \& R. E. Hodges (Eds.), The literacy dictionary: The vocabulary of reading and writing (p. 142). Newark, DE: International Reading Association.

Watson, S. (2008, February 13). How public schools work. Retrieved from http://www.people.howstuffworks.com/public-schools.htm

What teachers should know and be able to do. (2002). National Board for Professional Teaching Standards. Retrieved from http://www.nbpts.org/sites/default/files/what teachers_should know.pdf

Willms, J. D., Friesen, S. \& Milton, P. (2009). What did you do in school today? Transforming classrooms through social, academic and intellectual engagement. (First National Report) Toronto: Canadian Education Association.

Wilson, N. S., Grisham, D. L., \& Smetana, L. (2009). Investigating content area teachers' understanding of a content literacy framework: A yearlong professional development initiative. Journal of Adolescent \& Adult Literacy, 52(8), 708-718. 
Wright, E. S. (2017). Dialogic development in the situational leadership style. Performance Improvement, 56(9), 27-31.

Wong, H. K., \& Wong, R. T. (2012). Developing and retaining effective teachers and principals. Retrieved from www.effectiveteaching.com

Yin, R. K. (2009). Case study research: Design and methods (4th ed.). Thousand Oaks, CA: Sage.

Yin, R. K. (2012). Application of case study research (3rd ed.). Thousand Oaks, CA: Sage.

Zaccaro, S., Rittman, A., \& Marks, M. (2001). Team leadership. The Leadership Quarterly, 12(4), 451-483.

Zhao, M. (2012). Teachers' professional development from the perspective of teaching reflection levels. Chinese Education \& Society, 45(4), 56-67. 


\section{APPENDIXES}

\section{APPENDIX A}

\section{Recruitment email letter sent to all secondary ELA teachers}

Greetings,

As you may know, I am currently working on my dissertation to finish the course work for an EdD. from the University of Missouri, Columbia in Educational Leadership and Policy Analysis. I am conducting a research study about professional development (PD) both provided by the district and PD you pursue on your own. I am emailing to ask if you would consider being a participant in my study either in an individual interview or in a focus group interview of between four to eight participants.

Below is a link to a short survey which should take about 3 minutes to complete. This survey does collect email addresses so I may know who has responded in order to make follow-up contact in regards to setting an interview or focus group time and meeting location.

Participation in the study is completely voluntary and your answers will be anonymous when presented in the findings section of the study. No identifying information will be used or presented within the research study. All data are stored on the MU Campus for seven years after the study has been completed. You may withdrawal from participation or refuse to participate in the study without any penalty or loss of benefit at any time.

If you are interested, please click on the link for the survey and additional information. It would be most appreciated if you could complete the survey even if you do not wish to participate in the research study.

\section{https://docs.google.com/forms/d/1tJ75xYIG4vpsFr6IUKY110O8tKunNQPdhZPZ64RqbPI/edit} or if the above does not work, try...

https://docs.google.com/forms/d/1tJ75xYIG4vpsFr6IUKY110O8tKunNQPdhZPZ64RqbPI/edit?n o redirect $=$ true

If you have any questions, please do not hesitate to contact me at vicky.bryan@sjsd.k12.mo.us

Thank you for your time and consideration in participating in my study.

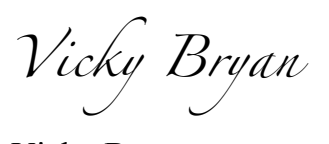

Vicky Bryan

Research Student

University of Missouri, Columbia

National Board Certified Teacher

ELA Advanced Placement \& IB World Literature Teacher 


\section{APPENDIX B}

\section{Recruitment Survey}

\section{Research Study Invitation}

This short survey is designed to gather potential participant information in regards to the research study conducted by Vicky Bryan as part of the Dissertation in Practice component for and EdD. in Educational Leadership and Policy Analysis from the University of Missouri, Columbia. The study is entitled:

TEACHERS AS AGENTS OF CHANGE: HOW KNOWLEDGE GAINED FROM SECONDARY ENGLISH LANGUAGE ARTS PROFESSIONAL DEVELOPMENT IMPACTS CLASSROOM PRACTICES

The purpose of this study is to gather teachers' thoughts and ideas about professional development (PD). Specifically, I want to understand what you do to make district presented ELA PD and PD you peruse on your own relevant in the classroom to help students learn.

Teachers have many opportunities throughout the year to grow their pedagogical content knowledge and try new teaching techniques in their classrooms. This study seeks to determine how secondary teachers use that newly gained knowledge to change their classroom practices. Additionally, the study will collect teacher responses as to how teachers define effective PD, how teachers know students are learning, and how teachers know they are growing professionally. Because little research has been devoted to the learning styles and ways ELA teachers use pedagogical content knowledge and reflection to improve their craft, obtaining your thoughts and experiences is important to future PD.

While this survey does collect personal information, no identifying information will be shared with anyone. All personal identifiers will be held completely confidential when evaluating collected data and writing the findings section of the dissertation. All collected data will be kept in a locked filing cabinet on the MU campus for seven years after the study has been completed; digitally collected data will be accessible only through a secured server network which is password protected.

Thank you so much for your time,

Vicky Bryan

Your email address (vicky.bryan@students.sjsd.k12.mo.us) will be recorded when you submit this form. Not vicky.bryan? Sign out

* Required

1. How many years have you taught, total? At SJSD and in other districts. *

Mark only one oval.

$$
\begin{aligned}
& \text { 1-5 years } \\
& 6-10 \text { years } \\
& 11-20 \text { years } \\
& 21-30 \text { years }
\end{aligned}
$$

2. Would you be willing to participate in the research study described above? * Mark only one oval.
$\bigcirc$ Yes
No

3. If you selected "yes" in the question above, in which of the following would you be willing to participate? Select all that apply. *

Check all that apply.

An individual face-to-face interview (20-30 minutes)

A focus group interview (30-60 minutes)

An individual phone interview (20-30 minutes)

None of the above 


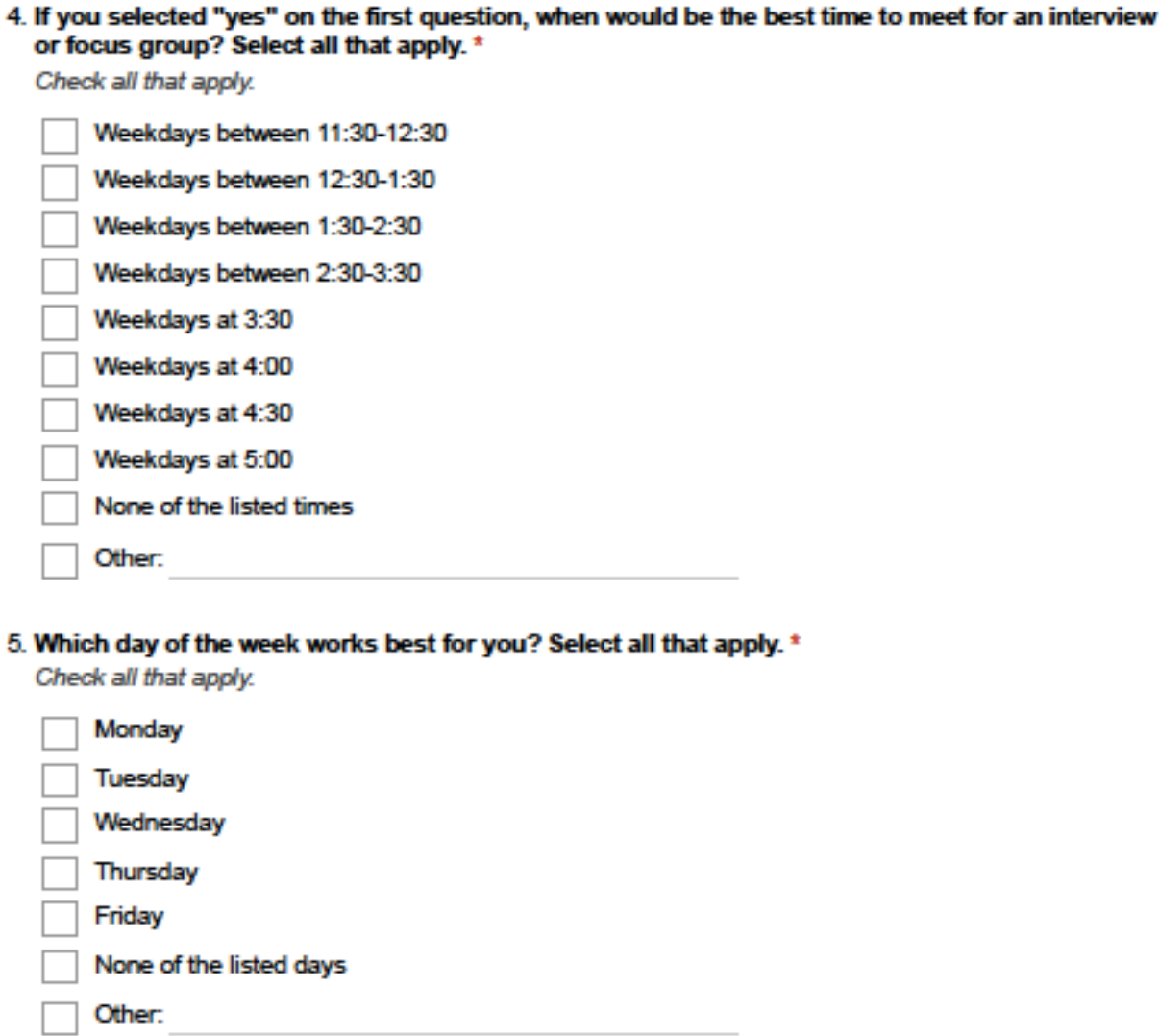

6. If you are willing to participate in this study, please provide an email and/or phone number which is best and most convenient to contact you.

Powered by

1日 Google Forms: 


\title{
APPENDIX C
}

\section{Participant Informed Consent Forms}

\author{
TEACHERS AS AGENTS OF CHANGE: \\ HOW KNOWLEDGE GAINED FROM SECONDARY ENGLISH LANGUAGE ARTS \\ PROFESSIONAL DEVELOPMENT IMPACTS CLASSROOM PRACTICES
}

\author{
INFORMED CONSENT
}

\section{Case Study:}

I will investigate how secondary English Language Arts (ELA) teachers, from one Midwest Missouri school district, have used pedagogical content knowledge gained from ELA professional development to change their individual classroom practices.

\section{Principal investigator:}

Vicky L. Bryan

\section{Institute:}

Northwest Missouri State University

University of Missouri Columbia

\section{Introduction:}

You are invited to participate in an individual interview or focus group to better the understanding of teachers' perceptions of professional development.

\section{Background information:}

This is a research study for a dissertation within the Educational Doctorate Program through the University of Missouri- Columbia and Northwest Missouri State University.

\section{Purpose of this research study:}

The purpose of this qualitative bounded case study is to explore how secondary English Language Arts teachers define and view professional development (PD) in one Midwest Missouri school district and how knowledge gleaned from PD supports teachers' classroom practices. As Goldschmidt and Phelps (2010) identify, when PD is studied the focus is "typically only [on] the relation of program and student achievement" and not on how teachers learn or transform acquired knowledge. Therefore, knowing ELA teachers' perspectives on PD is critical to initiating change from within schools and curricular departments.

\section{Procedures:}

Interviews: In this study I will ask focused questions about each participant's perception in regards to various aspects of professional development (PD) occurring in his/her current teaching district as well as personal PD pursuits. This interview should take no more than 30 minutes. 
Focus Groups: Participants will be asked to spend about 30-60 minutes of time with the researcher discussing professional development (PD) within the school district and personal PD pursuits.

Survey: Those invited to participate in the study will be asked to complete a short interest survey as well as a survey with five open-ended response questions about professional development.

The interviews and focus group will be audio recorded for ease of transcription for the researcher's purpose only. The surveys will be launched through Google forms; data will be obtainable to the researcher via a secure server which is password protected.

\section{Possible risks or benefits:}

There is no risk involved in this study except the donation of your valuable time. This research has the potential of having an impact on other schools and districts looking to provide effective professional development to English Language Arts teachers.

\section{Right of refusal to participate and withdrawal:}

Participants are free to choose to participate in the study. You may withdrawal from participation or refuse to participate in the study without any penalty or loss of benefit.

\section{Confidentiality:}

Any information you provide will remain confidential. Nobody except the principal investigators will have any access to it. Participant's name and identity will not be disclosed at any time. All collected data will be kept in a locked filing cabinet on the University of Missouri campus for seven years after the study has been completed.

\section{Review of interview/focus group:}

You will be given the opportunity to look over the transcript of the interview or focus group. It is important for participants to have an opportunity to request changes to any interview or focus group responses. As this is your words, it is thus your intellectual property, and this researcher will respect the requests of all participants to have their words read as they want them.

\section{Available Sources of Information:}

You may ask more questions about the study at any time. For questions about the study, contact Vicky Bryan at (816) 809-8262 or at vlb34c@,mail.missouri.edu

If you have any further questions you may contact Dr. Carole Edmonds (cake@nwmissouri.edu), the researcher's advisor. You may also contact the University of Missouri Campus Institutional Review Board (IRB) (which is a group of people who review the research studies to protect participants' rights) at (573) 882-3181 or umcresearchcirb@missouri.edu.

A copy of this Informed Consent form will be given to you before you participate in the research. 


\section{INFORMED CONSENT OF STUDY}

\section{AUTHORIZATION}

I have read and understand this consent form, and I volunteer to participate in this research study. I understand that I will receive a copy of this form. I understand that such interviews and related materials will be kept completely confidential, and that the results of this study may be published in an academic paper, presentation, journal, or book. I agree that any information obtained from this research may be used in any way thought best for this study.

\section{AUDIO-RECORDING}

I consent to be audio-recorded during the first, approximately 30 -minute interview or 3060-minute focus group. I understand I can decline to be recorded at any time.

Initials:

Participant's Name (Printed or Typed):

Date:

Participant's Signature:

Principal Investigator's Signature/

Person Obtaining Consent:

Vicky L. Bryan

Date: 


\section{APPENDIX D}

\section{Interview and Focus Group Questions}

How have secondary ELA teachers, from one Midwest Missouri school district, used pedagogical content knowledge gained from ELA PD to change their individual classroom practices?

- How do secondary ELA teachers define effective professional development?

- How do secondary ELA teachers implement change in their classroom practices due to newly gained pedagogical content knowledge?

- How do secondary ELA teachers know when classroom practice changes have influenced student learning?

- How do secondary ELA teachers know they are growing and/or transforming professionally?

\section{Interview Content Questions:}

\section{SECTION 1: DEFINITION OF EFFECTIVE PROFESSIONAL DEVELOPMENT}

1. How long have you been teaching?

2. What comes to mind when someone says "Professional Development"?

3. What makes PD "effective" for you?

4. What avenues have helped you to grow professionally?

5. What is your belief in the role PD plays in transformation of classroom practices?

\section{SECTION 2: TRANSFORMATION IN CLASSROOM PRACTICE}

6. Describe one instance when knowledge gained from PD (internal or external) influenced you to question past classroom practices.

7. What classroom practices have you changed due to the impact of this professional learning?

8. Focusing on one practice, describe how your classroom changed due to implementation.

9. What are the challenges or obstacles to transforming classroom practice? 


\section{SECTION 3: CULTIVATING STUDENT LEARNING THROUGH TRANSFORMATION IN CLASSROOM PRACTICE}

10. How did students' learning change with the implementation of new pedagogical knowledge?

11. How do you know their learning changed?

\section{SECTION 4: TRANSFORMATION IN PERSONAL GROWTH}

12. How do you know you are growing professionally?

13. What is your belief about the role reflection plays in professional development? 
APPENDIX E

Approval to Conduct Research within the School District

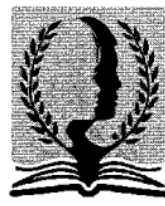

Research Checklist and Approval

School District

Please note- this is not the application

Date Submitted: 10/04/2017

Teachers as Agents of Change:

Research Proposal Title: How Knowledge Gained from Secondary English Language Arts Professional Development Impacts Classroom Practices

Principal Investigator(s): Vicky Lynn Bryan

Checklist

$\checkmark$ Completed "Application to Conduct Research in

Draft copy of "informed consent" letter to study population/parents, if applicable

$\checkmark$ Description of measurements and copies of any surveys

- Other

Approval of this research is contingent on adherence to district procedures as outlined

in the document entitled "Conducting Research in the School District" and

the information provided with the application. The district must be notified of any

substantive changes to the information contained in the application. The district

reserves the right to withdraw approval of research if the research is deemed to no

longer. be in the best interests of students, staff, or the district.

Research Application: XApproved_Denied

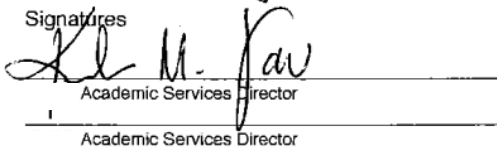

Academic Services Director

Supervisor/Principal of Program or Building

$+1$

October 2017 


\section{APPENDIX F}

\section{IRB Approval Letter and Amended Approval Letter}

May 07, 2018

Principal Investigator: Vicky Bryan

Department: Educational Leadership-EDD

Your IRB Application to project entitled TEACHERS AS AGENTS OF CHANGE: HOW KNOWLEDGE GAINED FROM SECONDARY ENGLISH LANGUAGE ARTS PROFESSIONAL DEVELOPMENT IMPACTS CLASSROOM PRACTICES was reviewed and approved by the MU Institutional Review Board according to the terms and conditions described below:

$\begin{array}{ll}\text { IRB Project Number } & 2009629 \\ \text { IRB Review Number } & 230856\end{array}$

Initial Application Approval Date May 05, 2018

IRB Expiration Date May 05, 2019

Level of Review Expedited

Project Status

Active - Open to

Enrollment

Expedited Categories

45 CFR 46.110.a(f)(6)

Risk Level

45 CFR 46.110.a(f)(7)

Type of Consent

Minimal Risk

HIPAA Category

Written Consent

Internal Funding

No HIPAA

CIDB Version/Date

Personal funds

Protocol Version/Date

N/A - N/A - October 05, 2017

N/A - N/A - October 05, 2017

The principal investigator (PI) is responsible for all aspects and conduct of this study. The PI must comply with the following conditions of the approval:

1. No subjects may be involved in any study procedure prior to the IRB approval date or after the expiration date.

2. All unanticipated problems must be reported to the IRB on the Event Report within 5 business days of becoming aware of the problem. Unanticipated problems are defined as events that are unexpected, related or possibly related to the research, and suggests the research places subjects or others at a greater risk of harm than was previously known or recognized. If the unanticipated problem was a death, this is reportable to the IRB within 24 hours on the Death Report.

3. On-site deaths that are not unanticipated problems must be reported within 5 days of awareness on the Death Report, unless the study is such that you have no way of knowing a 
May 17, 2018

Principal Investigator: Vicky Bryan

Department: Educational Leadership-EDD

Your Amendment Form v.1 to project entitled TEACHERS AS AGENTS OF CHANGE: HOW KNOWLEDGE GAINED FROM SECONDARY ENGLISH LANGUAGE ARTS PROFESSIONAL DEVELOPMENT IMPACTS CLASSROOM PRACTICES was reviewed and approved by the MU Institutional Review Board according to the terms and conditions described below:

$\begin{array}{ll}\text { IRB Project Number } & 2009629 \\ \text { IRB Review Number } & 237910 \\ \text { Initial Application Approval Date } & \text { May 05, } 2018 \\ \text { Approval Date } & \text { May 17, } 2018 \\ \text { IRB Expiration Date } & \text { May 05, 2019 } \\ \text { Level of Review } & \text { Expedited } \\ \text { Project Status } & \text { Active - Open to } \\ \text { Risk Level } & \text { Enrollment } \\ \text { Type of Consent } & \text { Minimal Risk } \\ \text { HIPAA Category } & \text { Written Consent }\end{array}$

The principal investigator (PI) is responsible for all aspects and conduct of this study. The PI must comply with the following conditions of the approval:

1. No subjects may be involved in any study procedure prior to the IRB approval date or after the expiration date.

2. All unanticipated problems must be reported to the IRB on the Event Report within 5 business days of becoming aware of the problem. Unanticipated problems are defined as events that are unexpected, related or possibly related to the research, and suggests the research places subjects or others at a greater risk of harm than was previously known or recognized. If the unanticipated problem was a death, this is reportable to the IRB within 24 hours on the Death Report.

3. On-site deaths that are not unanticipated problems must be reported within 5 days of awareness on the Death Report, unless the study is such that you have no way of knowing a death has occurred, or an individual dies more than 30 days after $\mathrm{s} /$ he has stopped or completed all study procedures/interventions and required follow-up.

4. All deviations (non-compliance) must be reported to the IRB on the Event Report within 5 business days of becoming aware of the deviation.

5. All changes must be IRB approved prior to implementation unless they are intended to 


\section{APPENDIX G}

District Archived Survey Questions from post-PD Surveys for 2017-2018

\section{Likert Scale Type Questions:}

- Question \#3 on all three surveys:

- The professional development increased my effectiveness with staff and/or students.

- Question \#9 on all three surveys:

- The professional development was useful in order to improve future student/organizational outcomes.

\section{Open Response Questions:}

- Question \#14 on August \& September surveys:

- Please give a brief description of your (insert date) professional development.

- Question \#15 on August \& September surveys:

- After the (insert date) professional development, what changes in your practice/profession are you likely to make?

- Question \#15 on February survey:

- Please give a brief description of what you believe is the single most important improvement that needs to be made to the district PD for next year.

- Question \#17 on February survey:

- Please give a one to five-word description of what you believe is critical to learn more about in the 2018-2019 school year in the district. 


\title{
APPENDIX H
}

\section{Interview and Focus Group Script}

\author{
Pre Interview/Focus Group: \\ Investigator will go over the information on the written consent forms and collect signed forms.
}

\section{For focus groups:}

"Welcome and thank you for participating in this focus group."

\section{For individual interview:}

"Thank you for agreeing to speak with me today."

"The purpose of this focus group/interview is to gather teachers' thoughts and ideas about professional development (PD). Specifically, I want to understand what you do to make district presented ELA PD and PD you peruse on your own relevant in the classroom to help students learn.

Teachers have many opportunities throughout the year to grow their pedagogical content knowledge and try new teaching techniques in their classrooms. This study seeks to determine how secondary teachers use that newly gained knowledge to change their classroom practices. Additionally, the study will collect teacher responses as to how teachers define effective PD, how teachers know students are learning, and how teachers know they are growing professionally. Because little research has been devoted to the learning styles and ways ELA teachers use pedagogical content knowledge and reflection to improve their craft, obtaining your thoughts and experiences is important to future PD within the district and the state."

\section{For focus groups:}

"I would like to remind you that to protect the privacy of focus group members, all transcripts will be coded with pseudonyms and ask that you not discuss what is discussed in the focus group with anyone else.

"The focus group/interview will last between 30-60 minutes and I will record the discussion using www.Rev.com to make sure that it is recorded accurately.

"Do you have any questions before we begin?"

\section{Post Interview/Focus Group:}

You've shared a lot of information with me about your thoughts on PD and teaching philosophy, and this has been very helpful to my research into how teachers utilize PD to change their classroom practices. At this point, would you summarize any final thoughts about PD and its role in changing classroom practice and student learning?

Thank you for your time and assistance, and when the transcript of this interview is ready, I will contact you for a shorter follow-up interview. I'll share the transcript with you, ask if you feel you have represented yourself accurately, let you know if I have any emergent interpretations or questions, and ask you if I am accurate in my interpretation of your data. This meeting will not be audio-recorded, but I will take notes. All collected data will be stored in a locked filing cabinet on the MU Campus for seven years after the study has been completed. 
VITA

The author of this research, Vicky Lynn (Kamphefner) Bryan, is a native Missourian. She grew up on a farm in northwest Missouri surrounded by cows, cats, corn, and lots of love. She has always been an independent learner and reader with the ability to imagine the unknown and transform the ordinary through her creative spirit. "Playing school" all over the house, she kept her stuffed animals in line, read aloud to the cats, as well as made worksheets and quizzes for her mom to take. When asked what she wanted to be when she grew up, Vicky promptly replied, "A teacher" before she was even in kindergarten. Over the years, amazing teachers helped make this dream a reality.

Vicky graduated from Platte County R-III School District in 1992 in the top 10\% of her class and then received a Bachelor's Degree in Secondary English Education from the University of Central Missouri, graduating summa cum laude in 1997. As a life-long learner Vicky earned a Masters in Liberal Arts with a focus in Literature and Art from Baker University in 2003, and an Ed. D in Educational Leadership and Policy Analysis from the University of Missouri in 2018. She has also earned National Board Certification and has been named in Who's Who Among America's Teachers.

Vicky has taught secondary English Language Arts classes such as Advanced Placement Language and Composition, International Baccalaureate Theory of Knowledge and World Literature Year 1, Creative Writing, Writing and Film, and grades 9-12 for the past 22 years. She has also taught Multi-cultural Literature and Creative Thinking courses for Baker University's graduate program. As well as holding various leadership positions in her district, Vicky has recently served as the Secondary ELA Curriculum Advisor. She has created and led a great deal of professional development 
for her building, district, community, local chapter of the National Writing Project, and the University of Nebraska's Women in Leadership Conference.

Vicky lives in a small Victorian house she loves redecorating and personalizing. Her hobbies include reading, traveling, and still "playing school." The relationships she builds with her students and watching them grow is the best part of teaching. They teach her every day and keep her young. 